\title{
MICROCHIP CAPILLARY ELECTROCHROMATOGRAPHY WITH PILLAR COLUMNS
}

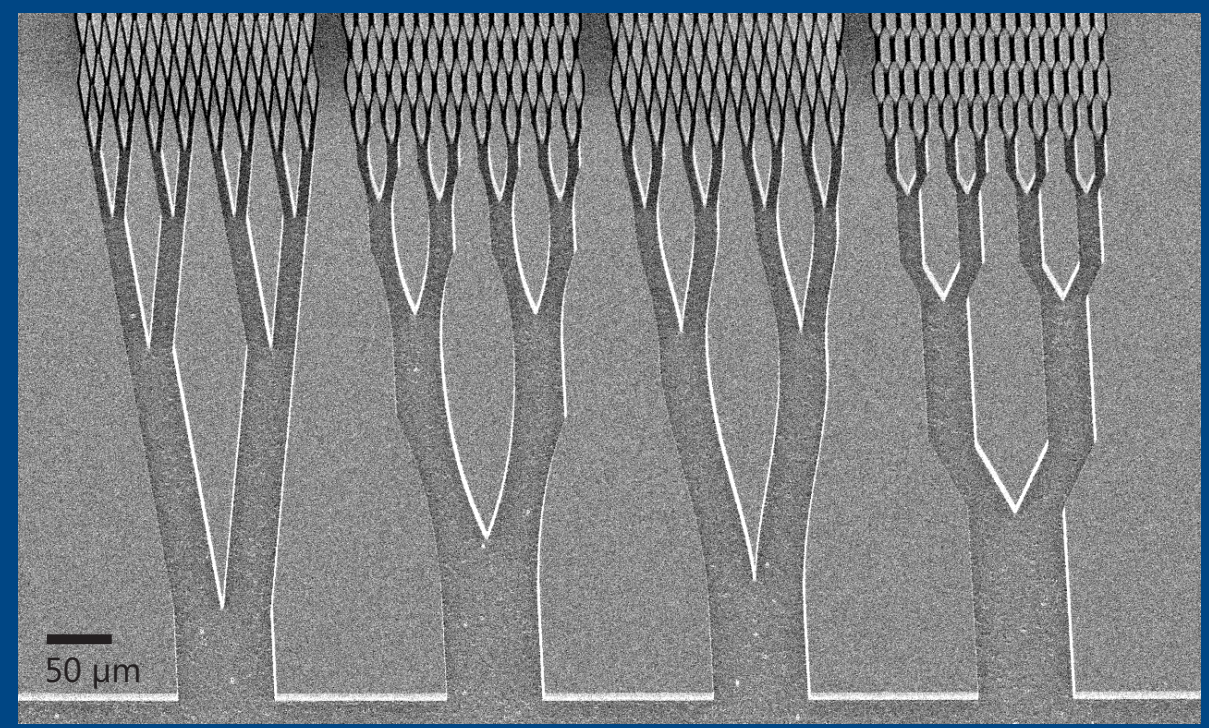

Sertan Sukas 


\section{Microchip Capillary Electrochromatography with Pillar Columns}

Sertan Sukas 
This work was financially supported by IWT-Flanders within the NextChrom project.

Nederlandse titel:

Microchip capillaire elektrochromatografie met pillaarkolommen

Samenstelling promotiecommissie:

voorzitter en secretaris:

prof.dr. G. van der Steenhoven Universiteit Twente

promotor:

prof.dr. ir. J.G.E. Gardeniers Universiteit Twente

referent:

dr.ir. D.M.W. De Malsche

Vrije Universiteit Brussel

leden:

prof.dr.ir. R.G.H. Lammertink Universiteit Twente

prof.dr.ir. J.E. ten Elshof Universiteit Twente

prof.dr.ir. G. Desmet

Vrije Universiteit Brussel

prof.dr. J.C.T. Eijkel

Universiteit Twente

prof.dr. E.M.J. Verpoorte

Rijksuniversiteit Groningen

Back cover: Learning from failures.

Microchip capillary electrochromatography with pillar columns

ISBN 978-90-365-3505-2

DOI 10.3990./1.9789036535052

URL http://dx.doi.org/10.3990/1.9789036535052

Printed by Gildeprint Drukkerijen, Enschede, The Netherlands

Copyright (C) 2013 by Sertan Sukas, Enschede, The Netherlands. All rights reserved. 


\title{
MICROCHIP CAPILLARY ELECTROCHROMATOGRAPHY WITH \\ PILLAR COLUMNS
}

\author{
DISSERTATION
}

to obtain

the degree of doctor at the University of Twente,

on the authority of the rector magnificus, prof.dr. H. Brinksma,

on account of the decision of the graduation committee, to be publicly defended

on Friday, 15 February 2013 at 16:45

by

Sertan Sukas

born on 1 August 1982

in Rize, Turkey 
This dissertation has been approved by:

Prof. dr. J.G.E. Gardeniers (promotor) 
to my angel... 



\section{Contents}

1 Introduction 1

1.1 Fundamentals of liquid chromatography . . . . . . . . . . . 3

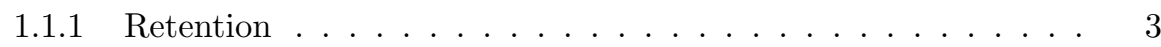

1.1.2 Chromatogram ..................... 4

1.1.3 Measure of band broadening: Theoretical plate height . . . . . 4

1.1.4 Resolution ................... 7

1.2 The characteristic of CEC: Electroosmotic pumping . . . . . . . 7

1.3 Landmarks of microchip CEC . . . . . . . . . . . . . . . . . . 10

1.4 Aim of study . . . . . . . . . . . . . . . . 13

1.5 Outline of the thesis . . . . . . . . . . . . . . . 14

2 Novel shape and placement definitions with retention modeling for solid microfabricated pillar columns for CEC and HPLC 19

2.1 Introduction . . . . . . . . . . . . . . . . . 20

2.2 Modeling . . . . . . . . . . . . . . . . . 21

2.2.1 Stationary flow modeling . . . . . . . . . . 23

2.2.2 Time dependent species transport \& retention modeling . . . . 24

2.3 Simulations . . . . . . . . . . . . . . . . . . 25

2.3.1 Model validation . . . . . . . . . . . . . . 26

2.3.2 Solution domain .................... 28

2.3.3 Shape optimization . . . . . . . . . . . . . . 29

2.4 Results and discussion . . . . . . . . . . . . . . . 33 
2.5 Concluding remarks

3 Performance evaluation of different design alternatives for microfabricated non-porous fused silica pillar columns for CEC 45

3.1 Introduction . . . . . . . . . . . . . . . . 46

3.2 Experimental . . . . . . . . . . . . . . . . 47

3.2.1 Fabrication . . . . . . . . . . . . . 47

3.2.2 Microchip design and layout . . . . . . . . . . . . 48

3.2.3 Chemicals ......................... 49

3.2.4 Chip coating procedure ................. 50

3.2.5 Experimental procedure .................. 51

3.2.6 Detection and data processing . . . . . . . . . . . 52

3.3 Results and discussion . . . . . . . . . . . . . . . 53

3.3.1 Non-retained species experiments . . . . . . . . . 53

3.3.2 Retained species experiments . . . . . . . . . . . 59

3.3.3 Kinetic plots ..................... 63

3.3.4 Separation experiment . . . . . . . . . . . 66

3.4 Concluding remarks . . . . . . . . . . . . . . . . 67

4 Design and implementation of injector/distributor structures for microfabricated non-porous pillar columns for CEC $\quad 71$

4.1 Introduction . . . . . . . . . . . . . . . . . 72

4.2 Experimental ......................... 73

4.2.1 Fabrication ....................... 73

4.2.2 Microchip design and layout . . . . . . . . . . . . 73

4.2 .3 Chemicals . . . . . . . . . . . . . . . . . 77

4.2.4 Chip coating procedure . . . . . . . . . . . 77

4.2.5 Experimental procedure . . . . . . . . . . . 77

4.2.6 Detection and data processing . . . . . . . . . . . 78

4.3 Results and Discussion . . . . . . . . . . . . . . . . 78

4.3 .1 Injection analyses . . . . . . . . . . . . . . 78

4.3.2 Design characterization experiments ........... 82 
4.3.3 Separation experiment ................. 84

4.4 Concluding remarks . . . . . . . . . . . . . . . . . 85

5 Fabrication of integrated porous glass for microfluidic applications 89

5.1 Introduction . . . . . . . . . . . . . . . . . . . . . 90

5.2 Experimental . . . . . . . . . . . . . . . . . 91

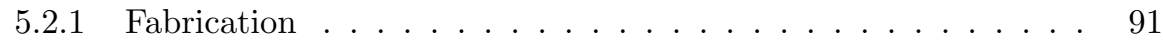

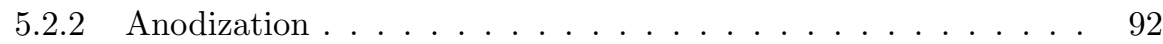

5.3 Results and discussion . . . . . . . . . . . . . . . . 93

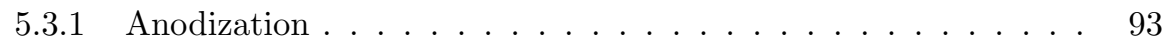

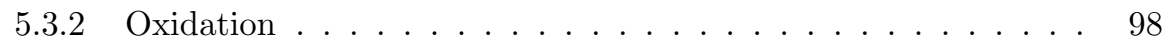

5.3.3 Characterization .................... 104

5.4 Concluding remarks . . . . . . . . . . . . . . . . . . . 109

6 Conclusion $\quad 115$

6.1 Summary ............................. 116

6.2 Future perspectives . . . . . . . . . . . . . . . 117

$\begin{array}{lr}\text { Samenvatting } & 123\end{array}$

$\begin{array}{lr}\text { Acknowledgements } & 125\end{array}$ 



\section{Chapter 1}

\section{Introduction}

In this chapter, an overview of capillary electrochromatography (CEC) is given. It is aimed to briefly describe the concepts applied in this thesis, focusing on the relevance to microchip applications. 
When you write "what is chromatography" in the search box of today's world's most popular search engine, it gives you this definition: The separation of a mixture by passing it in solution or suspension or as a vapor (as in gas chromatography) through a medium in which the components move at different rates [1]. The linguistic origin of the term "chromatography" and the history of the method were covered very well in the book by W.J. Lough and I.W. Wainer [2]. Briefly, a Russian botanist Michael Tswett was the inventor of the technique, who first publicly reported his studies in 1903. He used column liquid chromatography, in which the stationary phase was a solid adsorbent packed into the glass column and the mobile phase was a liquid. He published his first papers in 1906 in German [3, 4], where he also introduced the term "chromatography". As a major breakthrough, Martin and Synge carried out studies on the mathematical treatment of the chromatographic theory and proposed the famous "plate height" theory [5], which is accepted as the basis of the modern chromatography.

The first reported use of EOF in chromatography was by Strain in 1939 [6]. However, Pretorious and co-workers were the originators of CEC, as they reported its advantages over hydrodynamic chromatography [7], which are covered in the following sections. The history of CEC is reported in detail in the book by K.D. Bartle and P. Myers [8]. Table 1.1, which is reproduced from their book, briefly summarizes the landmarks in CEC.

Table 1.1: Landmarks in CEC [8].

\begin{tabular}{lll} 
Event & Year & Reference \\
\hline First report of use of EOF in chromatography & 1939 & {$[6]$} \\
\hline $\begin{array}{l}\text { Separation of polysaccharides using EOF through } \\
\text { colloidal membrane }\end{array}$ & 1954 & {$[9]$} \\
\hline Use of EOF in column chromatography & 1974 & {$[7]$} \\
\hline Electroosmosis in capillaries & 1981 & {$[10]$} \\
\hline CEC in open tubular columns & 1987 & {$[11]$} \\
\hline Theory of CEC and technique development & 1987,1991 & {$[12,13]$} \\
\hline Analysis of pharmaceutical compounds by CEC & 1994 & {$[14]$} \\
\hline
\end{tabular}




\subsection{Fundamentals of liquid chromatography}

As an analytical method, an aim of any chromatographic run is to determine the compounds of the target solution by means of separating them (qualitative analysis) and measuring their quantity individually (quantitative analysis). The separation is achieved via partitioning of the analyte (sample to be separated) between the mobile and stationary phases, which are liquid and solid, respectively in the case of liquid chromatography (LC). Figure 1.1 depicts the occurrence of this process in a closed channel system.

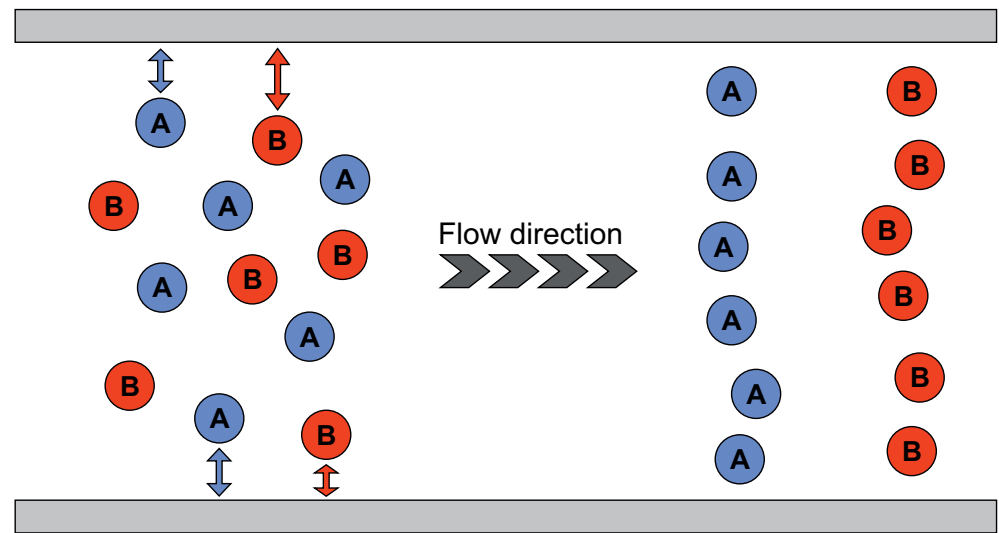

Figure 1.1: Partitioning of the analyte A and B between the mobile phase (carrier liquid) and the stationary phase (channel walls) inside the channel depending on their partitioning characteristics with the walls.

\subsubsection{Retention}

Molecules interact with both or either of the stationary and the mobile phases while they migrate through the column (separation channel). They are distributed within these two phases. At any time of the process, a single molecule can be present either in the stationary or in the mobile phase. Immobility of the analyte in the stationary phase causes it to be retained, which yields a slower migration speed. Therefore the migration speed of an analyte is determined by its affinity to the stationary and mobile phases. Since the cause of the separation is the differential migration of the analytes, 
the retention mechanism can be used for defining the characterization parameters of the process. Retention factor is defined as the ratio of the times that molecules spend in stationary phase to the mobile phase $[2,8]$ :

$$
k=\frac{t_{R}-t_{0}}{t_{0}}
$$

where $t_{R}$ is the retention time, which is the total elapsed time between the injection of the analyte and its exit from the column; $t_{0}$ is the elution time of a non-retained compound, which would have the same migration velocity as the mobile phase (or the eluent: carrier liquid).

\subsubsection{Chromatogram}

For monitoring the separation process, chromatograms are generated. They are basically the plots of the signals, which are obtained from the detectors, versus elapsed time. One or more detectors can be placed at fixed positions along the column, typically at the inlet (injection point) and/or the outlet, or a single one can be translated to catch the sample bands while they are migrating over the desired location. Figure 1.2 shows a typical chromatogram, which plots the concentration profile of the bands versus elapsed time. Sample peaks represent Gaussian profile.

\subsubsection{Measure of band broadening: Theoretical plate height}

Sample bands broaden during their migration through the column because of diffusive/dispersive and convective mechanisms. Band broadening reflects the efficiency of a chromatographic system. As it can be concluded from Figure 1.2, if the retained peaks would have broader base widths $(w)$ with the same center positions $\left(t_{R}\right)$, part of those peaks would coincide and it would not be possible to obtain separation under the same conditions. Therefore band broadening has to be minimized or the chromatographic system has to be run at its minimum band broadening point.

Seeking for an optimum operational point indicates a need for a characterization study. Hence the theoretical plate height [15] is proposed as an efficiency measure. 


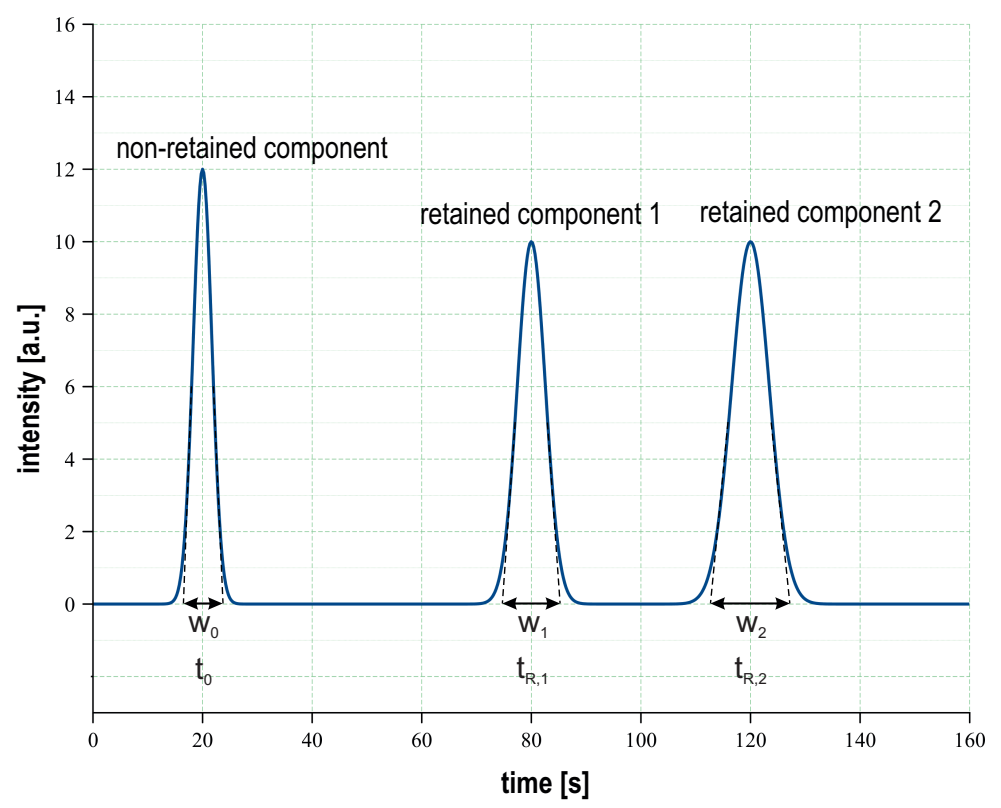

Figure 1.2: A typical chromatogram. Concentration profiles of the sample bands are plotted versus elapsed time. First peak represents the non-retained component, while the second and the third represent the separated components with different affinities. Time scale is relative to the time of injection.

Originally, it was proposed for distillation methods [5], where real plates were used, but later it was also applied for chromatographic processes with the same naming convention. The simplest definition would be that there exist certain number of theoretical plates, all of which have the same height (or length), that can be stacked in a column with a certain length. Higher plate count indicates higher efficiency, in other words narrower plates (lower plate height). The number of theoretical plates is defined as the square of the ratio of the retention time to peak variance:

$$
N={\frac{t_{R}}{\sigma}}^{2}
$$

where the peak variance is defined as a quarter of the base width:

$$
\sigma=\frac{w}{4}
$$

As it can be seen from Figure 1.2, the plate count can be easily calculated using 
the data extracted from a chromatogram. After that, the plate height is calculated by dividing the total column length to the number of plates:

$$
H=\frac{L}{N}
$$

For enabling the comparison of the performance of different columns, the theoretical plate height values calculated from the chromatogram data are plotted with respect to the linear (mobile phase) velocity of the system. Such plots are typically called van Deemter plots because van Deemter was the first to clearly identify the different contributions to the nonlinear relationship between the plate height and the mobile phase velocity in 1956 [16]. The proposed equation, which is also called van Deemter equation, was:

$$
H=A+B / u+C u
$$

where the A-term stands for Eddy diffusion, the B-term stands for longitudinal diffusion and the C-term stands for resistance to mass transfer of the analyte between the mobile and stationary phases. Figure 1.3 shows the typical van Deemter plot and the individual contributions from the terms.

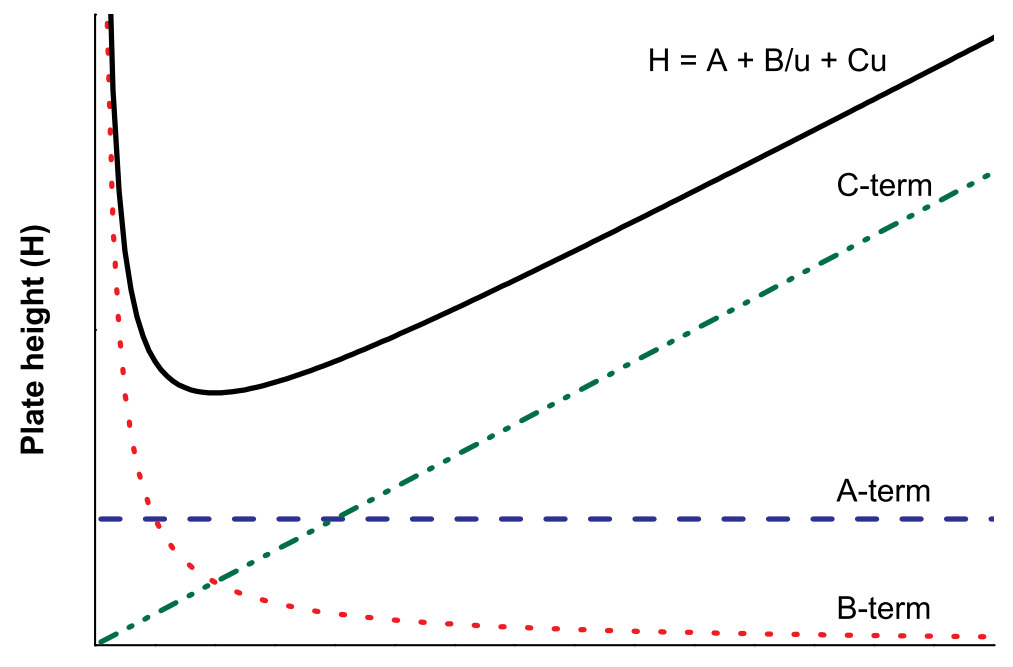

Linear velocity (u)

Figure 1.3: Typical van Deemter plot. 


\subsubsection{Resolution}

Defining the efficiency with the plate height concept, the selectivity is reflected by resolution. It is defined for measuring how well the two peaks are separated from each other. Resolution is the ratio of the difference in the retention times to the mean base widths of two consecutive peaks [17]. Once again referring to Figure 1.2, it can be expressed as:

$$
R s_{21}=\frac{t_{R, 2}-t_{R, 1}}{\left(w_{1}+w_{2}\right) / 2}
$$

Reaching $R s=1.5$ means that less than $1 \%$ of the peaks are overlapping. Having resolution values higher than this value is called baseline resolution, which indicates that a complete separation is achieved.

\subsection{The characteristic of CEC: Electroosmotic pumping}

CEC is one of the liquid chromatography (LC) techniques in which the liquid is driven by electroosmotic pumping. It can be considered another variant of high performance liquid chromatography (HPLC), where the mobile phase is driven with hydrodynamic pumping, with an option of including capillary electrophoresis (CE), where a charged sample moves under the effect of the electric field.

Electroosmotic flow (EOF) is generated by applying an electric field throughout the channel instead of pressure. EOF is originated from the presence of the electric double layer (EDL), which exists at the solid-liquid interface because of the partitioning of the ions between the two. When a solid is exposed to an aqueous solution, it generates a surface charge via ion adsorption from the liquid or the ionization of the functional groups at its surface. In the case of silica (including fused silica), which is the most commonly used material for CEC, the surface gains a negative charge because of deprotonation of the functional silanol groups. Due to the electrostatic forces, excessive ions in the solution are attracted by this negatively 
charged surface creating a double layer, which consists of both negative and positive ions. Closest to the solid surface, a monolayer of positive ions is created (in the case of silica, i.e. negatively charged solid surface), which is called Stern layer. Since the exerted electrostatic attraction force on the liquid ions is the highest on this layer, the Stern layer is immobile. An intermediate layer exists between the Stern layer and bulk solution which is called Diffuse layer. Electrostatic attraction still has an effect on the ions in the Diffuse layer, which consists of both positive and negative mobile ions, continuously exchanged with the bulk solution because of the charge imbalance. Further away from the solid surface the bulk liquid is present, which is assumed to be electroneutral. Figure 1.4 illustrates the EDL [18].

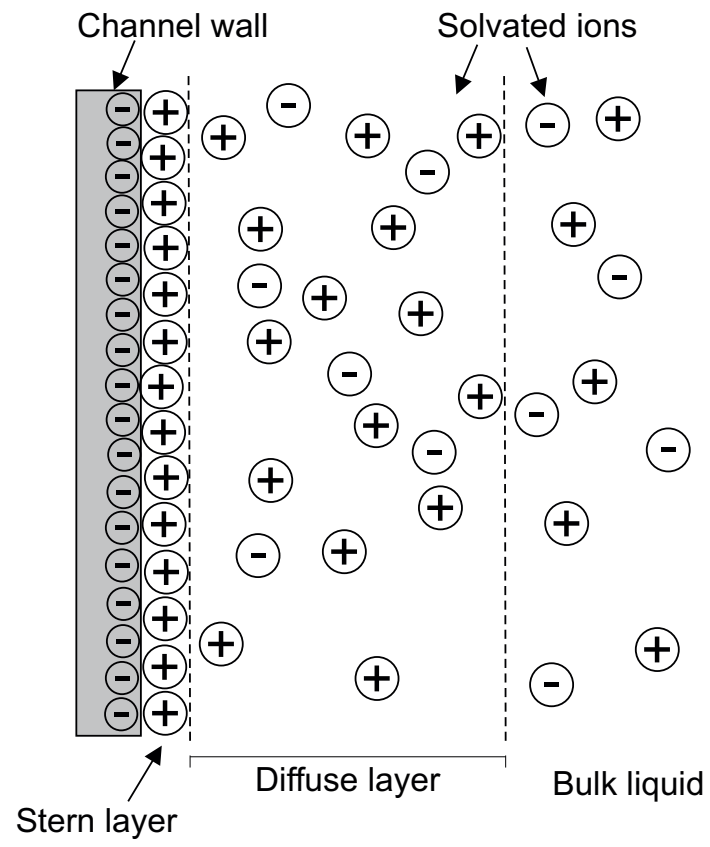

Figure 1.4: Illustration of the electric double layer (EDL) next to a negatively charged surface.

Presence of the EDL creates a potential, which decays exponentially as a function of distance from the solid surface. This is called zeta potential $(\zeta)$. The thickness of the $E D L(\delta)$ is defined as the distance between the Stern layer and a point in the bulk liquid at which the potential is 0.37 times the potential at the interface between the 
Stern and diffuse layer. It is calculated as [19]:

$$
\delta=\sqrt{\frac{\varepsilon_{r} \varepsilon_{0} R T}{2 c F^{2}}}
$$

where $\varepsilon_{r}$ is the relative permittivity of the liquid, $\varepsilon_{0}$ is the permittivity of vacuum, $R$ is the universal gas constant, $T$ is absolute temperature, $c$ is molar concentration and $F$ is Faradays constant. The zeta potential is dependent on the EDL thickness and defined as $[20]$ :

$$
\zeta=\frac{\delta \rho_{e}}{\varepsilon_{r} \varepsilon_{0}}
$$

where $\rho_{e}$ is the surface charge density. When the electric field is applied, the mobile ions in the diffuse layer move and pull the rest of the liquid, yielding the walls of the channel as slip boundaries (Figure 1.5). The linear velocity created by EOF is defined by the Smoluchowski equation [20]:

$$
\boldsymbol{u}_{e o}=\frac{\varepsilon_{r} \varepsilon_{0} \zeta}{\eta} \boldsymbol{E}
$$

where $\eta$ is the dynamic viscosity of the liquid and $E$ is the applied electric field.

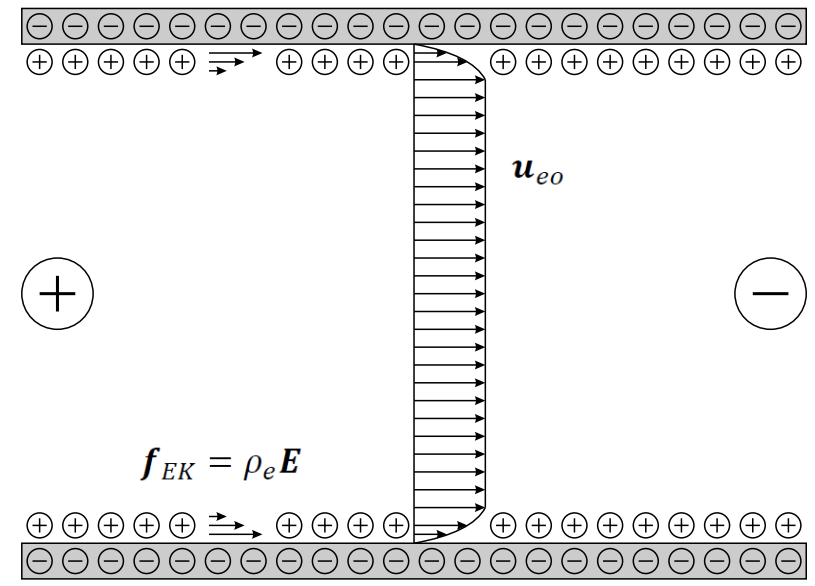

Figure 1.5: Illustration of EOF creation in a channel with negatively charged walls. $\boldsymbol{f}_{E K}$ represents the pulling body force.

Since the flow is generated from the walls by drag force and the bulk solution 
is electroneutral, the electric field has no effect on the bulk region. Therefore the flow profile becomes flat. The flow profile remains flat radially along the channel and independent of the channel size as long as the EDL thickness is negligible compared to the minimum channel dimension. Considering that commonly the EDL thickness stays within the 3-300 nm range, this assumption applies very well in microfluidic systems. Radial uniformity of the flow profile has an important effect on reducing the band broadening. Therefore it is possible to obtain higher plate counts for the same column structure with CEC than with HPLC [7, 13]. Figure 1.6 shows the differences in flow profiles in a channel with EOF and pressure driven (PD) modes of operation.

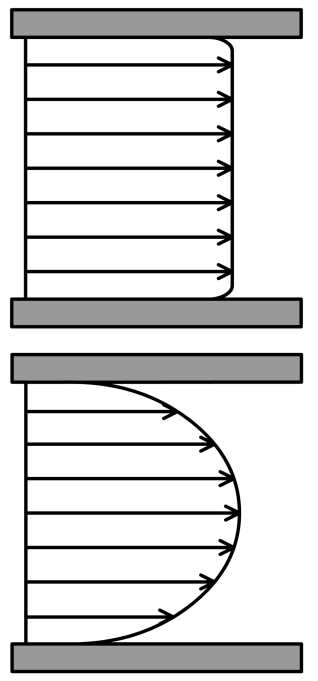

(a)

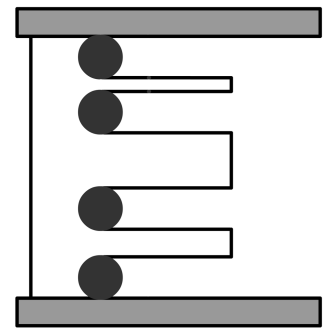

(b)

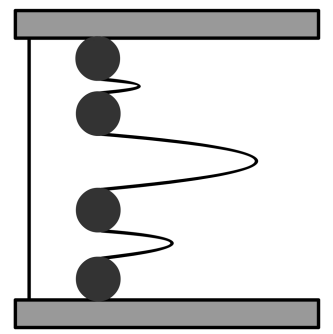

Figure 1.6: Flow profiles inside the channel with EOF (a) and PD (b) pumping with and without obstacles [19].

\subsection{Landmarks of microchip CEC}

In 1994, the first electrochromatographic separation on microchip was reported by Jacobson et al. [21]. Microchannels were fabricated by wet etching of glass and direct bonding of a cover plate onto it. Inner surfaces of trapezoidally shaped microchannels were functionalized as a stationary phase by coating with a monolayer of octadecylsilane (C18). Three neutral coumarin dyes were baseline separated in 170 
s using an effective separation channel length of $5.8 \mathrm{~cm}$, yielding plate heights of 5 and $45 \mu \mathrm{m}$ for C440 (almost non-retained) and C460 (the most retained), respectively (Figure 1.7).
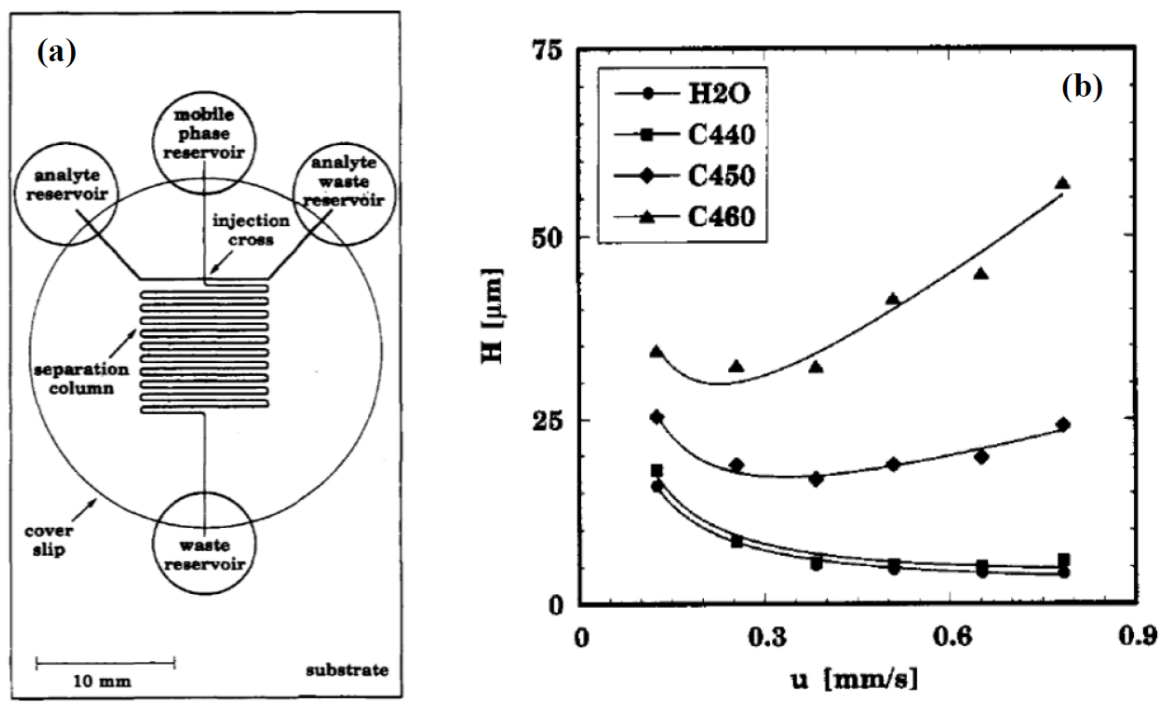

Figure 1.7: Channel design layout (a) and plate height vs. linear velocity plot of the coumarin dyes (b) of the first reported microchip electrochromatographic separation by Jacobson et al. [21]

In 2000, Oleschuk et al. reported the use of packed beds in microchip CEC [22]. They fabricated the microchip from quartz plates. A $330 \mathrm{pL}$ cavity was filled with 1.5-4.0 $\mu \mathrm{m}$ diameter $C_{18}$ coated silica beads through $1 \mu \mathrm{m}$ high weirs. The beads were loaded and removed from the cavity by means of electroosmotic pumping through a special introduction channel. This allowed the beads to be repeatedly exchanged. Fluorescein and BODIPY were separated in $200 \mu \mathrm{m}$ long column in $20 \mathrm{~s}$ with a resulting plate height of $2 \mu \mathrm{m}$ (Figure 1.8).

In 2000, Ericson et al. reported the use of continuous beds (monoliths) in microchip CEC [23]. The half-circular microchannels were wet etched in the quartz plate and an oxidized polysilicon/TEOS oxide stack was used to cover the channels. The separation column was a continuous rod of covalently linked $0.10 .4 \mu \mathrm{m}$ polymer microstructures. It was prepared by chemically initiated copolymerization. Following a pre-treatment for surface activation, the monomer solution was pumped into the 

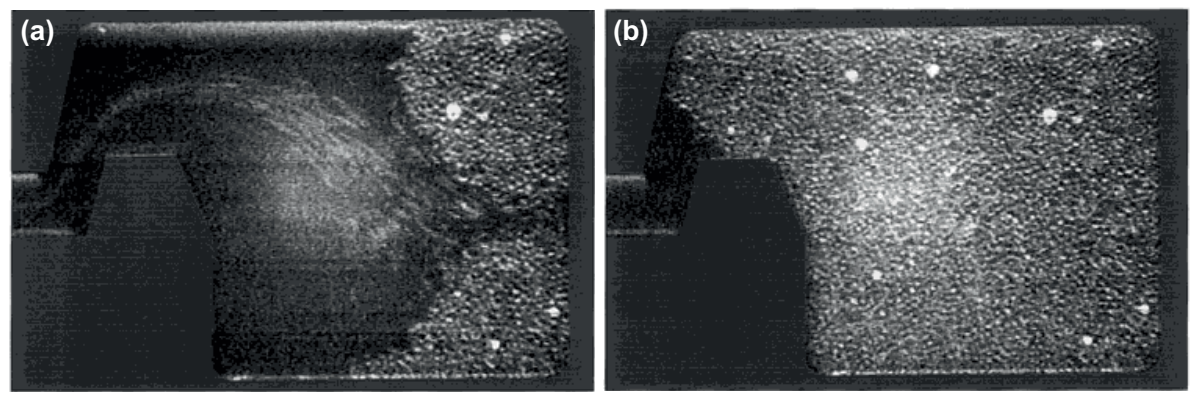

Figure 1.8: First reported packed bed microchip electrochromatography by Oleschuk et al. Images of the chamber at an initial stage of electrokinetic packing (a) and after it is completely filled with beads (b) [22].

separation channel by pressurizing the reservoir with nitrogen and left overnight for polymerization (Figure 1.9). Six alkylphenones and three tricyclic antidepressants were separated in $18 \mathrm{~min}$.
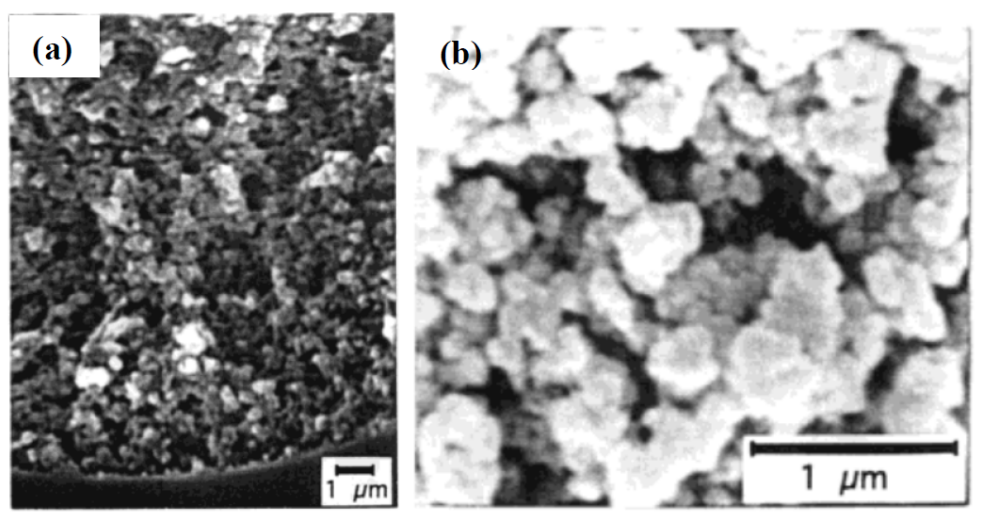

Figure 1.9: First reported chemically synthesized monolithic column for microchip CEC [23]. SEM images of macrostructure of the continuous bed.

In 1998, He et al. presented a microfabricated column format, collocated monolith support structures (COMOSS), as they called it. The design consisted in a collection of pillar columns, which were realized during the same fabrication step as the microchannels (Figure 1.10). The quartz substrate was dry etched in order to obtain vertical sidewalls. Since COMOSS were an integral part of the microfluidic device, the column was secured to avoid deformation during the CEC application. Additionally, the channel dimensions were no longer an issue for the packing process and the width 
of the channels could be varied independently of the size and shape of the support structures. The size of COMOSS were $5 \times 5 \times 10 \mu \mathrm{m}$ and they were separated by 1.5 $\mu \mathrm{m}$ wide and $10 \mu \mathrm{m}$ deep rectangular channels. The width and effective separation length of the separation column were $150 \mu \mathrm{m}$ and $4.5 \mathrm{~cm}$, respectively, yielding a total volume of $18 \mathrm{~nL}$. Column efficiency was evaluated using rhodamine 123 and a hydrocarbon stationary phase. Obtained plate height values were around $1.3 \mu \mathrm{m}$ in CEC mode of operation [24].

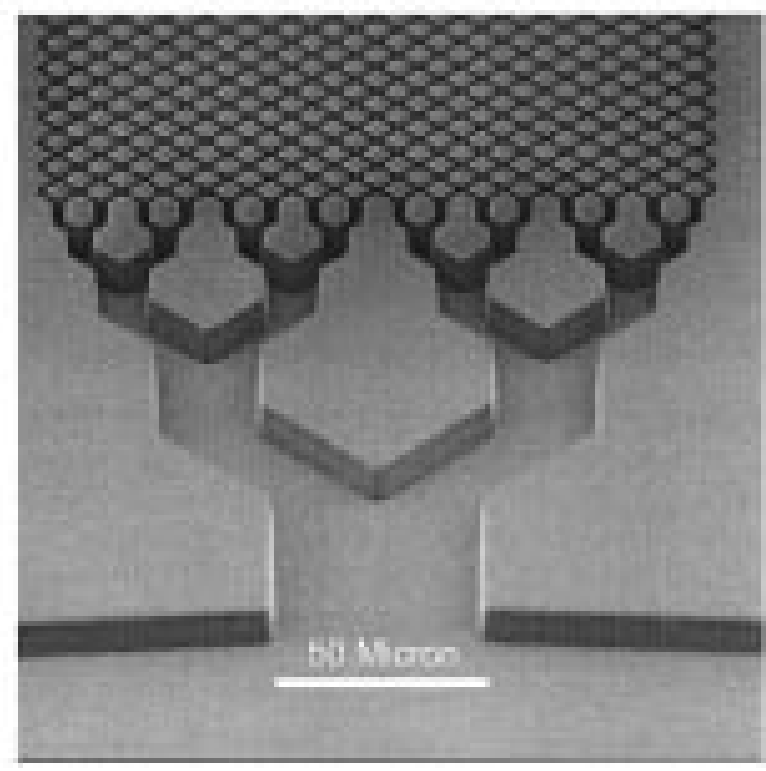

Figure 1.10: First reported microfabricated columns for microchip CEC by He et al. SEM image of COMOSS [24].

\subsection{Aim of study}

The introduction of microfabricated column structures for microchip liquid chromatography by Regnier and his co-workers in 1998 has shown the potential of microfabrication techniques. Whereas previous approaches relied on a reapplication of a conventional packed bed or chemically synthesized monolithic column technology in chip format, the COMOSS design was the first demonstration of a micromachined 
stationary phase support. Several follow up studies were performed. The Regnier team published a few papers on different column designs and materials [25-27]. Kutter and co-workers focused on different materials and detection methods [28, 29], keeping the same design layout as Regnier.

The main achievements that took this technology to a next level were accomplished not in CEC but in HPLC. Desmets group published a series of both theoretical and experimental studies on design, optimization and implementation of micromachined pillar systems [30-37]. Recently, De Malsche et al. proposed a solution to a major drawback of microfabricated pillar columns, which is the loadability, by introducing porous shell pillars fabricated by anodization of silicon [38]. Another approach addressing the same issue was reported by Detobel et al. proposing a sol-gel method to deposit a coating, in combination with the pillar column technology [39].

The aim of the study in this thesis is to explore the possibilities of further optimizing and characterizing pillar columns for microchip electrochromatography and perform similar achievements as mentioned above. Taking the advantage of the flat flow profile of EOF pumping without a pressure drop through the channel, it was aimed to reveal the potential of microchip CEC as a tool for high performance applications.

\subsection{Outline of the thesis}

In Chapter 2, a theoretical simulation study is performed for optimizing the shape and placement of the pillar columns. A new foil definition is introduced as a superior geometry definition among the reported basic geometrical shapes in the literature. The placement of the pillars is standardized with an equivalent channel width definition by keeping the hydrodynamic balance. Lastly, a first order modeling of chromatographic reactions for solid pillars is implemented and simulation results are presented for different cases including electrokinetic and pressurized pumping.

In Chapter 3, the proposed and analyzed design alternatives are implemented and the columns are realized in fused silica microchips. The experiments are performed in both retained and non-retained conditions with neutral coumarin dyes. The results 
are presented with plate height graphs and kinetic plot method (for the first time for a microchip CEC system). Lastly, a separation is performed using the foil-shaped pillars.

In Chapter 4, a new approach is presented for designing an injector/distributor structure for pillar columns. Instead of the typical bifurcated distributor/collector layout, the foil definition was applied to define the injector geometry, yielding a narrow and flat profile for the injected sample with enhanced concentration arising from the stacking effect. Injection experiments and mobility measurements are reported for comparing the new design with the typical bifurcated injector. Lastly, a separation experiment is performed.

In Chapter 5, fabrication of an integrated porous glass layer on structured surfaces for electrokinetic applications is presented. The fabrication method, starting from the anodization of silicon followed by conversion of the porous silicon layer into porous silica glass by means of thermal oxidation, is described step by step together with an optimization of process parameters. The critical points of fabrication for realization of the microchips are also discussed. Lastly, the porous glass layer is characterized optically and electrically.

In Chapter 6, conclusions are drawn and perspectives for future developments are discussed.

\section{References}

[1] (17 September 2012). Available: https://www.google.com.

[2] W. J. Lough and I. W. Wainer. High Performance Liquid Chromatography, Fundamental Principles and Practice. Blackie Academic \& Professional, Glasgow, 1996.

[3] M. Tswett. Adsorptionsanalyse und chromatographische methode. anwendung auf die chemie des chlorophylls. Berichte der Deutschen Botanischen Gesellschaft, 24:384, 1906.

[4] M. Tswett. Physikalisch-chemische studien über das chlorophyll. die adsorptionen. Ber Deutsch Bot Ges, 24:316-323, 1906.

[5] AJP Martin and RLM Synge. A new form of chromatogram employing two liquid phases: A theory of chromatography. 2. application to the micro-determination 
of the higher monoamino-acids in proteins. Biochemical Journal, 35(12):1358, 1941.

[6] H.H. Strain. On the combination of electrophoretic and chromatographic adsorption methods. Journal of the American Chemical Society, 61(5):1292$1293,1939$.

[7] V. Pretorius, BJ Hopkins, and JD Schieke. Electro-osmosis: A new concept for high-speed liquid chromatography. Journal of Chromatography A, 99:23-30, 1974 .

[8] Keith D. Bartle and Peter Myers. Capillary Electrochromatography. RSC Chromatography Monographs. The Royal Society of Chemistry, Cambridge, 2001.

[9] DL Mould and RLM Synge. Separations of polysaccharides related to starch by electrokinetic ultrafiltration in collodion membranes. Biochemical Journal, $58(4): 571,1954$.

[10] J.W. Jorgenson and K.D.A. Lukacs. High-resolution separations based on electrophoresis and electroosmosis. Journal of Chromatography A, 218:209-216, 1981.

[11] T. Tsuda. Electrochromatography using high applied voltage. Analytical Chemistry, 59(3):521-523, 1987.

[12] JH Knox and IH Grant. Miniaturisation in pressure and electroendosmotically driven liquid chromatography: Some theoretical considerations. Chromatographia, 24(1):135-143, 1987.

[13] JH Knox and IH Grant. Electrochromatography in packed tubes using 1.5 to 50 $\mu \mathrm{m}$ silica gels and ods bonded silica gels. Chromatographia, 32(7):317-328, 1991.

[14] NW Smith and MB Evans. The analysis of pharmaceutical compounds using electrochromatography. Chromatographia, 38(9):649-657, 1994.

[15] J. Calvin Giddings. Dynamics of Chromatography, Part 1: Principles and Theory. Marcel Dekker, New York, 1965.

[16] JJ Van Deemter, FJ Zuiderweg, and A Klinkenberg. Longitudinal diffusion and resistance to mass transfer as causes of nonideality in chromatography. Chemical Engineering Science, 5(6):271-289, 1956.

[17] J.H. Knox. Practical aspects of lc theory. Journal of Chromatographic Science, 15(9):352-364, 1977.

[18] G. Karniadakis, A. Beskok, and N. Aluru. Microflows and nanoflows: fundamentals and simulation, volume 29. Springer, New York, 2005.

[19] JH Knox. Thermal effects and band spreading in capillary electro-separation. Chromatographia, 26(1):329-337, 1988. 
[20] James P. Landers. Handbook of Capillary and Microchip Electrophoresis and Associated Microtechniques. CRC Press, Boca Raton, FL, 2008.

[21] S.C. Jacobson, R. Hergenröder, L.B. Koutny, and J.M. Ramsey. Open channel electrochromatography on a microchip. Analytical Chemistry, 66(14):2369-2373, 1994.

[22] R.D. Oleschuk, L.L. Shultz-Lockyear, Y. Ning, and D.J. Harrison. Trapping of bead-based reagents within microfluidic systems: on-chip solid-phase extraction and electrochromatography. Analytical Chemistry, 72(3):585-590, 2000.

[23] C. Ericson, J. Holm, T. Ericson, and S. Hjertén. Electroosmosis-and pressuredriven chromatography in chips using continuous beds. Analytical Chemistry, $72(1): 81-87,2000$.

[24] B He, N Tait, and F Regnier. Fabrication of nanocolumns for liquid chromatography. Analytical Chemistry, 70(18):3790-3797, 1998.

[25] FE Regnier. Microfabricated monolith columns for liquid chromatography. sculpting supports for liquid chromatography. Journal of High Resolution Chromatography, 23(1):19-26, 2000.

[26] Benjamin E. Slentz, Natalia A. Penner, and Fred Regnier. Geometric effects of collocated monolithic support structures on separation performance in microfabricated systems. Journal of Separation Science, 25(15-17):1011-1018, 2002.

[27] Xiang Zhang and Fred E. Regnier. Analysis of channel-geometry effects on separation efficiency in rectangular-capillary electrochromatography columns. Journal of Chromatography A, 869(1-2):319-328, 2000.

[28] Omar Gustafsson, Klaus B. Mogensen, and Jörg P. Kutter. Underivatized cyclic olefin copolymer as substrate material and stationary phase for capillary and microchip electrochromatography. Electrophoresis, 29(15):3145-3152, 2008.

[29] Klaus B. Mogensen, Fredrik Eriksson, Omar Gustafsson, Rikke P. H. Nikolajsen, and Jörg P. Kutter. Pure-silica optical waveguides, fiber couplers, and high-aspect ratio submicrometer channels for electrokinetic separation devices. Electrophoresis, 25(21-22):3788-3795, 2004.

[30] J. Billen, P. Gzil, J. De Smet, N. Vervoort, and G. Desmet. Slow analyte diffusion effects on the a-term band broadening in macromolecular liquid chromatography separations. Analytica Chimica Acta, 557(1-2):11-18, 2006.

[31] J Billen, P Gzil, N Vervoort, GV Baron, and G Desmet. Influence of the packing heterogeneity on the performance of liquid chromatography supports. Journal of Chromatography A, 1073(1-2):53-61, 2005.

[32] M De Pra, W De Malsche, G Desmet, PJ Schoenmakers, and WT Kok. Pillarstructured microchannels for on-chip liquid chromatography: Evaluation of the permeability and separation performance. Journal of Separation Science, 30(10):1453-1460, 2007. 
[33] M. De Pra, W. Th Kok, J. G. E. Gardeniers, G. Desmet, S. Eeltink, J. W. van Nieuwkasteele, and P. J. Schoenmakers. Experimental study on band dispersion in channels structured with micropillars. Analytical Chemistry, 78(18):6519$6525,2006$.

[34] J De Smet, P Gzil, N Vervoort, H Verelst, GV Baron, and G Desmet. Influence of the pillar shape on the band broadening and the separation impedance of perfectly ordered 2-d porous chromatographic media. Analytical Chemistry, 76(13):3716-3726, 2004.

[35] Gert Desmet, David Clicq, and Piotr Gzil. Geometry-independent plate height representation methods for the direct comparison of the kinetic performance of lc supports with a different size or morphology. Analytical Chemistry, 77(13):40584070, 2005.

[36] P. Gzil, J. De Smet, N. Vervoort, H. Verelst, G. V. Baron, and G. Desmet. Computational study of the band broadening in two-dimensional etched packed bed columns for on-chip high-performance liquid chromatography. Journal of Chromatography A, 1030(1-2):53-62, 2004.

[37] P Gzil, N Vervoort, GV Baron, and G Desmet. Advantages of perfectly ordered 2-d porous pillar arrays over packed bed columns for lc separations: A theoretical analysis. Analytical Chemistry, 75(22):6244-6250, 2003.

[38] W. De Malsche, D. Clicq, V. Verdoold, P. Gzil, G. Desmet, and H. Gardeniers. Integration of porous layers in ordered pillar arrays for liquid chromatography. Lab Chip, 7(12):1705-1711, 2007.

[39] F. Detobel, S. De Bruyne, J. Vangelooven, W. De Malsche, T. Aerts, H. Terryn, H. Gardeniers, S. Eeltink, and G. Desmet. Fabrication and chromatographic performance of porous-shell pillar-array columns. Analytical Chemistry, 82(17):7208-7217, 2010. 


\section{Chapter 2}

\section{Novel shape and placement definitions with retention modeling for solid microfabricated pillar columns for CEC and HPLC}

A novel design approach for optimizing the shape of microfabricated pillar columns for liquid chromatography is presented. 2-D flow simulations are performed with a focus on electrokinetically driven flow, in order to evaluate the performance of the new method. The proposed foil shape is compared with geometrical shapes known from literature, for various arrangements. It yields a much more uniform velocity field distribution and a decrease in plate height values up to $25 \%$. In addition to shape optimization, a new method for spatial arrangement of structures is presented. With the aim of conserving the hydrodynamic balance, the axial spacing of the pillars is adjusted according to the proposed equivalent width approach. When compared with a fixed interpillar spacing in all directions, it increases the flow uniformity and results in an $18 \%$ lower plate height. A new direct simulation approach is implemented to model both flow field and retention for solid microfabricated pillar structures in the 2-D domain. This model, which defines retention as inward/outward fluxes through the wall surfaces as first order reactions, enables monitoring of the time dependent process and an evaluation of the parameters affecting performance. The meaning of the obtained results in a practical setting, with limitations in photolithography and microfabrication, will be highlighted.

This chapter has been published as Novel shape and placement definitions with retention modeling for solid microfabricated pillar columns for CEC and HPLC, Sukas, S., Desmet, G., and Gardeniers, H.J.G.E. Electrophoresis, 2010, 31(22), 3681-3690. 


\section{$2.1 \quad$ Introduction}

When the idea of using microfabricated pillar structures for liquid chromatography was first introduced by He et al [1], it was shown that it is possible to reach much lower plate heights by using such structures compared to conventional packed columns. It was demonstrated that microfabricated pillars are more preferable than packed beds since the definition by photolithography offers perfectly ordered column structures. This fact initiated several studies in which different geometrical shapes, such as circles, diamonds, hexagons, in various arrangements were optimized and compared in terms of performance, both experimentally $[2,3]$ or theoretically [4-10]. In this study, we will follow up on these optimization studies, by reconsidering some of the basic assumptions, in order to achieve a more applicable comparison of lithographically defined shapes.

In order to design or evaluate the performance of the shape of the column structure, one should first construct the right design environment. Since experimental studies are based on observations, exploring the effects of every possible driving mechanism is either impossible or time consuming even without taking into account the labor for fabrication. However, once a valid model is constructed, computational studies offer the ability of playing with the system variables and evaluating their effects independently in much shorter time periods. On the other hand, the validity of the model is strongly dependent on its accuracy. In order to get accurate results for complex problems, such as retention modeling in chromatography, one needs high computational power. Together with the rapid development in computer technology in the last decades, Gzil and co-workers published valuable papers on modeling of retention in $\mathrm{LC}$ for microfabricated porous pillars $[6,7]$. They defined retention as the mobility difference of the analyte in mobile and porous stationary phases. Different mobilities of the sample arose from different diffusion coefficients defined for mobile and stationary phases according to the experimental data for conventional columns with porous particles. In other words, retentive conditions were imitated by this method. One important limitation of this model, which is directly related to the present study, is that retention disappears when the internal porosity of the column 
structures is set to zero. Yet it is also known from experimental work that excellent retention can be achieved with monolayers of e.g. C18-molecules on solid particles or non-porous pillars [11]. Since for such columns the sample molecules are mobile only in the mobile phase and immobile on the particle or pillar surface, it is not possible to define a sample that is continuously mobile and has a variable mobility due to its migration within different zones. Therefore Gzil's model does not apply to non-porous columns and a different model is needed to describe retention for solid pillars.

Referring to the above mentioned issues, the first aim of this study is to explore the possibility of defining and further optimizing the shape of the microfabricated column structures, while the second aim is to construct a new computational model for retention modeling, which is valid for non-porous column structures, and to apply this model to both EK and PD flow cases. The paper will have a focus on EK flow, which is the driving force applied in capillary electrochromatography, CEC, a method that has been implemented in a chip format both with polymeric monoliths as column material [12] as well as with micromachined pillar structures [1, 3, 13]. As has been pointed out by Knox [14], a striking feature of CEC compared to pressure-driven HPLC is that for the same column the reduced plate heights in CEC (with a minimum value of 1 ) are lower than in HPLC (with a minimum value of 2 ), which was ascribed to the more uniform velocity profile in EK flow. Knox furthermore suggested that in CEC still a further decrease in the reduced plate height is possible, by improving the uniformity of the packing, as he calls it.

In previous work it was demonstrated both theoretically [5-8] and experimentally $[2,11,15,16]$ that reduced plate heights for HPLC in columns with micromachined cylindrical pillars can be significantly lower than 1 . In this paper we will theoretically investigate how low the reduced plate height can be in a shape-optimized micromachined CEC column.

\subsection{Modeling}

The modeling performed in this study can be divided into two main parts. The first part is stationary flow modeling, after which in a second step, time dependent 
retention modeling will be performed, using the data obtained from flow modeling. The key performance indicator to be derived from the modeling is the (reduced) plate height, as a function from the main adjustable variable in chromatography, the (reduced) velocity of the liquid through the column.

In this study we will restrict ourselves to $2 \mathrm{D}$ simulations, mainly because 3D simulations are very time-consuming and therefore can only be performed for relatively small column sections. It has been pointed out in a number of publications that for pressure driven flow, 2D simulations may give a very good first order estimate of sample dispersion in pillar columns, but they do not include the very important additional band broadening caused by the top and bottom walls of the column, which is a dispersion of the Taylor-Aris type, caused by molecular diffusion across streamlines moving with different velocities. This band broadening has been studied in great detail by $3 \mathrm{D}$ simulations in a number of recent publications $[17,18]$. Of particular interest to the present work are the results of De Smet et al. [17], who have concluded that, for a typical aspect ratio (i.e. height-to-width ratio of etched features) values between 4:1 and 10:1 (state-of-the-art Directional Reactive Ion Etching, DRIE, to micromachine pillars in silicon would allow for an aspect ratio of ca. 20 at the most [19]), the band broadening in terms of plate heigh for the 3D evaluation are significantly larger than the $2 \mathrm{D}$ results, by a factor 1.5 around the minimum in the van Deemter curve (reduced velocity of ca. 20) and up to a factor of 5 in the large velocity regime (reduced velocity of 70). The additional contribution to the plate height, due to top and bottom walls, has similar behavior as the C-term in the van Deemter equation (see below), which means that it increases linearly with velocity. The $3 \mathrm{D}$ simulation results have been confirmed by experimental work [20].

For the EK flow case, due to the near-plug velocity profile, the situation is much less dramatic, and in particular for high pillar structures achievable with DRIE, which are the pillars we are considering in this study, the contribution of the top and bottom walls may be neglected. 


\subsubsection{Stationary flow modeling}

In order to determine the flow field for both EK and PD flows, incompressible NavierStokes equations [21] are solved:

$$
\begin{gathered}
\rho(\boldsymbol{u} \cdot \nabla) \boldsymbol{u}=-\nabla p+\mu \nabla^{2} \mathbf{u}+\boldsymbol{f}_{E K} \\
\nabla \cdot \boldsymbol{u}=0
\end{gathered}
$$

where $p$ is the pressure, $\boldsymbol{u}$ is the velocity field, $\rho$ is the fluid density, $\mu$ is the viscosity, and $\boldsymbol{f}_{E K}$ is the EK body force. Continuity equation (Equation 2.2) represents the conservation of mass.

When solving for EK flow, the body force term in Equation 2.1 for constant electric permittivity is defined as:

$$
\boldsymbol{f}_{E K}=\rho_{e} \boldsymbol{E}
$$

where $\rho_{e}$ is charge density, and $\boldsymbol{E}$ is applied electric field.

Driving mechanism for the creation of the flow for the EK case (called electroosmotic flow, EOF) is the shear effect of the migrating ions in the mobile region of the EDL. If the thickness of the EDL is negligible compared to a characteristic dimension of the flow channel (in our case the minimal spacing between pillars), this shear effect can be considered as a slipping wall. In order to calculate this slip velocity, the Helmholtz-Smoluchowski equation is used [21]:

$$
\boldsymbol{u}_{e o}=\frac{-\zeta \varepsilon}{\mu} \boldsymbol{E}
$$

Where $\zeta$ is the zeta potential (here taken equal to a value of $-100 \mathrm{mV}$, typical for fused silica surfaces in aqueous analytes at neutral $\mathrm{pH}$ ), and $\varepsilon$ is the electric permittivity (here taken equal to that of water). In this study we will restrict ourselves to cases where the EDL is much smaller that the mentioned characteristic dimension, so that EDL overlap is avoided. The effect of EDL overlap has to be taken into 
account if downscaling of pillars, to give spacings below ca. $100 \mathrm{~nm}$, is considered $[22]$.

For the PD case, the flow is generated by pumping liquid from the inlet(s). Therefore, a pressure drop is generated throughout the microchannel. Since there is no applied electrical potential and the injected species are considered to not cause any induced charging, the EK body force in Equation 2.1 vanishes.

\subsubsection{Time dependent species transport \& retention modeling}

After solving for the steady state flow field, in other words determining the velocity distribution, a neutral marker is injected virtually and its concentration profile is monitored while it is migrating within the carrier liquid. Therefore, a convectiondiffusion-migration equation [23] is used for both EK and PD flow cases:

$$
\frac{\partial c}{\partial t}=-\nabla\left(c \boldsymbol{u}-D \nabla c+\frac{z F D c}{R T} \boldsymbol{E}\right)+r
$$

where $c$ is concentration, $D$ is diffusivity, $z$ is the valence of the ionic species, $F$ is Faradays constant, $R$ is gas constant, and $T$ is temperature. The last term in Equation 2.5, $r$ represents the reaction rate inside the bulk fluid, which is taken as zero.

The retention modeling is performed by defining the adsorption-desorption reactions as inward/outward fluxes on the wall surfaces within the domain. Surface reaction as an outward flux term (negative value means the flux is inward) is defined as $[24]$ :

$$
\boldsymbol{n}=k_{a} c_{m}-k_{d} c_{s}
$$

Where $k_{a}$ and $k_{d}$ are first order forward and backward rate constants, $c_{m}$ is the concentration of the species in mobile phase, and $c_{s}$ is the concentration of the species in stationary phase (adsorbed). Defining the flux term and selecting the surface of the stationary phase as a solution domain, Equation 2.5 can be reformed without convective and diffusive terms since the species are immobile in this zone. Therefore 
the time rate of change of the concentration of the adsorbed species becomes equal to the surface reaction rate, which is represented as:

$$
\frac{\partial c}{\partial t}=k_{a} c_{m}-k_{d} c_{s}
$$

Before solving this equation set, one last conversion should be defined. As mentioned, the term $c$ in Equation 2.5 represents the concentration of the species in the bulk liquid (mobile phase), therefore concentration per volume. On the other hand, the concentration term for the mobile species in Equations 2.6 and 2.7 is defined on the surface of the stationary phase, consequently it represents the concentration per surface area. Making the conversion, $c_{m}$ is defined as:

$$
c_{m}=\varphi c
$$

where $\varphi$ is the phase ratio, which is defined as the ratio of the mobile phase (bulk liquid) volume to the stationary phase (total active surface) area in the determined solution domain.

\subsection{Simulations}

Flow simulations were performed with COMSOL Multiphysics ${ }^{T M}$ [25], which is a Finite Element Method based multiphysics software. Instead of modeling with a graphical user interface, the entire solution process including the geometry creation, meshing, solving, and post processing was executed with MATLAB scripts. Such a method was preferred instead of writing own codes from scratch, because it not only saves time by implementing the time consuming post-processing step, but also increases the accuracy of the solution by using the advanced meshing and stable solver capabilities of the software. Simulations were typically performed with the automatic time step function of the finite element solver, where the maximum time step was based on the mean velocity calculated from the stationary flow solution. 


\subsubsection{Model validation}

In order to check the validity of the model, flow simulations were performed for a 2-D straight channel geometry. As was discussed above, the applicability of a 2-D model for a prediction of the plate heights in a practical PD case is limited, so the numbers given below only serve as a first-order estimate and as a means for comparison of geometries.

The results for the straight channel geometry were compared with analytical solutions for theoretical plate height values. An array of parallel plates would be the ideal chromatographic column, however, in practice even the slightest defect in one of the channels formed by the plates would dramatically change separation performance. An example from the field of gas chromatography was given in the work of Schisla et al., who have demonstrated that even a $1 \%$ deviation in the diameters of capillaries can increase plate heights by an order of magnitude [26]. Although geometrical definition by photolithography is very advanced, such a strict tolerance on microchannel fabrication can not be considered to be realistic, particularly if one takes into account that methods like Deep Reactive Ion Etching, DRIE, which are needed to shape the vertical walls of the channels into e.g. silicon, may exhibit very slight lateral etching or tapering [19], or scalloping [16].

The analyzed geometry was selected as $100 \mu \mathrm{m}$ long and $1.6 \mu \mathrm{m}$ wide 2-D microchannel. It was divided into 5 parts each was $20 \mu \mathrm{m}$ long in longitudinal direction.

For the EK case, the EOF is generated by applying a finite potential to the inlet and keeping the outlet potential as zero. Electric field values between $0.1 \mathrm{kV} / \mathrm{cm}$ to $2 \mathrm{kV} / \mathrm{cm}$ were chosen, so that different velocities were analyzed.

For the PD case, the flow is generated by defining an inward velocity at the inlet, while the pressures at inlet and outlet, which are initially the same, are left to adjust in order to develop a pressure gradient along the channel which matches the set inlet velocity. Like the EK case, several inlet velocities were set in a range between 0.7 $\mathrm{mm} / \mathrm{s}$ to $14 \mathrm{~mm} / \mathrm{s}$.

As an injection method, a finite length (1 $\mu \mathrm{m}$ base width) neutral marker was 
placed at the first interface (20 $\mu \mathrm{m}$ far from the inlet) instead of feeding the sample continuously from the inlet. The concentration profile of the injected marker was monitored and the peaks were plotted over elapsed time and from that, the $H$ values were calculated for each interface.

There are several parameters required to be defined prior to calculate $H$. For the interface $i$, the zeroeth moment of the Gaussian distribution represents the peak area $A_{i}$ and is defined as [27]:

$$
M_{0, i}=A_{i}=\int_{i} c d t
$$

where $t$ is time, and $c$ is the concentration distribution plotted at the position of the interface. The first moment of the Gaussian distribution represents the retention time, which is the time required for the peak mean to arrive at the interface departing from the point of injection. Retention time is expressed as [27]:

$$
M_{1, i}=t_{R, i}=\frac{1}{A_{i}} \int_{i} c t d t
$$

The second moment of the Gaussian distribution represents the peak dispersion, which is defined as [27]:

$$
M_{2, i}=\sigma_{i}{ }^{2}=\frac{1}{A_{i}} \int_{i} c t^{2} d t-t_{R, i}{ }^{2}
$$

Finally, the theoretical plate height for the travel of the peak from interfaces $i$ to $j$ is determined by the following formula [27]:

$$
H_{j i}=\frac{\sigma_{j}{ }^{2}-\sigma_{i}{ }^{2}}{\left(t_{R, j}-t_{R, i}\right)^{2}} L_{j i}
$$

where $L_{j i}$ is the distance between the interfaces $i$ and $j$.

After calculating the plate height values for different velocities, the results were fitted with the van Deemter equation [28], which relates the plate height with the mobile phase velocity:

$$
H=A+B / u+C u
$$


The $A, B$, and $C$ terms obtained from this fit were compared with analytical solutions provided for the same geometry. Since the analyzed geometry was an open channel, there is no eddy diffusion observed, therefore the A term is zero. Analytical representations of $H$ for EK and PD cases are defined as [29, 30]:

$$
\begin{array}{r}
H_{E K}=\frac{l_{i n j}^{2}}{12 L_{s e p}}+\frac{2 D_{m}}{u}+\left(\frac{k}{1+k}\right)^{2} \frac{d^{2} u}{6 D_{m}}+\frac{2 k}{(1+k)^{2}} \frac{u}{k_{d}} \\
H_{P D}=\frac{l_{i n j}^{2}}{12 L_{\text {sep }}}+\frac{2 D_{m}}{u}+\frac{2}{210} \frac{1+9 k+25.5 k^{2}}{(1+k)^{2}} \frac{d^{2} u}{6 D_{m}}+\frac{2 k}{(1+k)^{2}} \frac{u}{k_{d}}
\end{array}
$$

where $l_{i n j}$ is the length of the injected plug, $L_{s e p}$ is the separation distance, $D_{m}$ is the diffusion coefficient of the analyte in the mobile phase, $u$ is the linear velocity of the mobile phase, $d$ is the width of the channel, and $k$ is the retention factor, which is defined as the ratio of the adsorption rate constant to desorption rate constant, i.e. $k=k_{a} / k_{d}$. Neglecting the contribution of injection to $H$ (first terms in Equations 2.14 and 2.15 ), the $B$ and $C$ terms can be defined as:

$$
\begin{gathered}
B_{E K}=B_{P D}=2 D_{m} \\
C_{E K}=\left(\frac{k}{1+k}\right)^{2} \frac{d^{2}}{6 D_{m}}+\frac{2 k}{(1+k)^{2}} \frac{1}{k_{d}} \\
C_{P D}=\frac{2}{210} \frac{1+9 k+25.5 k^{2}}{(1+k)^{2}} \frac{d^{2}}{6 D_{m}}+\frac{2 k}{(1+k)^{2}} \frac{1}{k_{d}}
\end{gathered}
$$

Flow simulations were performed for $k_{d}=25001 / \mathrm{s}, k=2$, and $D_{m}=10^{-9}$ $\mathrm{m}^{2} / \mathrm{s}$. Comparing the results of the simulations, the constructed model showed perfect agreement with the analytical solutions for both flow cases (Table 2.1).

\subsubsection{Solution domain}

The solution domain used in this study consisted of five successive unit cells extracted from an infinitely long and wide 2-D microchannel. Several parameters were defined 
Table 2.1: Comparison of the simulation results with analytical solutions for $A, B$, and $C$ terms of the van Deemter equation. Values calculated for $H$ are in $\mu \mathrm{m}$ and for $u$ in $\mathrm{mm} / \mathrm{s}$.

\begin{tabular}{ccccc} 
& \multicolumn{2}{c}{ Electrokinetic } & \multicolumn{2}{c}{ Pressure Driven } \\
\cline { 2 - 5 } & Analytical & Simulation & Analytical & Simulation \\
\hline A & 0 & $4.82 \mathrm{E}-7$ & 0 & $3.35 \mathrm{E}-6$ \\
\hline B & 2 & 2 & 2 & 2 \\
\hline C & 0.36741 & 0.36741 & 0.50557 & 0.50557 \\
\hline
\end{tabular}

for creating the unit cell geometry (Figure 2.1).

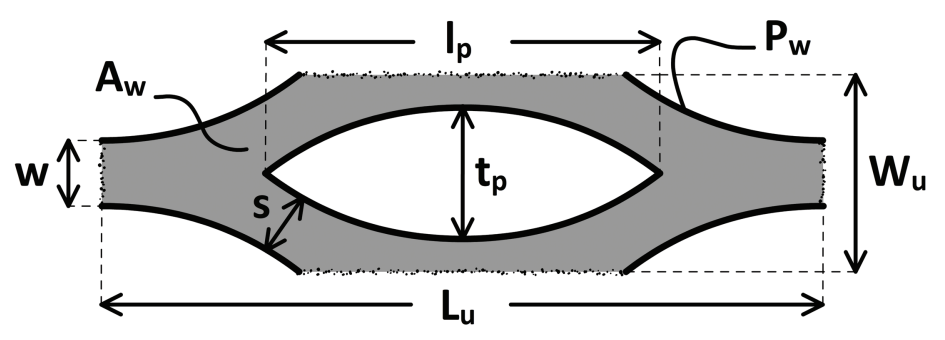

Figure 2.1: Illustration of the unit cell geometry. $L_{u}$ : unit cell length, $W_{u}$ : unit cell width, $l_{p}$ : pillar length, $t_{p}$ : pillar thickness, $s$ : minimum spacing, $w$ : entrance width, $A_{w}$ : wetted area, $P_{w}$ : wetted perimeter.

Flow simulations were performed in order to evaluate the performance of the pillar shapes. Walls were defined as surfaces acting as a stationary phase and the open boundaries, except inlet and outlet, were defined as symmetry boundaries. For the EK case, flow was driven from the pillar walls by electroosmotic mobility, which was calculated from the given zeta potential and viscosity for the determined electric field distribution. For the PD case, the velocities on the pillar walls were set to zero. Like in the model validation study, the interior boundaries were used for monitoring the concentration of the analyte as it passed these boundaries (Figure 2.2).

\subsubsection{Shape optimization}

To enhance chromatographic performance in terms of capacity and efficiency, a high stationary-to-mobile phase ratio and low disturbance of the flow field, leading to a 


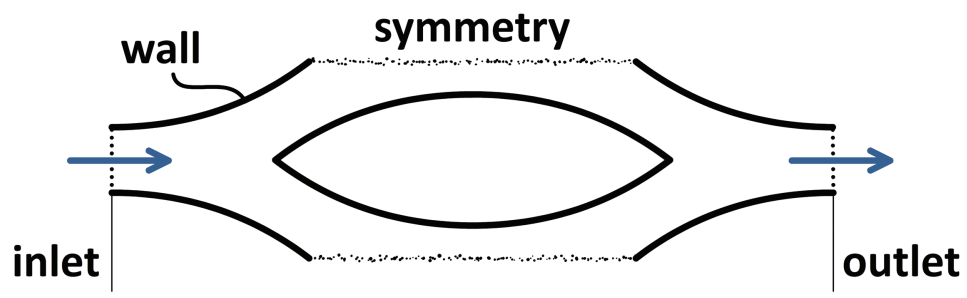

Figure 2.2: Illustration of the boundary conditions used in this study.

more uniform velocity distribution, are required, respectively. The former can be accomplished by using porous columns [11] or increasing the density of structures inside the channel, or more generally, by maximizing pillar surface area per column volume. Increasing pillar density for the same column volume principally means fabricating pillars with smaller dimensions. As it has been established that the reduced plate height principally does not change when the pillar (or particle) diameter is made smaller [31], which implies that the absolute plate height would scale linearly with the pillar footprint, it would be advantageous to develop pillar columns with as small as possible pillars. To exploit the advantage the porosity should be kept the same, which means that principally also the spacing between the pillars should be scaled down. The latter, as we have already indicated above, may become the bottleneck in the development, as the spacing is only a fraction of the pillar diameter, and therefore will be the first dimensional parameter that will suffer from photolithography or DRIE limitations. Another limitation, as was also mentioned above, in CEC is the spacing regime where EDL overlap starts to occur, which is where the model used in this paper would not be valid any longer. A full study of the effect of downsizing pillar shape is however beyond the scope of this work.

In the present study we restrict our modeling work to the aim of increasing the flow uniformity for structural dimensions in the range of several micrometers, which should be relatively easy to accomplish with state-of-the-art photolithography and micromachining processes. Since above we have established that the chosen 2-D model is valid for simple parallel channels, we now have (with the restrictions that 2-D simulations have) the ability to study different pillar shapes and their effects on performance, in order to find the optimum shape for the application. Besides 
previously studied geometrical shapes, such as circles, diamonds and hexagons, we will also introduce a new foil shape definition, for reasons which will be elaborated below.

In order to increase the uniformity in the flow field, local variations in velocity magnitude, i.e. stagnant or high velocity regions, should be minimized. Figure 2.3 shows the velocity field for EK flow around a circular pillar as a blunt body with large stagnant regions, causes sticking of the sample as it passes over the body, and as a result dispersion will increase dramatically. The observed maximum velocity for an applied electric field of $1 \mathrm{kV} / \mathrm{cm}$ was almost $11 \mathrm{~mm} / \mathrm{s}$, while the mean velocity was around $5.7 \mathrm{~mm} / \mathrm{s}$. These results show good qualitative agreement with previous modeling work [32].

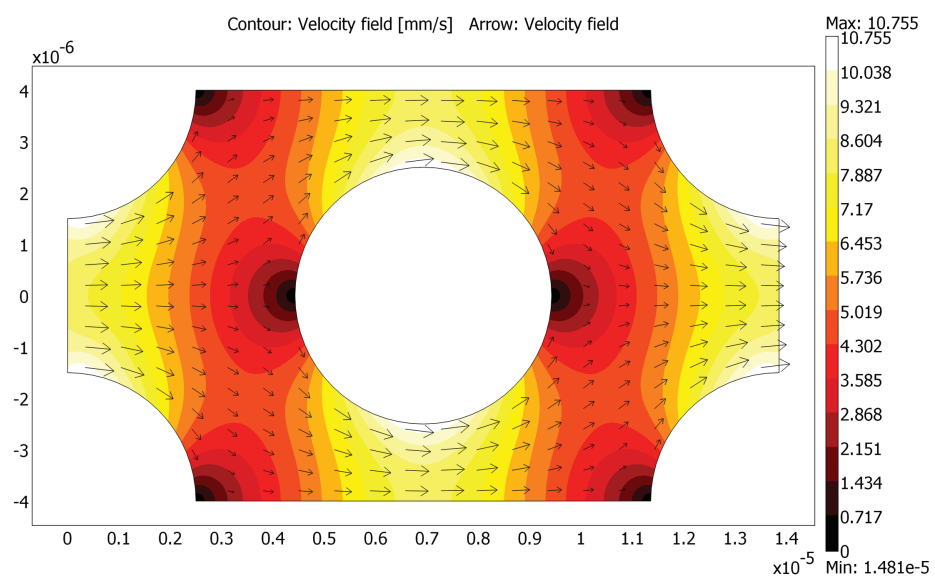

Figure 2.3: Velocity field distribution for EK flow over a circular pillar. Large stagnant regions can be seen upstream and downstream of the body, as black regions corresponding to zero velocity. Flow direction is left to right.

As a first step of the design procedure, streamlined bodies, which are high aspect ratio structures without abrupt changes in cross-section (i.e. width in 2-D), were selected as a shape definition. An airfoil, a well-known streamlined body, was selected as a starting point. Since it is favorable for avoiding sample dispersion to have no velocity components other than those in the flow direction, the uniformity of the flow field around a symmetric airfoil section was evaluated first. For an applied electric 
field of $1 \mathrm{kV} / \mathrm{cm}$, the mean velocity was found to be $6.43 \mathrm{~mm} / \mathrm{s}$, while the maximum velocity was around $10 \mathrm{~mm} / \mathrm{s}$ (Figure 2.4).

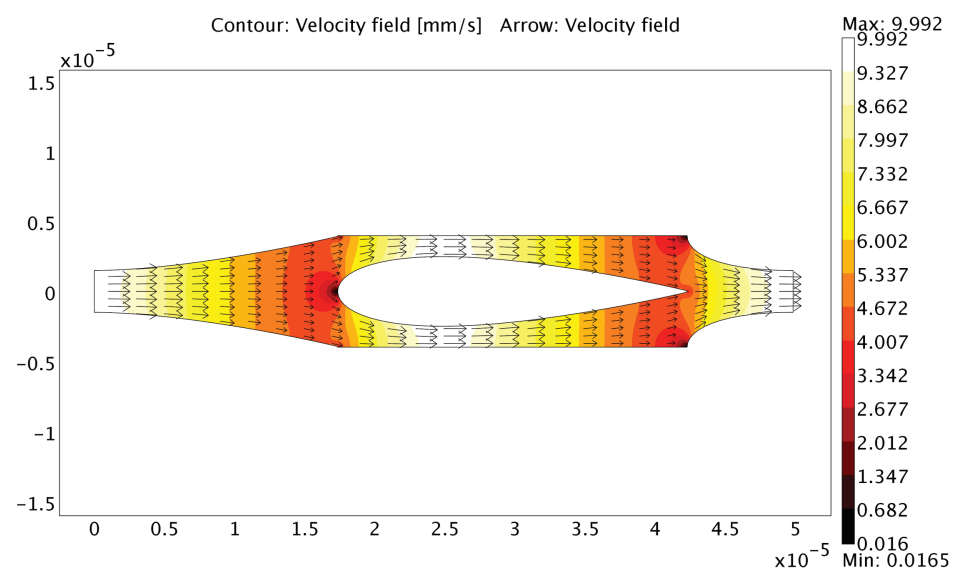

Figure 2.4: Velocity field distribution for EK flow over a symmetric airfoil-shaped pillar. A small stagnant region at the leading edge of the foil can be observed. Flow direction is left to right.

Although the obtained flow field was much more uniform than for a blunt body, there was still a small stagnant region left around the leading edge. In order to avoid this region, a custom foil shape was defined, which yields to displacement of the maximum thickness point to the center of the structure and to a more compact placement throughout the microchannel.

Using the basic definition for a symmetric airfoil, a $4^{\text {th }}$ order polynomial was defined for creating the upper geometry:

$$
y_{u}=a_{0} \sqrt{x}+a_{1} x+a_{2} x^{2}+a_{3} x^{3}+a_{4} x^{4}
$$

Above equation was solved for 5 control parameters to obtain the upper half of the geometry: 1. Pillar length, 2. Pillar thickness, 3. Position of maximum thickness, 4. Radius of curvature at leading edge, 5. Slope at trailing edge. The bottom half was obtained by taking a mirror plane along the chord of the foil.

Besides on shape, flow uniformity also depends on the placement of the microstructures; in other words, the change in resistance against fluid motion. 
Maintaining hydrodynamic balance ideally means to keep the channel cross-section constant along the flow direction. However, in practice only hexagons fulfill this requirement. Therefore, a geometry-independent method is required, which is found by a new equivalent width definition for placing the microfabricated column structures. Briefly, the approach is defining the axial pillar spacing (the entrance width of the unit cell) as the width of an empty channel with the same length and total fluid area as the unit cell (Figure 2.5).

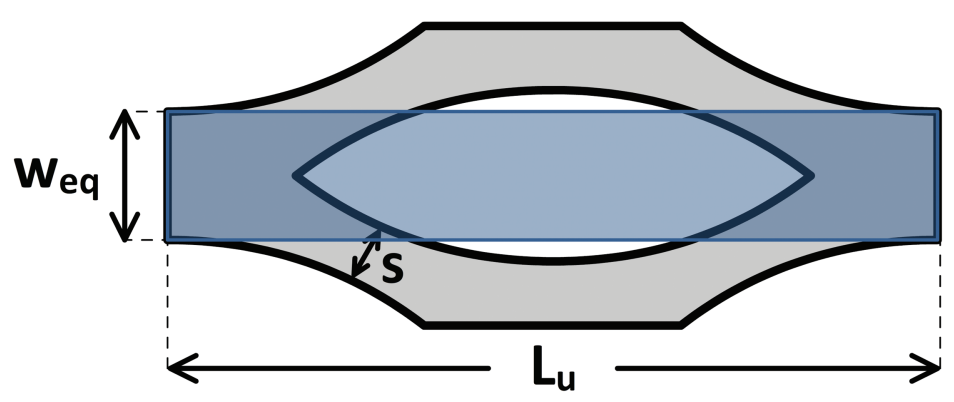

Figure 2.5: Illustration of equivalent width definition.

In order to evaluate the validity of the definition, EOF simulations were performed for a foil shape with $25 \mu \mathrm{m}$ length, $5 \mu \mathrm{m}$ width and $3 \mu \mathrm{m}$ minimum interpillar spacing. It is found that, with this approach, the mean flow velocity increases from $0.65 \mathrm{~mm} / \mathrm{s}$ to $0.68 \mathrm{~mm} / \mathrm{s}$, while the maximum velocity decreases from $0.96 \mathrm{~mm} / \mathrm{s}$ to $0.76 \mathrm{~mm} / \mathrm{s}$, i.e. a more uniform velocity distribution is obtained. In addition to the calculated equivalent value, several different entrance widths were analyzed and the lowest plate height was obtained around the proposed equivalent width (Figure 2.6).

\subsection{Results and discussion}

Flow simulations together with retention modeling were performed in 2-D for both EK and PD flow cases. Various alternative pillar geometries were assessed to evaluate the effect of different shape definitions, and from these the diamond and hexagonal shapes were selected for comparison with the foil definition since these structures were superior in performance compared to the other geometries, such as circles. Although a 


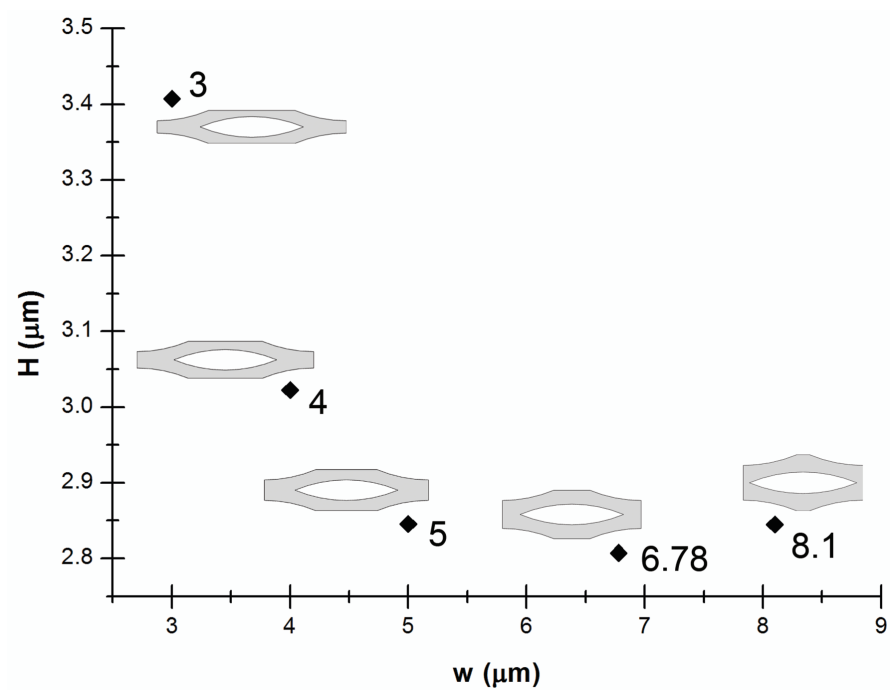

Figure 2.6: Dependence of plate height for various axial pillar spacings, for the EK case. The lowest plate height value is reached around the calculated equivalent width $(6.78 \mu \mathrm{m})$ for the analyzed geometry. $E=100 \mathrm{~V} / \mathrm{cm}$.

mesh-independent solution was reached for 25,000 elements per unit cell, simulations were performed with more than 40,000 elements with adaptive mesh refinement for the velocity profile, in order to increase accuracy. Additionally, an automatic timestepping feature was used for retention modeling, which increases the convergence, hence the accuracy of the solution by scaling the step size in every time-step according to the calculated residuals. The same physical properties and modeling approach were used as described above in the model validation section.

In a first step, unit cells with different aspect ratios were tested, from which it turned out that it is favorable to have an as high as possible aspect ratio. However, a too high aspect ratio in our experience may turn out to be difficult to fabricate. Therefore for further study a unit cell with an aspect ratio of 5 was selected, or more specifically, the length and width of the unit cell (Figure 2.1) were defined as $20 \mu \mathrm{m}$ and $4 \mu \mathrm{m}$, respectively. Next, various values of the external porosity, which is the ratio of the wetted area to the total unit cell area, were investigated, but because the different external porosities had no significant influence on the pillar shape comparison study, the external porosity was set at 0.4 , as it yields a more compact placement 
within the selected unit cell geometry. Furthermore, an external porosity of 0.4 is a common value for conventional columns and therefore has been the preferred choice in simulations of pillar columns [5-8]. The following steps in the procedure were to first calculate the total area of the pillars and next define the tip angle of the structure. This procedure makes it possible to fit a geometry with a fixed surface area within a unit cell. An evaluation of possible tip angles showed that smaller tip angles yield better performance.

Using the foil shape definition, a significant increase in flow uniformity was obtained. For the EK case with an applied electric field of $1 \mathrm{kV} / \mathrm{cm}$, the observed maximum and minimum velocity was $7.38 \mathrm{~mm} / \mathrm{s}$ and $6.46 \mathrm{~mm} / \mathrm{s}$, respectively, while the mean velocity was $7.01 \mathrm{~mm} / \mathrm{s}$, to be compared to a velocity of $7.08 \mathrm{~mm} / \mathrm{s}$ for an empty channel with the same electric field. Being the best alternative to the foil definition, the diamond shape yielded maximum, minimum, and mean velocities of $13.95 \mathrm{~mm} / \mathrm{s}, 5.16 \mathrm{~mm} / \mathrm{s}$, and $7.01 \mathrm{~mm} / \mathrm{s}$, respectively. From this it can be concluded that, the foil definition offers a much more uniform velocity distribution, which has a direct effect on sample dispersion. The sharp corners on the sides of the diamond structure cause local high velocity regions which decrease the flow uniformity significantly, while the foil shape offers an almost uniform distribution throughout the flow domain (Figure 2.7).

It was found that, despite the differences in flow uniformity, including retention in the simulations does not render significantly different plate height values. This especially holds for the diamond and foil shapes (Figure 2.8). The reason is that retention plays the dominant role in plate height determination and for these two configurations, as can be seen in Figure 2.7, the total wetted perimeters are almost the same. The results of the simulations without retention also did not yield much difference, which can be explained by the fact that the high aspect ratio structure within a compact unit cell placement greatly eliminates the effects of the geometrical definition. Therefore, the performance of the structures is not only dependent on the definition of the shape, but also on the definition of the unit cell geometry and the pillar density.

For the PD case, the trend in velocity distribution found for different arrangements 


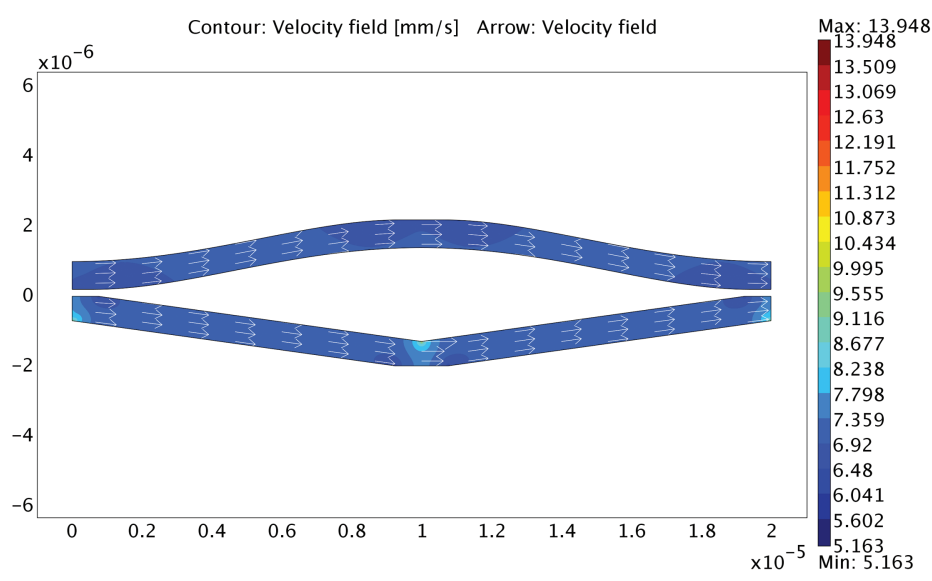

Figure 2.7: Velocity distribution for foil (top) and diamond (bottom) shapes for EK flow case for $1 \mathrm{kV} / \mathrm{cm}$ applied electric field. Note the non-uniform velocity area (light blue to green) in the diamond case.

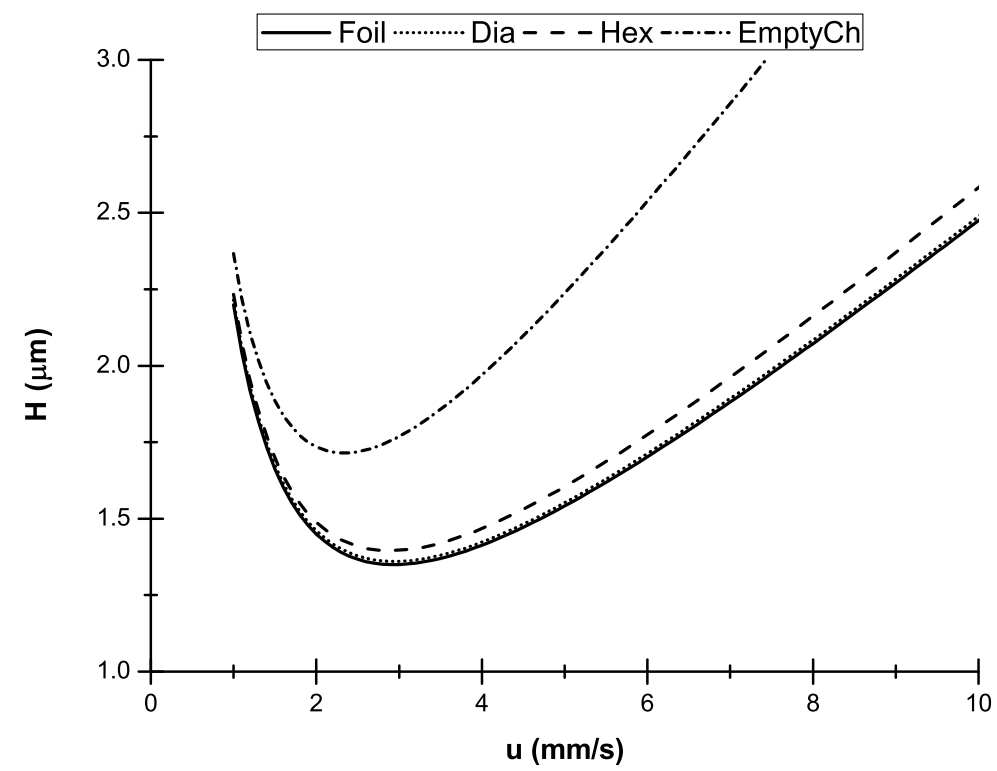

Figure 2.8: Plate height vs. mean velocity for the EK flow case. 
were not different from that for the EK case. For $7 \mathrm{~mm} / \mathrm{s}$ inlet velocity, the observed maximum resp. mean velocities were $11.09 \mathrm{~mm} / \mathrm{s}$ resp. $7.07 \mathrm{~mm} / \mathrm{s}$ for foil and 9.69 $\mathrm{mm} / \mathrm{s}$ resp. $6.20 \mathrm{~mm} / \mathrm{s}$ for diamond structures (Figure 2.9), while the mean velocity for an empty channel for the same inlet velocity was $6.94 \mathrm{~mm} / \mathrm{s}$. The same holds for the plate height distribution for different velocities (Figure 2.10).

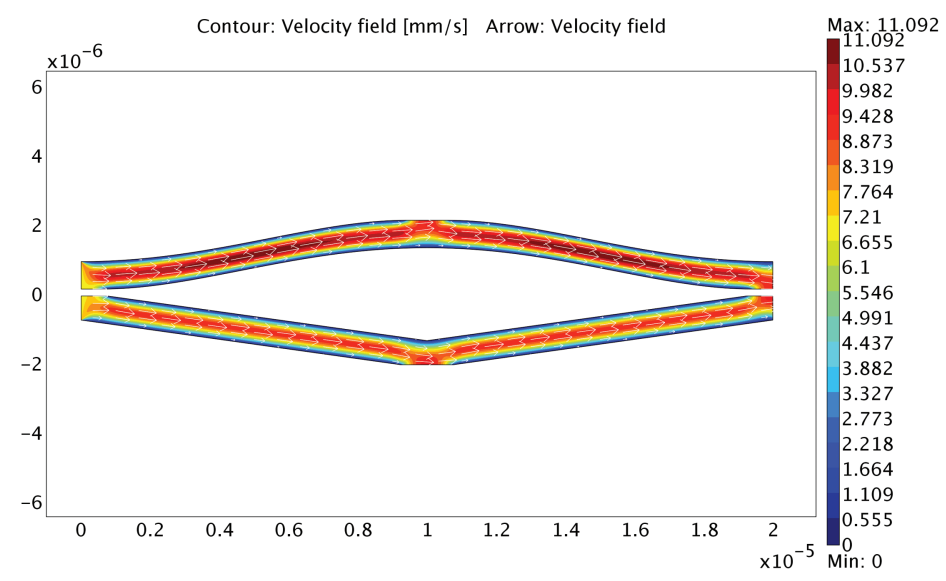

Figure 2.9: Velocity distribution for foil (top) and diamond (bottom) shapes for the $\mathrm{PD}$ flow case, for $7 \mathrm{~mm} / \mathrm{s}$ inlet velocity.

Theoretical studies give the ability to design, evaluate and compare almost any possibility in an ideal environment. From a theoretical point of view, setting the boundaries of the solution domain and then fixing the extracted area from it seems to be a valid approach. On the other hand, from an engineering perspective, one would first determine the limits of the fabrication in order to realize the microfluidic channels. This implies that the best approach is to first determine the minimum spacing achievable, which is typically determined by the limits of the chosen method of lithography, followed by determining the highest possible aspect ratio of the structures. Since it was found in this study that structures with a minimized interpillar spacing and a maximized aspect ratio are preferred, the most practical way would be defining the thickness and the length of the pillars and placing them inside the microchannel as compact as possible. Based on our experience in microfabrication, following this approach led us to a thickness and length of the pillars of $5 \mu \mathrm{m}$ and 


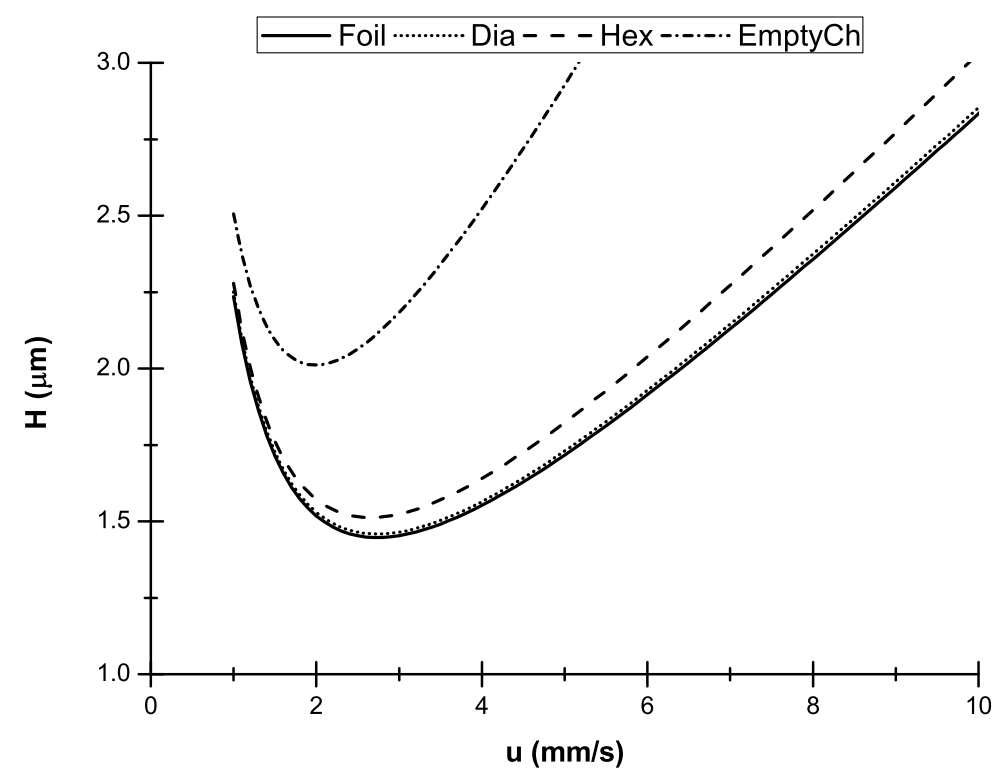

Figure 2.10: Plate height vs. mean velocity for the PD flow case.

$25 \mu \mathrm{m}$, respectively, while the minimum interpillar spacing was set at $3 \mu \mathrm{m}$, where the spacing is the crucial parameter, both from a theoretical and a practical point of view. Flow simulations were performed for both the EK and PD cases, for the same conditions as used for the previous study. This time reduced parameters were preferred for demonstration of the results, since the total area of the pillars was not the same. For adequate comparison, we apply an equivalent diameter, which was calculated as:

$$
d_{e q}=\sqrt{\frac{4 A_{p}}{\pi}}
$$

where $A_{p}$ is the pillar area.

Using the above definition, plate height and velocity parameters were nondimensionalized as:

$$
h=\frac{H}{d_{e q}}
$$




$$
v=\frac{u_{0} d_{e q}}{D_{m}}
$$

where the parameter $v$ has the characteristics of a Péclet number. For the just described practical approach, it turns out that foil definition offers a significant performance increase. Figure 2.11 demonstrates the plate height dependence to the mean velocity in reduced parameters. This result shows the potential of the foil shape as a geometry definition. Note also that the EK case always gives a better performance than the PD case, for the same geometry, which is an inherent effect of the flow velocity distributions for these cases. The difference between the two cases will in practice even be much larger, due to the effects of the top and bottom walls in a real 3-D situation, as was discussed above.

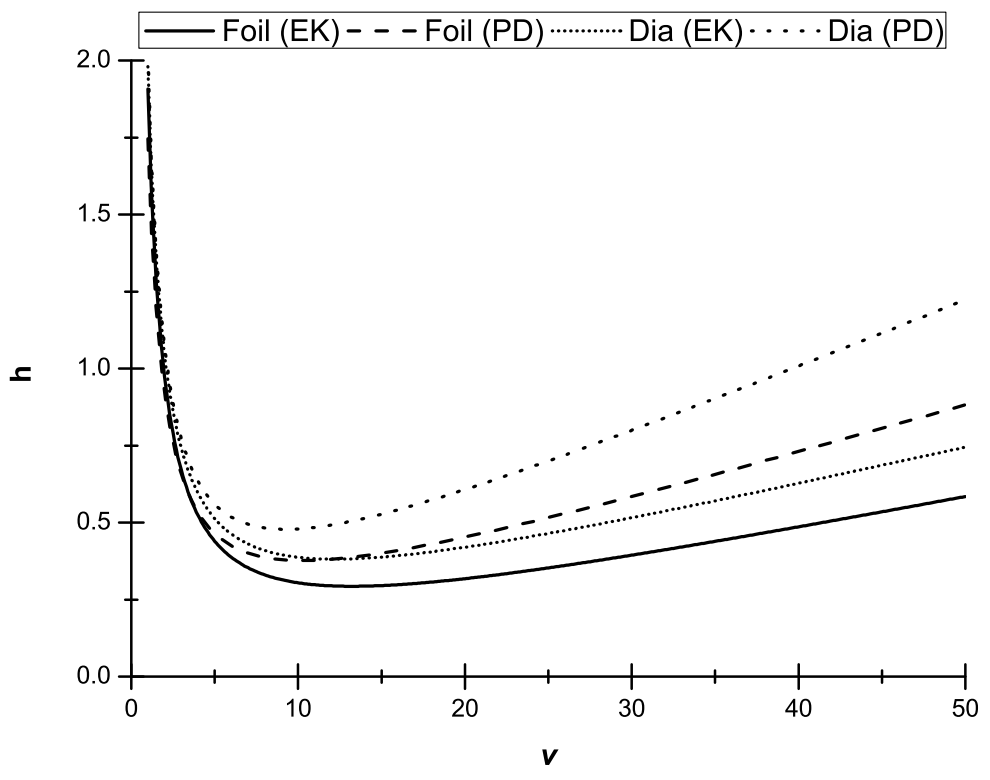

Figure 2.11: Plate height vs. mean velocity graph for reduced parameters, both for the PD and the EK cases.

We would like to make a few remarks on the practical implications of the conclusion that the foil shape would be the preferred pillar geometry for CEC and HPLC applications. An important factor is how feasible it would be to fabricate such a geometry, considering the limitations of the fabrication technology already mentioned. 
Particularly relevant would be the lateral etching of deep structures, as it occurs in DRIE of silicon, and even more in DRIE of silicon dioxide. Sharp tips, even if the chosen photolithography would allow them to be patterned in a photoresist or another resistant layer, do not survive such DRIE processes. In preliminary experiments of DRIE of fused silica substrates aimed at air-foil shaped geometries based on early simulation results, we observed a loss of around 10-15\% in the length of pillars with a designed length of $50 \mu \mathrm{m}$ for the sharpest possible tips that fitted with the geometrical constraints. It is clear that increasing the tip angle would decrease this loss during etching, but would also decrease the performance, since the aspect ratio and the tip angle for air foil shapes (but also for diamond shapes) are inversely proportional.

Figure 2.12 may assist in the definition of photolithographic mask features for an arrangement with foil shapes. The figure shows as an example a circle intersection, which yields a foil geometry with ca. $23^{\circ}$ tip angles. Basically, the construction uses the intersection of two circles, where the thickness of the air foil can be adjusted by moving the circles, while the length can be adjusted by playing with the radius of the circles.

\subsection{Concluding remarks}

The possibilities of defining and/or optimizing the shape of microfabricated column structures for increasing the chromatographic performance of applications in CEC (and to a lesser extend HPLC) were studied. In order to perform the optimization study, a theoretical model was constructed for solving the flow field together with the retention for non-porous pillar structures in 2-D solution domain. The proposed approach was validated by comparing its results with the analytical solutions for a simple geometry. Then, a new foil definition for the shape and equivalent width definition for the placement of the pillars were introduced. Several different cases were analyzed for evaluating the feasibility of the proposed design and its potential in terms of higher performance was demonstrated.

While performing such a study, it is difficult to determine which parameters should be chosen for geometry definition and creating the unit cell. Various cases were 


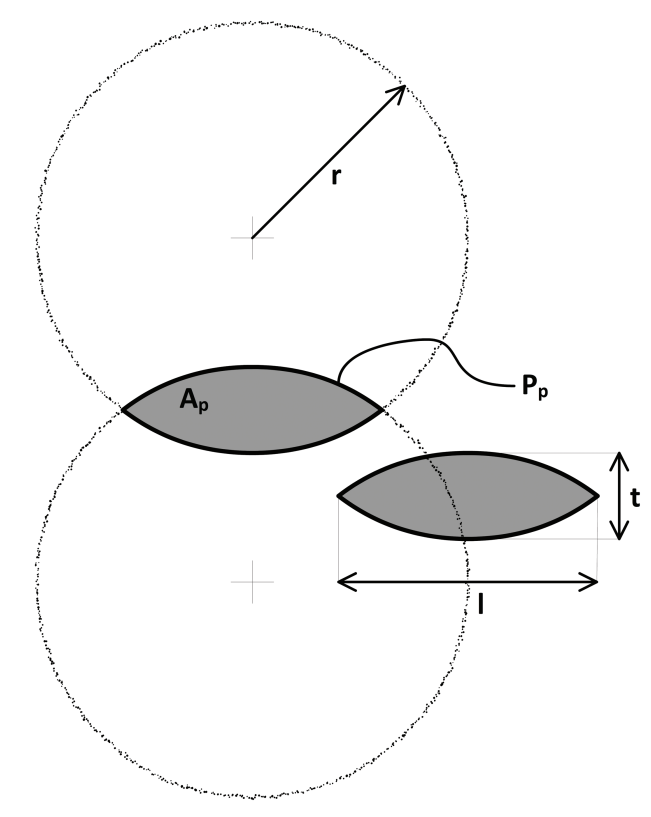

Figure 2.12: Illustration of foil shape created by circle intersection.

studied, such as fixing the total wetted perimeter and external porosity, setting the same aspect ratio for the structures, setting a minimum spacing for the predefined unit cell regardless of the external porosity and the aspect ratio of the structure, etc. Although in many cases the diamond was more favorable than the hexagon, for some cases the hexagon offered higher performance depending on the applied constraints. Although the performance increase was not remarkable in every case, overall the foil definition yielded the best performance.

\section{References}

[1] B He, N Tait, and F Regnier. Fabrication of nanocolumns for liquid chromatography. Analytical Chemistry, 70(18):3790-3797, 1998.

[2] M De Pra, W De Malsche, G Desmet, PJ Schoenmakers, and WT Kok. Pillarstructured microchannels for on-chip liquid chromatography: Evaluation of the permeability and separation performance. Journal of Separation Science, 30(10):1453-1460, 2007. 
[3] FE Regnier. Microfabricated monolith columns for liquid chromatography. sculpting supports for liquid chromatography. Journal of High Resolution Chromatography, 23(1):19-26, 2000.

[4] J Billen, P Gzil, N Vervoort, GV Baron, and G Desmet. Influence of the packing heterogeneity on the performance of liquid chromatography supports. Journal of Chromatography A, 1073(1-2):53-61, 2005.

[5] J De Smet, P Gzil, N Vervoort, H Verelst, GV Baron, and G Desmet. Influence of the pillar shape on the band broadening and the separation impedance of perfectly ordered 2-d porous chromatographic media. Analytical Chemistry, 76(13):3716-3726, 2004.

[6] P Gzil, J De Smet, N Vervoort, H Verelst, GV Baron, and G Desmet. Computational study of the band broadening in two-dimensional etched packed bed columns for on-chip high-performance liquid chromatography. Journal of Chromatography A, 1030(1-2):53-62, 2004.

[7] P Gzil, N Vervoort, GV Baron, and G Desmet. Advantages of perfectly ordered 2-d porous pillar arrays over packed bed columns for lc separations: A theoretical analysis. Analytical Chemistry, 75(22):6244-6250, 2003.

[8] P Gzil, N Vervoort, GV Baron, and G Desmet. General rules for the optimal external porosity of lc supports. Analytical Chemistry, 76(22):6707-6718, 2004.

[9] JJ Kirchner and EF Hasselbrink Jr. Dispersion of solute by electrokinetic flow through post arrays and wavy-walled channels. Analytical Chemistry, 77(4):1140 $1146,2005$.

[10] N Vervoort, J Billen, P Gzil, GV Baron, and G Desmet. Importance and reduction of the sidewall-induced band-broadening effect in pressure-driven microfabricated columns. Analytical Chemistry, 76(15):4501-4507, 2004.

[11] W. De Malsche, H. Gardeniers, and G. Desmet. Experimental study of porous silicon shell pillars under retentive conditions. Analytical Chemistry, 80(14):5391$5400,2008$.

[12] F. Svec. Cec: selected developments that caught my eye since the year 2000. Electrophoresis, 30(S1):S68-S82, 2009.

[13] F.E. Regnier, B. He, S. Lin, and J. Busse. Chromatography and electrophoresis on chips: critical elements of future integrated, microfluidic analytical systems for life science. Trends in Biotechnology, 17(3):101-106, 1999.

[14] John H. Knox. Band dispersion in chromatography - a new view of a-term dispersion. Journal of Chromatography A, 831(1):3-15, 1999.

[15] M. De Pra, W. Th Kok, J. G. E. Gardeniers, G. Desmet, S. Eeltink, J. W. van Nieuwkasteele, and P. J. Schoenmakers. Experimental study on band dispersion in channels structured with micropillars. Analytical Chemistry, 78(18):6519$6525,2006$. 
[16] W. De Malsche, H. Eghbali, D. Clicq, J. Vangelooven, H. Gardeniers, and G. Desmet. Pressure-driven reverse-phase liquid chromatography separations in ordered nonporous pillar array columns. Analytical Chemistry, 79(15):5915-5926, 2007.

[17] J. De Smet, P. Gzil, GV Baron, and G. Desmet. On the 3-dimensional effects in etched chips for high performance liquid chromatography-separations. Journal of Chromatography A, 1154(1):189-197, 2007.

[18] X. Yan, Q. Wang, and H.H. Bau. Dispersion in retentive pillar array columns. Journal of Chromatography A, 1217(8):1332-1342, 2010.

[19] M.J. de Boer, JGE Gardeniers, H.V. Jansen, E. Smulders, M.J. Gilde, G. Roelofs, J.N. Sasserath, and M. Elwenspoek. Guidelines for etching silicon mems structures using fluorine high-density plasmas at cryogenic temperatures. Journal of Microelectromechanical Systems, 11(4):385-401, 2002.

[20] H. Eghbali, W. De Malsche, J. De Smet, J. Billen, M. De Pra, W.T. Kok, P.J. Schoenmakers, H. Gardeniers, and G. Desmet. Experimental investigation of the band broadening originating from the top and bottom walls in micromachined nonporous pillar array columns. Journal of Separation Science, 30(16):26052613, 2007.

[21] George Karniadakis, Ali Beskok, and Narayan Aluru. Microflows and Nanoflows, Fundamentals and Simulation. Springer, New york, 2005.

[22] Fabio Baldessari and Juan G. Santiago. Corrigendum to "electrokinetics in nanochannels. part i. electric double layer overlap and channel-to-well equilibrium" [j. colloid interface sci. 325 (2008) 526-538]. Journal of Colloid and Interface Science, 331(2):549, 2009.

[23] Jacob H. Masliyah and Subir Bhattacharjee. Electrokinetic and Colloid Transport Phenomena. Wiley-Interscience, New Jersey, 2006.

[24] J. Calvin Giddings. Dynamics of Chromatography, Part 1: Principles and Theory. Marcel Dekker, New York, 1965.

[25] COMSOL Inc. Burlington, MA.

[26] DK Schisla, H. Ding, PW Carr, and EL Cussler. Polydisperse tube diameters compromise multiple open tubular chromatographyw. AIChE journal, 39(6):946953, 1993.

[27] W. J. Lough and I. W. Wainer. High Performance Liquid Chromatography, Fundamental Principles and Practice. Blackie Academic \& Professional, Glasgow, 1996.

[28] JJ Van Deemter, FJ Zuiderweg, and A Klinkenberg. Longitudinal diffusion and resistance to mass transfer as causes of nonideality in chromatography. Chemical Engineering Science, 5(6):271-289, 1956. 
[29] JC Giddings. The role of lateral diffusion as a rate-controlling mechanism in chromatography. Journal of Chromatography A, 5:46-60, 1961.

[30] SC Jacobson, R Hergenroeder, LB Koutny, and JM Ramsey. Open channel electrochromatography on a microchip. Analytical Chemistry, 66(14):2369-2373, 1994.

[31] H. Poppe. Some reflections on speed and efficiency of modern chromatographic methods. Journal of Chromatography A, 778(1):3-21, 1997.

[32] A. Van Theemsche, P. Gzil, C. Dan, J. Deconinck, J. De Smet, N. Vervoort, and G. Desmet. Theoretical comparison of the band broadening in nonretained electrically and pressure-driven flows through an ordered chromatographic pillar packing. Analytical Chemistry, 76(14):4030-4037, 2004. 


\section{Chapter 3}

\section{Performance evaluation of different design alternatives for microfabricated non-porous fused silica pillar columns for CEC}

An experimental study comparing the performance of different designs for microfabricated column structures for microchip capillary electrochromatography is presented. The work is a follow-up to our previously published modeling and simulation study on the same topic. Experiments were performed using fused silica microchips with and without octadecyltrimethoxysilane coating for non-retained and retained modes of operation, respectively. Showing the same trends as the modeling results, the foil shape produces a significant decrease in plate height with an increase of around $15 \%$ in mobile phase velocity in non-retained measurements of Coumarin 480. Measured plate heights at $1 \mathrm{kV} / \mathrm{cm}$ applied electric field were 0.77, 1.33 and $1.42 \mu \mathrm{m}$ for foil, diamond and hexagon, respectively. Chromatographic runs of 4480 yielded minimal plate height values of 1.85 and $3.28 \mu \mathrm{m}$ for foil and diamond, respectively. The optimization of the shape and placement of the structures appeared to have a considerable impact on the achievable performance.

This chapter has been published as Performance Evaluation of Different Design Alternatives for Microfabricated Nonporous Fused Silica Pillar Columns for Capillary Electrochromatography, Sertan Sukas, Wim De Malsche, Gert Desmet, and Han J.G.E. Gardeniers. Anal. Chem., 2012, 84 (22), pp 9996-10004 


\subsection{Introduction}

In 1998 Regnier and co-workers introduced the idea of using microfabricated column structures [1] for liquid chromatography (LC) as a promising concept with the potential of replacing packed column technology by microchips. Several followup studies of this work have since been published [2-11]. Regnier and his team published an experimental capillary electrochromatography (CEC) comparison of different geometries of their "collocated monolithic support structures" (COMOSS), viz. (channel depths of 1.6 to $10 \mu \mathrm{m}$, pillar gaps of 2 to $4 \mu \mathrm{m}$; pillar shapes included diamonds with sides of 5 to $11 \mu \mathrm{m}$, and their elongated and extended versions) [3]. The application of microfabricated pillars for CEC has been continued by Kutter and co-workers during the last decade [4,5], with a focus on fabrication methods and substrate materials, and on in-line optical detection. Desmet's group published a series of theoretical and experimental papers discussing performance measures of microfabricated column structures, with a focus on high performance liquid chromatography (HPLC), but including also some work on CEC [7-11].

Since the published work up to now has left the impression that the performance of CEC using COMOSS may still be improved, one reason being that micromachining technology has significantly advanced to a state where it is now possible to fabricate almost perfectly vertical structures in silicon and fused silica, we have continued the previous studies in order to find the ultimate performance of COMOSS for CEC. Our theoretical study in the field of CEC on the optimization of the shape and positioning of the microfabricated column structures coupled with retention modeling for solid pillars was published in 2010 [12]. A new geometry was introduced instead of using the basic geometrical shapes used by others, and its performance was compared with the ones from literature. In 2-dimensional ideal conditions, the proposed foil shape yielded a moderate increase in performance (in terms of plate height) among the other alternatives. To complete the research on the performance of design alternatives for solid microfabricated fused silica pillar columns for CEC, in the present study the validity of the earlier proposed definitions and boundary conditions will be experimentally evaluated. 


\subsection{Experimental}

\subsubsection{Fabrication}

Being the most commonly used material for CEC applications both in conventional and micro scale systems, fused silica was selected as a structural material because it is mechanically robust, optically transparent down to the UV regime, electrically stable and durable in terms of surface properties, while commercial substrates are of very good optical quality with almost no inhomogeneity. Microchips were fabricated with a simple 2-mask process as illustrated in Figure 3.1. First, a $1 \mu \mathrm{m}$ thick poly-silicon layer was deposited via LPCVD (Tempress Systems) on a $100 \mathrm{~mm}$ fused silica wafer with $500 \mu \mathrm{m}$ thickness (Schott Lithotech) directly after cleaning in liquid and fuming nitric acid solutions. A $1.2 \mu \mathrm{m}$ thick photoresist (Olin 907-12) layer was spin-coated at $4000 \mathrm{rpm}$ followed by UV-photolithography for transferring the channel layout. The poly-Si layer was etched through by DRIE (Adixen AMS100SE). The patterned poly-Si layer was used as a hard mask for etching fused silica by another DRIE step (Adixen AMS100DE). Subsequently, a thick photoresist film (Ordyl BF410) was laminated on the backside of the wafer and patterned with UV-photolithography. The film served as a mask for through etching of the wafer to open the access holes for the fluidic connections, via powder blasting (with $29 \mu \mathrm{m}$ alumina particles), using an in-house built setup. After powder blasting, the wafer was first washed with DIwater and then immersed in acetone and isopropanol, respectively. The poly-Si layer was stripped in $\mathrm{KOH}$ solution after a cleaning cycle in nitric acid. Next, a bare fused silica wafer was cleaned with the same procedure and directly bonded with the processed wafer in order to obtain closed channels. The bonded stack was kept in a high temperature furnace for the permanent bond for 36 hours with ramping up to a maximum temperature of $1080{ }^{\circ} \mathrm{C}$ and cooling down back to room temperature with specified rates. As a final step, the stack was diced and individual microchips were fabricated successfully (Figures $3.2 \& 3.3$ ). 


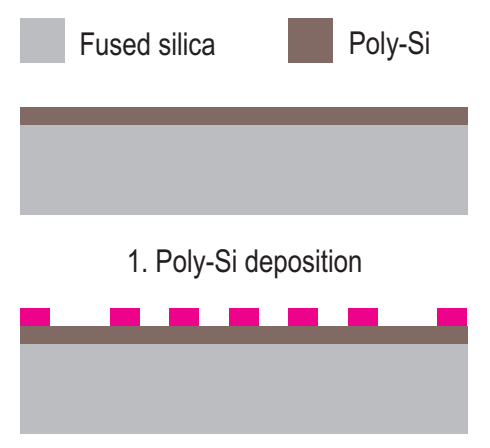

2. PR spinning and patterning

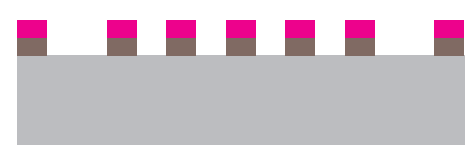

3. Poly-Si dry etching

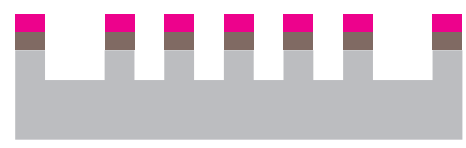

4. Fused silica dry etching

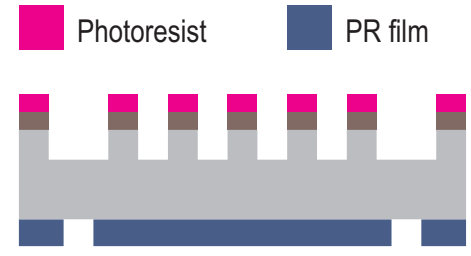

5. PR film coating and patterning

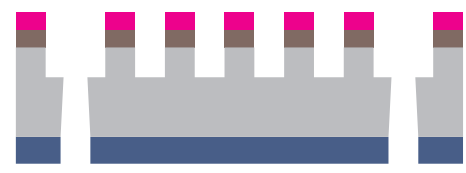

6. Powder blasting access holes

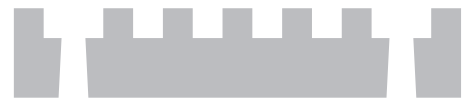

7. Cleaning \& $\mathrm{KOH}$ etching

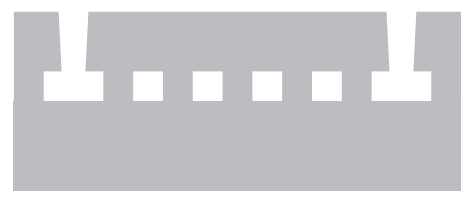

8. Thermal bonding

Figure 3.1: Fabrication process flow for fused silica microchips.

\subsubsection{Microchip design and layout}

As mentioned in the introductory part of the paper, the same design configurations as in the previously published theoretical work [12] were evaluated in this experimental study. A unit cell, which was extracted from an infinitely long and wide microchannel, was selected as the domain of interest in the previous study. The reason was to have the ability to make a fair comparison by setting all the critical design parameters, other than geometry definitions, the same. The designs to be evaluated were diamond and hexagons as the known basic geometric shapes, and foils with two different tip angles as the newly proposed shapes. Keeping the same unit cell definition, Table 3.1 summarizes the varied geometrical properties.

For a fair comparison, the same chip design was implemented for all shape alternatives, including a simple cross injector with bifurcating distributor structures, see Figure 3.2. 
Table 3.1: Design parameters of column geometries evaluated in this study. From left to right: Foil $0^{\circ}$ tip angle, Foil $25^{\circ}$ tip angle, Diamond $16^{\circ}$ tip angle, Hexagon $50^{\circ}$ tip angle. Common parameters are unit cell length: $62.5 \mu \mathrm{m}$, unit cell width: 12.5 $\mu \mathrm{m}$, external porosity: 0.4 , channel depth: $10 \mu \mathrm{m}$.

\begin{tabular}{rcccc} 
& & & & \\
\hline Pillar length & $58.6 \mu \mathrm{m}$ & $45.4 \mu \mathrm{m}$ & $57.8 \mu \mathrm{m}$ & $39.3 \mu \mathrm{m}$ \\
\hline Pillar width & $7.5 \mu \mathrm{m}$ & $7.5 \mu \mathrm{m}$ & $8.1 \mu \mathrm{m}$ & $7.5 \mu \mathrm{m}$ \\
\hline Wetted perimeter & $236.7 \mu \mathrm{m}$ & $185.0 \mu \mathrm{m}$ & $233.3 \mu \mathrm{m}$ & $39.3 \mu \mathrm{m}$ \\
\hline Minimum spacing & $2.37 \mu \mathrm{m}$ & $1.95 \mu \mathrm{m}$ & $2.17 \mu \mathrm{m}$ & $2.27 \mu \mathrm{m}$ \\
\hline
\end{tabular}

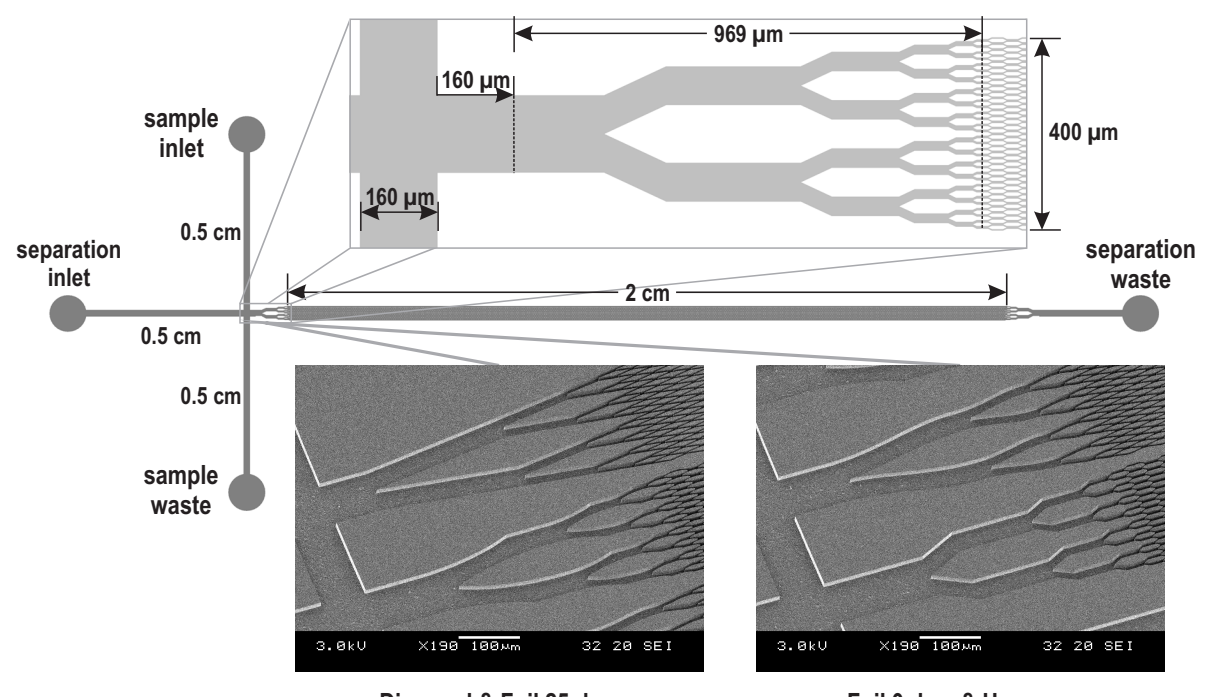

Diamond \& Foil 25 deg.

Foil 0 deg. \& Hexagon

Figure 3.2: Common design of the microchips. To inject a sample, a simple cross layout was implemented, connected to a distributor structure placed $160 \mu \mathrm{m}$ downstream of the injection cross. The $160 \mu \mathrm{m}$ wide main channel was split into 32 equally wide channels by splitting the channels at half their width at each of the 5 branching steps. Column length was set to $2 \mathrm{~cm}$ by placing a collector, which was the mirror image of the distributor, at the end of the column. The total separation channel length was $3 \mathrm{~cm}$ wherein 32 and 320 structures were placed in axial and longitudinal directions, respectively. The bottom row represents SEM pictures of the distributor structures taken from microchips with the same design. The drawing only shows a hexagonal pillar layout example for simplicity.

\subsubsection{Chemicals}

Buffer solutions were prepared by diluting $20 \mathrm{mM}$ sodium tetraborate stock solutions with deionized water and mixing with acetonitrile (ACN), yielding $10 \mathrm{mM}$ sodium 

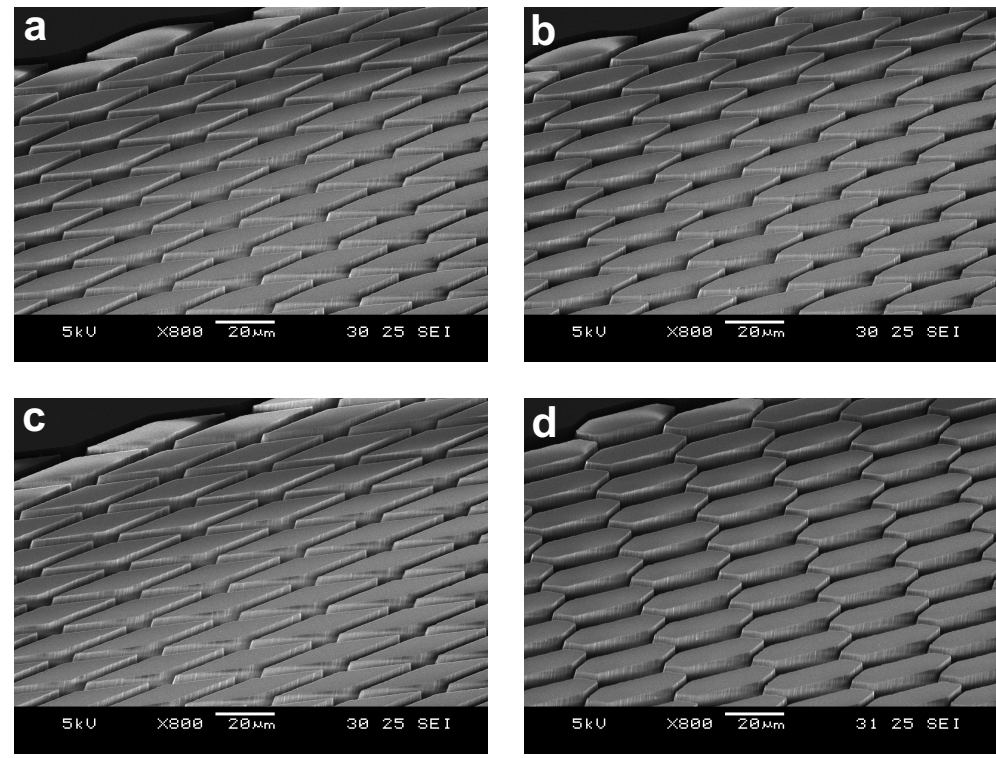

Figure 3.3: SEM pictures of fabricated column structures. (a) Foil $0^{\circ}$ tip angle, (b) Foil $25^{\circ}$ tip angle, (c) Diamond $16^{\circ}$ tip angle, (d) Hexagon $50^{\circ}$ tip angle.

tetraborate buffers with 50\% ACN composition. The coumarin dyes (C440, C460, C480, C540) were dissolved in HPLC-grade methanol in order to prepare sample stock solutions which will be diluted while dispensing into the reservoirs during the experiments. All the required chemicals were purchased from Sigma-Aldrich (Zwijndrecht, The Netherlands).

\subsubsection{Chip coating procedure}

Inner surfaces of the microchannels were coated with hydrophobic C18 monolayers in order to enable measurements under chromatographic retentive conditions. The applied procedure for coating was based on the one described by Kutter [13]. Since the microchips were fabricated in a cleanroom environment and kept sealed until the moment of starting the experiments, no additional cleaning was applied before the coating process. CNC-machined aluminum holders were used for interfacing the microchip inlet/outlets with the home made coating setup. Prepared solutions were flushed using Harvard Apparatus PHD 2000 syringe pumps (VWR International BV, Roden, The Netherlands) with Hamilton gastight glass syringes (VWR) through 150 
$\mu \mathrm{m}$ inner diameter fused silica tubing from Upchurch Scientific (VWR). In order to have leak-free connections of tubing to the microchips, Upchurch nanoport connectors (VWR) were screwed and tightened through the holes of the holder. First, the microchips were flushed with HPLC-grade methanol with a flow rate of $1 \mu \mathrm{L} / \mathrm{min}$ for $3 \mathrm{~h}$. Then, toluene (Sigma-Aldrich), which was dried over a 3 molecular sieve (SigmaAldrich) overnight, was pumped for $5 \mathrm{~h}$ with a flow rate of $0.5 \mu \mathrm{L} / \mathrm{min}$. Subsequently, the coating solution was passed through with a flow rate of $0.2 \mu \mathrm{L} / \mathrm{min}$ for a duration of $12 \mathrm{~h}$. The solution was prepared by mixing octadecyltrimethoxysilane (SigmaAldrich) with dry toluene in a 10:90 volumetric ratio. Right before flushing, $5 \mu \mathrm{L}$ of triethylamine was added as a catalyst for every $1 \mathrm{ml}$ of prepared solution. As the last two steps, toluene was pumped for $5 \mathrm{~h}$ at $0.3 \mu \mathrm{L} / \mathrm{min}$ and methanol was pumped for $3 \mathrm{~h}$ at $0.5 \mu \mathrm{L} / \mathrm{min}$. Solutions were flushed continuously through the separation waste channel of the microchips and excessive solvents were collected from other reservoirs into plastic containers, which were disposed after every run.

\subsubsection{Experimental procedure}

Microchips were placed in a CNC-machined plastic (acetal copolymer) holder, which allows both interfacing the Nanoport connections for liquid pumping and having around $200 \mu \mathrm{L}$ reservoirs sealed on top of each inlet/outlet opening. First, methanol was flushed for $10 \mathrm{~min}$. with a flow rate of $10 \mu \mathrm{L} / \mathrm{min}$ through the microchannels in order to wet the entire internal surface. Then sodium tetraborate buffer $(\mathrm{pH} 9$, $10 \mathrm{mM}$ concentration with 50:50 ACN volumetric composition) was pumped with a flow rate of $5 \mu$ Lmin for 20 min. Switching between methanol and buffer streams was accomplished via a manual valve. Considering that the total internal volume of the microchips is $64 \mathrm{~nL}$, pumping $100 \mu \mathrm{L}$ ensures that methanol is completely replaced with the buffer. After having the microchannels loaded, all the reservoirs were also filled with the buffer solution. Then $10 \mu \mathrm{L}$ of $10 \mathrm{mM}$ C480 solution was dispensed into the sample inlet reservoir, which yielded a dilution to 5\%. Subsequently, platinum wires, which serve as the electrodes, were immersed inside the reservoirs. The voltages were applied with an 8 channel high voltage power supply (Labsmith HVS448-6000D, Mengel Engineering, Virum, Denmark). Injection was performed by applying 900 
$\mathrm{V} / \mathrm{cm}$ electric field through the injection channel with pinching [14]. Then the accumulated sample at the injection cross was directed into the separation channel by applying electric fields varying from 0.1 to $1 \mathrm{kV} / \mathrm{cm}$. The same procedure was applied for both coated and uncoated devices (Table 3.2).

Table 3.2: Applied electric potentials at the reservoirs for the injection and the separation.

\begin{tabular}{lcccc} 
& Sample inlet & $\begin{array}{c}\text { Sample } \\
\text { outlet }\end{array}$ & $\begin{array}{c}\text { Separation } \\
\text { inlet }\end{array}$ & $\begin{array}{c}\text { Separation } \\
\text { outlet }\end{array}$ \\
\hline Injection & $900 \mathrm{~V}$ & $0 \mathrm{~V}$ & $600 \mathrm{~V}$ & $600 \mathrm{~V}$ \\
\hline Separation & $0 \mathrm{~V}$ & $0 \mathrm{~V}$ & $300-3000 \mathrm{~V}$ & $0 \mathrm{~V}$ \\
\hline
\end{tabular}

\subsubsection{Detection and data processing}

Fluorescence spectroscopy was implemented as a detection method. A Leica DMI5000M inverted microscope system (Leica Microsystems, Rijswijk, The Netherlands) which has an integrated motorized stage with electronic position control, was used for the experiments. As a light source a Leica EL6000 unit, equipped with a mercury short-arc lamp (Osram HXP-R120W/45C VIS, Leica Microsystems), was applied. Fluorescent emission from the sample was passed through a Leica filter cube: D, which consists of an excitation filter (band-pass 355-425 nm), a dichromatic mirror $(455 \mathrm{~nm})$ and a suppression filter (long-pass $470 \mathrm{~nm})$. The experiments were monitored using a Leica DFC300FX color camera attached to the microscope. Sample peaks were recorded at positions every $5 \mathrm{~mm}$ of the separation channel starting from the point of injection. Resulting movie files were first decomposed into image sequences via VirtualDub (open source software), then the concentration profiles were plotted with ImageJ (open source) by image processing. As a last step before the calculations, the plotted peaks were fitted as a Gaussian profile and the variances together with the residence times were directly extracted using OriginPro 8 software (Origin Lab Corporation, USA). 


\subsection{Results and discussion}

\subsubsection{Non-retained species experiments}

This set of experiments was performed with bare fused silica microchips without any surface treatment (i.e. no stationary phase), which ensures an operation in non-retentive conditions. The concentration profile of the fluorescent dye C480 was monitored as described in the previous section. The presence of this neutral dye at the applied low concentration of around $0.1 \mathrm{mM}$ caused no disturbance in the electric field distribution in the channel. Consequently, the migration of the corresponding zone of this dye expresses the mobile phase velocity at the applied electric fields. One of the key parameters to characterize an electrokinetic system is mobility. Therefore, the first parameter to be discussed as a performance measure for the different column geometries is the obtained velocity at a fixed voltage. Figure 4.9 shows the variation of the mobile phase velocity with respect to the applied electric field. The relationship between these two parameters was linear, as expected, except for the high velocity region, where the mobility curve slightly deviated from linearity when the potential drop exceeded $2 \mathrm{kV}$. This deviation can most likely be explained by a Joule heating effect caused by power dissipation throughout the channel at higher electric currents. This causes an increase in the temperature, therewith an increase in diffusion coefficient and mobility, which is directly related to it $[15,16]$. In the following plate height analysis, the effect of joule heating on radial diffusion was neglected. For the electric field of $733 \mathrm{~V} / \mathrm{cm}$, the measured mobile phase velocities were $1.25,1.15,1.14$ and $1.06 \mathrm{~mm} / \mathrm{s}$ for foil with $0^{\circ}$, foil with $25^{\circ}$, hexagon and diamond, respectively. These values of the electroosmotic flow (EOF) velocity, generated without surface treatment of the inner walls of the fused silica channels, are high enough for performing CEC experiments close to the optimal velocity for chromatographic separations (see below).

One of the design rules for the microchips was minimizing the variation in the total cross section throughout the channels, since such a variation gives a non-uniform axial velocity distribution and therewith additional zone dispersion. As a result, the 


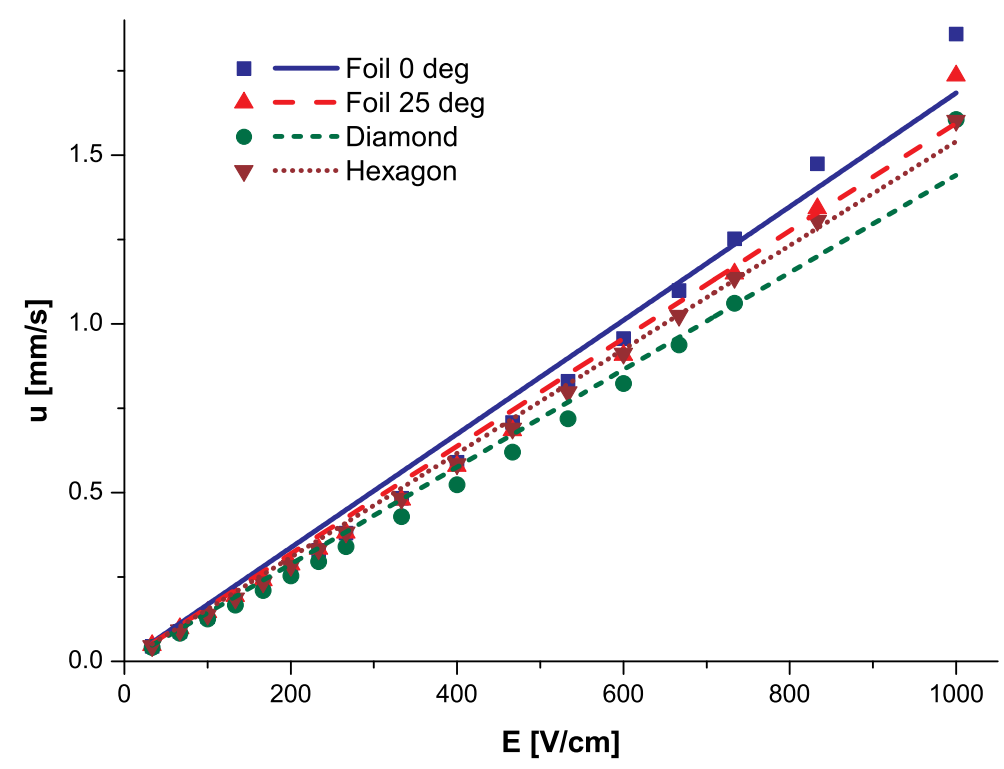

Figure 3.4: Variation of the mobile phase velocity with applied electric field. A linear curve fit intercepting at $(0,0)$ was implemented. Measured values of the electroosmotic mobility, which is the slope of the fitted curves, are $1.68 \mathrm{E}-8 \mathrm{~m}^{2} / \mathrm{Vs}$ for foil with $0^{\circ} \mathrm{s}$ tip angle, $1.60 \mathrm{E}-8 \mathrm{~m}^{2} / \mathrm{Vs}$ for foil with $25^{\circ} \mathrm{s}$ tip angle, $1.54 \mathrm{E}-8 \mathrm{~m}^{2} / \mathrm{Vs}$ for hexagon, and $1.44 \mathrm{E}-8 \mathrm{~m}^{2} / \mathrm{Vs}$ for diamond.

simulated linear velocities of the mobile phase for all design alternatives were the same and exhibited only a $1 \%$ decrease compared to an empty channel [12]. However, experimental measurements resulted in a higher decrease in mean flow velocities e.g. a $5 \%$ decrease for the foil with $0^{\circ}$ and $20 \%$ for diamond, with respect to the empty channel.

Being a streamlined body, optimized for minimizing the disturbances through the flow field in the axial direction, the foil shape with $0^{\circ}$ tip angle yielded the highest mobility. Increasing the tip angle in the same geometry definition still produces higher velocities when compared with the other alternatives. These results prove that using such optimized structures minimizes the guidance of the electric field, and hence the flow field, to lateral directions, consequently enabling higher velocity components in axial direction.

In order to check the reliability of the measurements, the monitored velocities at different points in the separation channels were compared. The variances in the 
measured values were always within a $2 \%$ window, which proves the reliability of the data.

The other important parameter for evaluating the performance of the columns is band broadening. In order to investigate the occurrence of this phenomenon for the studied designs and also enable the possibility of assessing the CEC performance of such systems, theoretical plate heights were determined by the following formula [17]:

$$
H_{j i}=\frac{\sigma_{j}{ }^{2}-\sigma_{i}{ }^{2}}{\left(t_{R, j}-t_{R, i}\right)^{2}} L_{j i}
$$

Where $H_{j i}$ is the theoretical plate height determined between the interfaces $i$ and $j, \sigma^{2}$ is the peak variance, $t_{R}$ is the retention time, and $L_{j i}$ is the distance between the interfaces $i$ and $j$. Figure 3.5 illustrates the plate height dependency on mobile phase velocity for the non-retained case. As expected, data sets for each shape alternative yielded close values. Since setting a fixed domain size and external porosity limited the number of independent parameters for geometry definitions, the differences in shapes did not result in a significant effect on the performance for such high aspect ratio (length/width) structures for the non-retained case, which is in agreement with our previous modeling study [12].

After calculating the plate height values for different mobile phase velocities, the results were fitted with the van Deemter equation [18], which relates the plate height with the mobile phase velocity as:

$$
h=A+B / \nu+C \nu
$$

with $h$ and $v$ the reduced plate height and the linear velocity, respectively. These parameters are rendered dimensionless using [19]:

$$
\begin{gathered}
h=\frac{H}{d_{e q}} \\
\nu=\frac{u_{0} d_{e q}}{D_{m}}
\end{gathered}
$$

with $D_{m}$ the axial diffusion coefficient and $d_{e q}$ the equivalent diameter, which is 


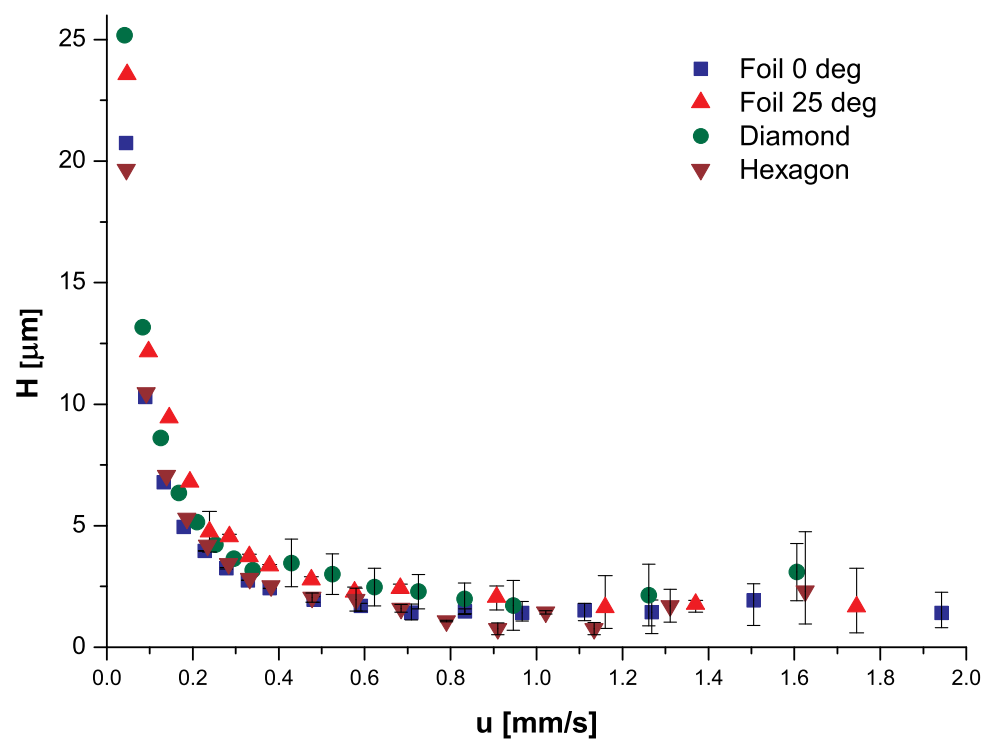

Figure 3.5: Plate height versus mobile phase velocity for non-retained case.

defined as:

$$
d_{e q}=\sqrt{\frac{4 A_{p}}{\pi}}
$$

with $A_{p}$ the cross-sectional area of the pillar in $x y$-plane, which coincides with the flow direction. The $A, B$ and $C$ terms are assumed to be constants, where the $A$-term represents eddy diffusion, the $B$-term represents longitudinal diffusion, and the $C$-term represents resistance to mass transfer.

As can be concluded from Equation 3.5, $d_{e q}$ is defined as the diameter of a circular pillar with the same area in the $x y$-plane [20]. Since in conventional CEC applications columns are packed with spherical particles, their diameters are used as a reduction parameter. In order to compare the performance of microfabricated columns having custom shapes with conventional systems or with other microsystems with different column geometries, the equivalent diameter definition was selected. Alternatively, domain size (since unit cells were defined as building blocks of the column) or minimum channel spacing on the plane which is perpendicular to the flow direction may be defined as reduction parameter [20]. Since it is not possible to assess 
the relative validity or accuracy of these reduction parameters, the external porosity, the unit cell size and the interpillar spacing in lateral direction were kept constant for all the geometry alternatives.

Figure 3.6 illustrates the fitted van Deemter curves for reduced parameters, using the equivalent cylindrical pillar diameter as a reduction parameter. Simulation data was also represented as a single curve, as the variations of the fitted constants were negligible for different shapes. The foil shape with $0^{\circ}$ angle yielded the lowest plate height values, with a slight deviation from the simulation results, while the $25^{\circ}$ alternative showed a similar trend with a shift upwards. Diamond and hexagon shapes produced curves between that of the respective foil shapes, while the latter resulted in a higher performance.

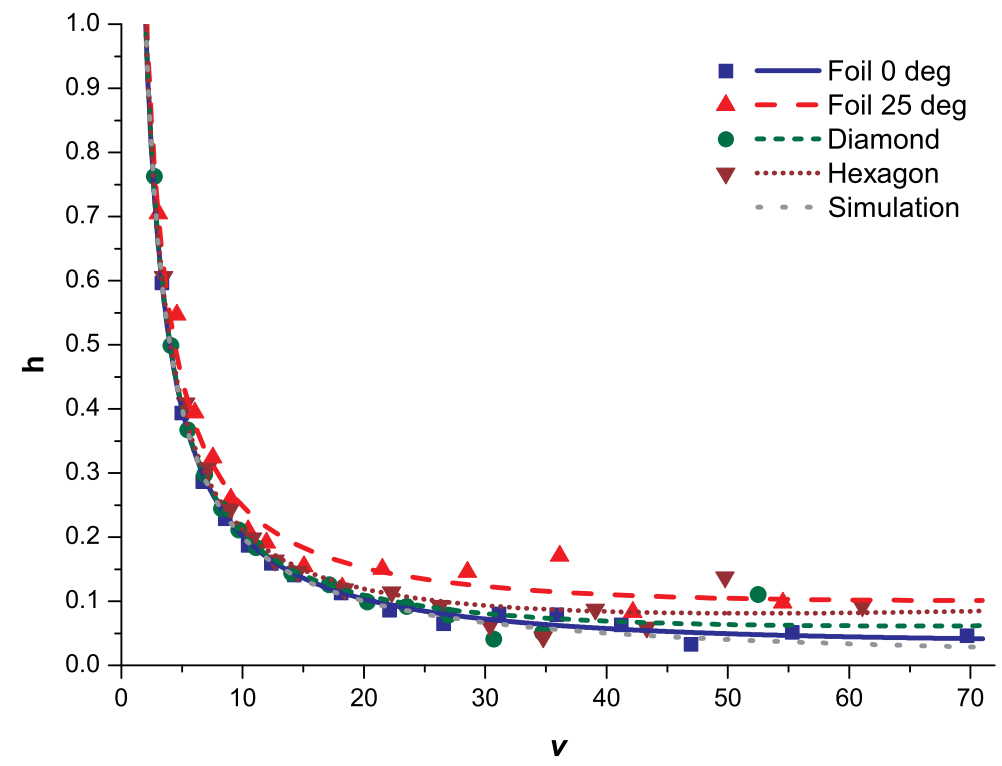

Figure 3.6: Plate height vs. velocity for reduced parameters for non-retained case. Experimental results for different shapes are also compared with the simulations. The span of the $x$-axis (reduced velocity) is limited to the experimental working range. Simulation curve represents the data for all geometries.

In order to be able to discuss the physical meaning of the results in more detail and compare the characteristics of the designs in all aspects, the constants of the fitted van Deemter curves are summarized in Table 3.3. 
Table 3.3: $A, B$ and $C$ terms of the fitted van Deemter curves for the studied design alternatives. $R^{2}$ and reduced $\chi^{2}$ values were 0.999 and $0.0001,0.990$ and 0.0010, 0.997 and 0.0004, 0.991 and 0.0006 for Foil 0 deg., Foil 25 deg., Diamond and Hexagon, respectively.

Foil 0 deg. Foil 25 deg. Diamond Hexagon Simulation

\begin{tabular}{llllll}
\hline $\boldsymbol{A}$ & 0.00000 & 0.04389 & 0.00000 & 0.00463 & 0.00000 \\
\hline $\boldsymbol{B}$ & 1.99623 & 2.00016 & 2.00062 & 2.00024 & 2.00000 \\
\hline $\boldsymbol{C}$ & 0.00019 & 0.00041 & 0.00047 & 0.00073 & 0.00000 \\
\hline
\end{tabular}

Since the $A$-term depends on the channel geometry, in other words the randomness of the flow paths of the migrating species, higher aspect ratio structures produced better results. As shown in Table 3.1, the foil with $0^{\circ}$ and the diamond structures had a much higher aspect ratio (length over width) than the other two. Comparing the pillar lengths with the unit cell length, the $0^{\circ}$ foil and the diamond structures yielded merging and splitting microchannels with small coupling zones, where the $25^{\circ}$ foil and the hexagon structures produced wide and narrow microchannels coupled one after another in an alternating pattern. As a result, the $0^{\circ}$ foil and diamond structures had no contribution to the plate height since they do not provide propagation of eddy diffusion. The $A$-term for the hexagon structure was one order of magnitude smaller than that for the $25^{\circ}$ foil, because of its straight microchannels in longitudinal direction, where the $25^{\circ}$ foil structure had a much higher radius of curvature as a source of dispersion.

The hexagon structure yielded the lowest effective diffusion coefficient, since it was the only alternative which gave the ability to preserve the constant cross section along the channel. Therefore the fluctuations in the flow field (increasing/decreasing mean flow velocity during migration) in this case are minimized. Although it was not possible to keep the cross section constant with a foil shape, the $0^{\circ}$ alternative resulted in only $2 \%$ increase, because of its optimized geometry and placement definition [12]. The $B$-term, as expected, is very close to 2 and is virtually the same for all the alternative designs.

With the absence of retention, the $C$-term strongly depends on the column design. Therefore, the foils, which are streamlined, hydrodynamically optimized structures and also placed with the rule of preserving the hydrodynamic balance, produced 
much better results compared to diamond and hexagon structures.

\subsubsection{Retained species experiments}

These experiments were performed with the $\mathrm{C} 18$ coated channels to realize retained conditions. C480 was again monitored to characterize the microchannels. Only 2 variants among the 4 were selected for this study. The foil with $0^{\circ}$ was the best candidate according to the non-retained measurements, while the one with $25^{\circ}$ was the worst. For that reason the latter was eliminated. Since the performance of the diamond shape was better than that of the hexagon shape, the latter was eliminated, also because it produces a much lower wetted surface (Table 3.1), which is directly proportional to the retention coefficient and therefore should be as large as possible, considering the non-porous nature of the structures. Furthermore, it was shown in our previous theoretical study [12] that a foil with $0^{\circ}$ tip angle and the diamond design were the best two alternatives. Figure 3.7 shows the measured plate heights at different mobile phase velocities. For practical reasons, the calculated velocities of C440 as the least retained compound were taken as the corresponding mobile phase velocities. The lowest plate height values were around 2.3 and $3.5 \mu \mathrm{m}$ for foil and diamond, respectively. In our modeling study, the foil shape yielded moderately lower plate heights than the diamond structure, however, the experimental results show that the foil shape has a significantly better performance than the diamond design.

Unlike in the non-retained case, the van Deemter equation was inadequate for producing a proper fit for the retained experiments. The $A$-terms, which were absent in the non-retained measurements, turned out to be negative in order to have a proper fit for Equation 3.2. This finding does not make sense physically: A negative A-term represents an anti-dispersive mechanism, which, instead of to broaden, would cause the peak to shrink. The only known peak compression effect for liquid separation methods is electrokinetic stacking [21], which generally is asymmetric, while here we observe symmetric Gaussian peaks. There is no reason to assume that stacking would have occured in our experiments. Furthermore, by definition, the $A$-term is a measure of disorder within the flow path, which cannot be less than non-existing. In other words, the ideal condition, yielding a zero $A$-term, is a perfectly straight path line for 


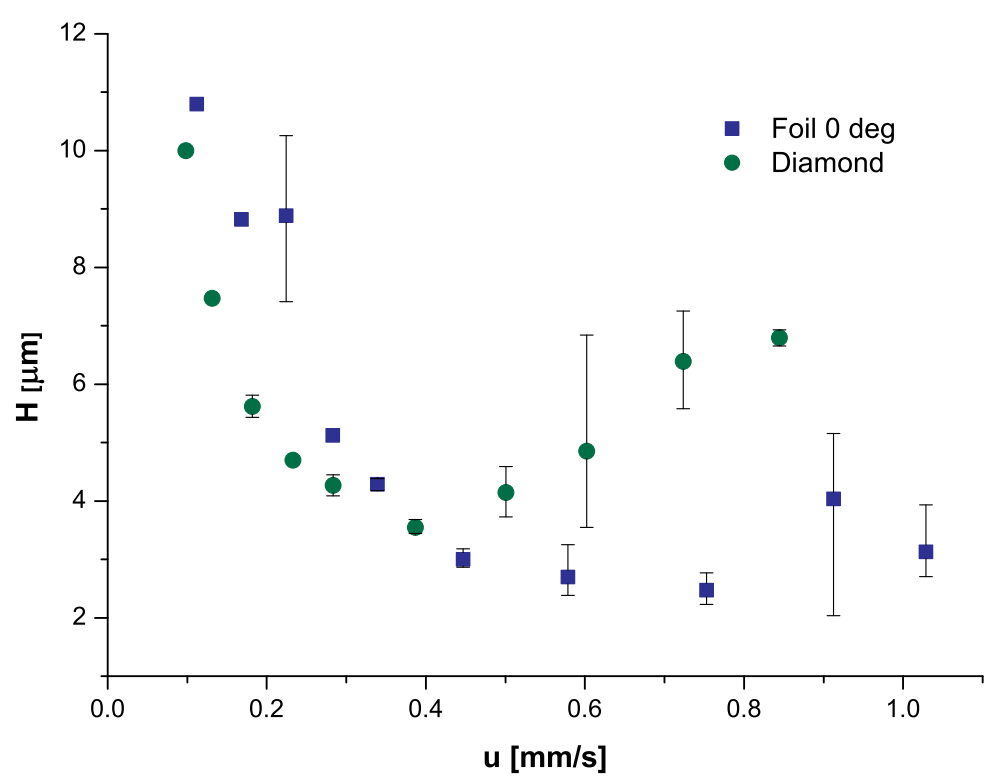

Figure 3.7: Plate height for the dye C480 versus mobile phase velocity for retained case.

each individual molecule migrating through the column.

In order to find an explanation, a literature search was performed, from which it was found that a negative $A$-term is sometimes observed in gas chromatography (GC) [22] and the possible reasons for such a phenomenon were either compression of the gaseous species or local variations in coating quality. To compensate for these effects, the exit velocity of the system was taken as the mobile phase velocity and with that, the $A$-term became positive. Since compressibility is out of the question for liquid chromatography (LC) and the applied measurement technique in this study is completely different from that in GC applications, this provides no satisfactory explanation for the occurrence of the negative $A$-term in our work. Furthermore, in our case the liquid velocity at every $5 \mathrm{~mm}$ of the separation channel was measured to check whether the linear velocity decreases along the channel while sample migrates towards the outlet. A negligible change was found indicating that the migration velocity of the peaks was almost constant. The velocities at control points were not measured directly but calculated with respect to the migration time of the sample from one node to another, which in principle gives mean velocities. Having these 
mean velocities at every $5 \mathrm{~mm}$ interfaces unchanged along the channel, eliminates the necessity of a direct measurement of the exit velocity.

Kutter and co-workers reported an open channel microchip CEC application [13] with a coumarin dye mixture for the same hydrophobic coating as was applied in this study. They provided a plate height versus linear velocity plot for C460 for 3 different channel depths, which includes both measured data points and fitted van Deemter curve, but they did not report the resulting constants of the used fitting equation. We have extracted the experimental data from their figure, and fitted them with Equation 3.2 with a positive $A$-term limitation and re-plotted with the same axes scales. The reproduced curve with a non-negative A-term restriction failed to converge to Kutter's original plot. Following the same fitting procedure for the data of Regnier and co-workers, who reported a modeling study on open channel CEC [23], again it was found that fitting was not successful with a non-negative $A$-term. Since the work of Regnier as discussed above was a modeling study, improper coating may be ruled out as an explanation for improper fitting.

It was concluded that setting the $A$-term as a velocity independent constant was an oversimplification, which caused loss of data for defining the relationship between the plate height and the mobile phase velocity. As described by Knox [24, 25], the $A$-term was selected as a parameter which changes with the linear velocity. Being the most comprehensive option, the Knox \& Parcher equation [26] was selected as a starting point for revealing the relationship. However, the constant $A$-term was eliminated since the $A$-terms of the van Deemter fits for the non-retained case were also missing. Therefore, the used equation for fitting the data of the retained experiments was a generalized Knox equation [25]:

$$
h=A \nu^{n}+B / \nu+C_{s} \nu
$$

where $n$ is the power of the linear velocity, which is a constant parameter. In addition to its characteristics mentioned in the previous section, the $A$-term also includes the effects of dispersive mechanisms in the mobile phase including retention, where $C_{s}$-term defines the effect of retention in the stationary phase. Figure 3.8 
illustrates the fitted curves for the reduced parameters. The parameters of the generalized Knox equation fitted to the experimental data are summarized in Table 3.4 .

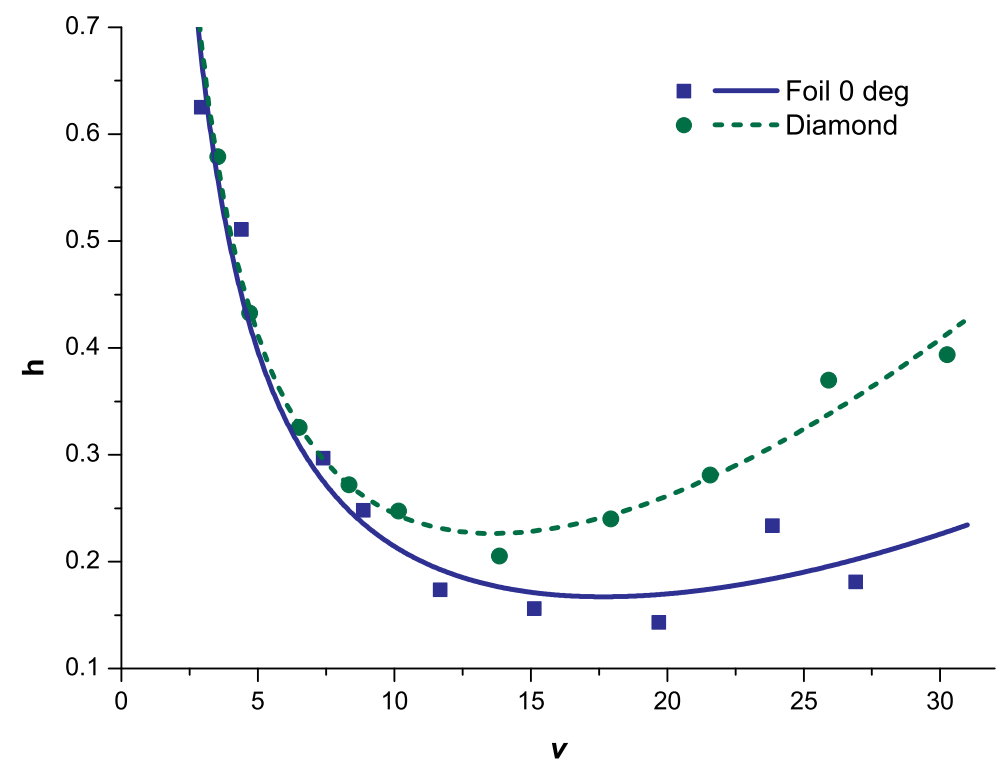

Figure 3.8: Plate height vs. velocity for reduced parameters for retained case.

Having $R^{2}$ values larger than 0.94, the generalized Knox equation produced better fits. It was also shown previously [26] that this equation provides a good estimate for low reduced velocities $(30<\nu<300)$, which was the case in this work. Setting the parameter $n$ as zero yields the typical van Deemter equation, which appeared to be the best fit for non-retained measurement data.

Table 3.4: Coefficients of the fitted generalized Knox equations for foil and diamond under retentive conditions. $R^{2}$ and reduced $\chi^{2}$ values were 0.939 and $0.0018,0.978$ and 0.0003 for $0^{\circ}$ Foil and Diamond, respectively.

\begin{tabular}{rcc} 
& $\mathbf{0}^{\circ}$ Foil & Diamond \\
\hline $\boldsymbol{A}$ & 0.00019 & 0.00064 \\
\hline $\boldsymbol{B}$ & 1.96244 & 1.99857 \\
\hline $\boldsymbol{C}_{s}$ & 0.00000 & 0.00000 \\
\hline $\boldsymbol{n}$ & 1.98463 & 1.84453 \\
\hline
\end{tabular}

As a hydrodynamically optimized geometry, the foil shape yielded a much lower 
$A$-term than the diamond shape. Using the generalized Knox equation, this term now includes the effects of mass transfer limitations in the mobile phase. In other common expressions this contribution is often referred to as the $C_{m}$-term [26].

The obtained $B$-term had again a similar value as in the other cases, which was observed after reduction using the same parameters as described above. This is expected as it represents the diffusion of the sample in the mobile phase, where the same dye and buffer were used for all the experiments.

The $C_{s}$-term, which represents the mass transfer resistance in the stationary phase, was absent using the generalized Knox equation. The channel walls were coated with monolayers as described previously, therefore there was no solute transport within the stationary phase, which yielded no contribution for the $C$-term in this equation. For a more comprehensive study, more data points containing several combinations of mobile phase composition and concomitant retention factors would be needed, especially in the $C$-term region. For this specific requirement shorter channels should be fabricated to avoid resistive heating at these high velocity data points. This is beyond the scope of the current paper but will be treated in a future study.

\subsubsection{Kinetic plots}

The quality of a packing is determined by both the theoretical plate height values and the electroosmotic mobility. To allow for a direct interpretation of the combined values, an analogue of the kinetic plot method [27] in pressure driven mode can be constructed for electrically driven separations. First, the number of plates and the analysis time are defined as

$$
\begin{aligned}
& N=\Delta V\left[\frac{\mu_{0}}{u_{0} H}\right]_{\exp } \\
& t_{0}=\Delta V\left[\frac{\mu_{0}}{u_{0}^{2}}\right]_{\exp }
\end{aligned}
$$

where $\Delta V$ is the differential electric potential applied throughout the channel, $\mu_{0}$ is the measured electroosmotic mobility, $u_{0}$ is the measured linear velocity, and $H$ 
is the calculated plate height. Figure 3.9 represents the kinetic performance of the analyzed structures for the non-retained case for $6 \mathrm{kV}$ voltage drop.

The superior permeability and plate count of the foil shape with $0^{\circ}$ angle is clearly reflected in Figure 3.9, as the time to generate $\mathrm{N}$ plates is the lowest for all considered $N$ values. This is in contrast with typical kinetic plots based on pressure propulsion comparing different features with identical porosities [27], where in a uniformly packed configuration improved plate heights occur at the expense of larger pressure drops. The length that is required to operate the foil shape with $0^{\circ}$ angle under non-retained conditions at the kinetically most favorable condition is $3.67 \mathrm{~cm}$, which corresponds to 54,800 plates that are generated in a time frame of 13 s only.

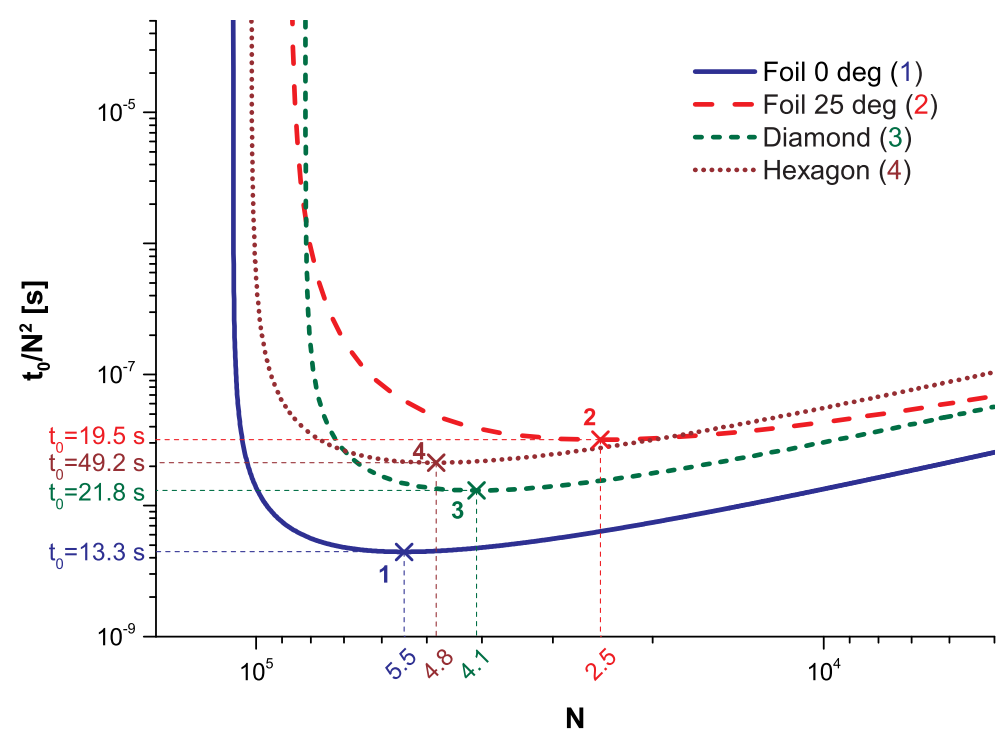

Figure 3.9: Kinetic plot representation of the relationship between the analysis time and the produced number of plates. (x) represents the optimum working points for each alternative. 1: $N_{\text {opt }}=54,824, t_{0}=13.33 \mathrm{~s}, L=3.67 \mathrm{~cm} ; \mathbf{2}: N_{\text {opt }}=24,737, t_{0}$ $=19.48 \mathrm{~s}, L=4.32 \mathrm{~cm} ; 3: N_{o p t}=40,890, t_{0}=21.82 \mathrm{~s}, L=4.34 \mathrm{~cm} ; 4: N_{\text {opt }}=$ $48,121, t_{0}=49.23 \mathrm{~s}, L=6.75 \mathrm{~cm}$. Applied voltage drop was $6 \mathrm{kV}$.

It is of course more relevant to represent the kinetic performance under retained conditions, expressing the number of plates now in effective number of plates $N_{e f f}$. The following expressions describe the kinetic performance under retained conditions: 


$$
\begin{gathered}
N_{e f f}=N \frac{k^{2}}{(1+k)^{2}} \\
t_{R}=t_{0}(1+k)
\end{gathered}
$$

with $k$ the retention factor, $t_{R}$ the retained elution time and $t_{0}$ the void time. Figure 3.10 represents the kinetic performance of the proposed foil shape with $0^{\circ}$ tip angle for the monitored fluorescent dyes. For a retained component with a relatively large retention coefficient (given the non-porous nature of the pillars) of $k=2.54$, a channel length of $14.8 \mathrm{~cm}$ would be required to generate the highest number of plates per unit of time, i.e. $N_{\text {eff }}=28,036$ in about $13 \mathrm{~min}$.

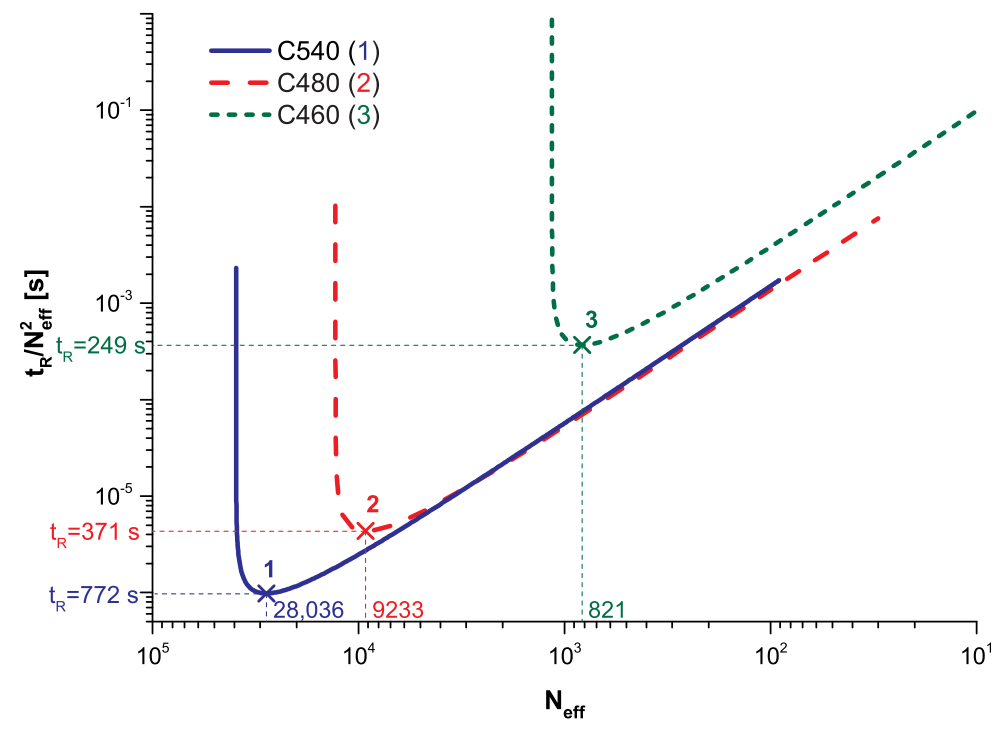

Figure 3.10: Kinetic plot representation of the separation performance of the foil shape with $0^{\circ}$ for C460, C480 and C540, respectively. (x) represents the optimum working points for each alternative. 1: $N_{\text {eff }}=28,036, t_{R}=772 \mathrm{~s} ; \mathbf{2}: N_{\text {eff }}=9,233$, $t_{R}=371 \mathrm{~s} ; 3 \mathbf{3}: N_{\text {eff }}=821, t_{R}=249 \mathrm{~s}$. Applied voltage drop was $6 \mathrm{kV}$. Optimum channel length was $14.8 \mathrm{~cm}$ for all cases. 


\subsubsection{Separation experiment}

With the aim of finding the optimized column design for CEC, a separation experiment of 4 coumarin dyes (C440, C460, C480, C540) was performed. Figure 4.10 illustrates the separated 3 bands: C460, C480 and C540 at $5 \mathrm{~mm}$ downstream of the injection point. Although its separation from the injected plug could be monitored within the first $300 \mu \mathrm{m}$, it was not possible to distinguish the C440 signal from the background noise at the detection point, due to limited camera sensitivity. Separation of all dyes was achieved in less than 25 seconds with very high resolution, which confirms that baseline resolution can easily be reached at very short separation lengths, hence within a very short time of operation.

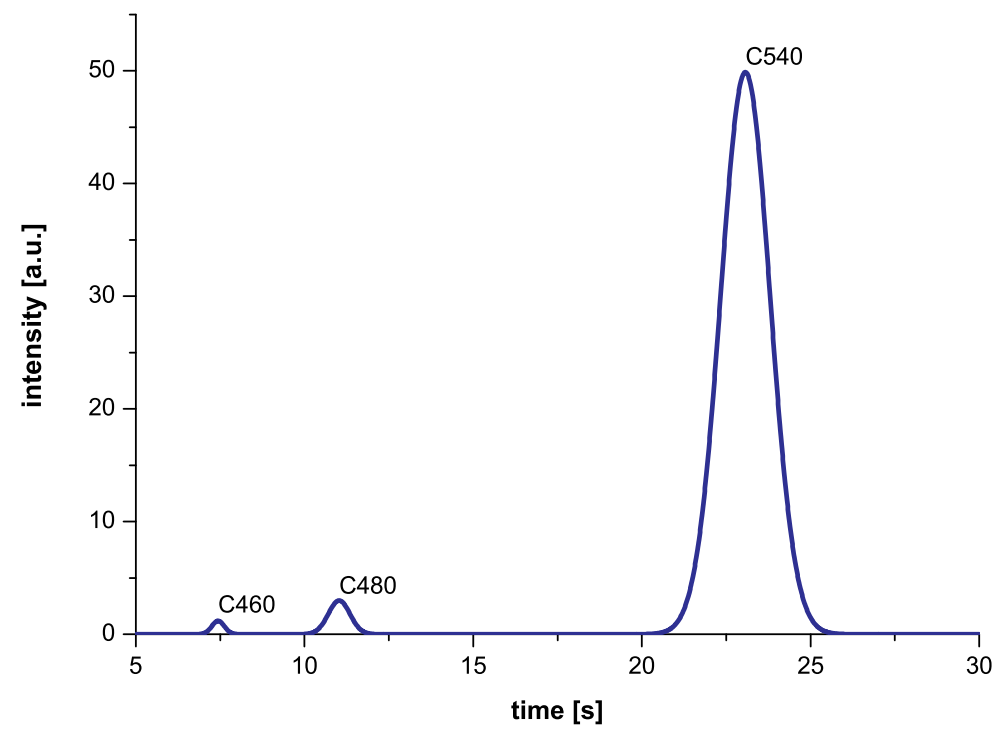

Figure 3.11: 3 coumarin dyes (C460, C480, C540) separated at $500 \mathrm{~V} / \mathrm{cm}\left(L_{\text {sep }}=5\right.$ $\left.\mathrm{mm}, u_{0}=0.77 \mathrm{~mm} / \mathrm{s}\right)$. Stationary phase: octadecyltrimethoxysilane, mobile phase: $10 \mathrm{mM}$ sodium tetraborate $(\mathrm{pH} \mathrm{9)}$ with 50:50 ACN volumetric ratio. Horizontal axis represents elapsed time after injection. Measured retention factors: $k_{C 460}=0.14$, $k_{C 480}=0.7$ and $k_{C 540}=2.54$. Measured resolutions: $R_{C 480-C 460}=7.14, R_{C 540-C 480}$ $=11.5$. 


\subsection{Concluding remarks}

Experimental validation of the previously reported design and optimization method was performed and it was confirmed that the performance of the microfabricated column structures can be maximized by the newly proposed foil definition. More specifically, it was possible to reach 1.8 million plates per meter for non-retained mode and 540,000 for an analyte with a retention factor of $k=0.86$ without any further optimization for side-wall effects or channel depth (which was fixed at 10 $\mu \mathrm{m})$. Moreover, the lowest reduced plate height was around 0.06 for non-retained runs at the optimum working potential.

\section{References}

[1] B He, N Tait, and $\mathrm{F}$ Regnier. Fabrication of nanocolumns for liquid chromatography. Analytical Chemistry, 70(18):3790-3797, 1998.

[2] FE Regnier. Microfabricated monolith columns for liquid chromatography. sculpting supports for liquid chromatography. Journal of High Resolution Chromatography, 23(1):19-26, 2000.

[3] Benjamin E. Slentz, Natalia A. Penner, and Fred Regnier. Geometric effects of collocated monolithic support structures on separation performance in microfabricated systems. Journal of Separation Science, 25(15-17):1011-1018, 2002 .

[4] Klaus B. Mogensen, Fredrik Eriksson, Omar Gustafsson, Rikke P. H. Nikolajsen, and Jörg P. Kutter. Pure-silica optical waveguides, fiber couplers, and high-aspect ratio submicrometer channels for electrokinetic separation devices. Electrophoresis, 25(21-22):3788-3795, 2004.

[5] Omar Gustafsson, Klaus B. Mogensen, and Jörg P. Kutter. Underivatized cyclic olefin copolymer as substrate material and stationary phase for capillary and microchip electrochromatography. Electrophoresis, 29(15):3145-3152, 2008.

[6] JJ Kirchner and EF Hasselbrink Jr. Dispersion of solute by electrokinetic flow through post arrays and wavy-walled channels. Analytical Chemistry, 77(4):1140$1146,2005$.

[7] P Gzil, N Vervoort, GV Baron, and G Desmet. Advantages of perfectly ordered 2-d porous pillar arrays over packed bed columns for lc separations: A theoretical analysis. Analytical Chemistry, 75(22):6244-6250, 2003. 
[8] J De Smet, P Gzil, N Vervoort, H Verelst, GV Baron, and G Desmet. Influence of the pillar shape on the band broadening and the separation impedance of perfectly ordered 2-d porous chromatographic media. Analytical Chemistry, 76(13):3716-3726, 2004.

[9] J Billen, P Gzil, N Vervoort, GV Baron, and G Desmet. Influence of the packing heterogeneity on the performance of liquid chromatography supports. Journal of Chromatography A, 1073(1-2):53-61, 2005.

[10] M. De Pra, W. Th Kok, J. G. E. Gardeniers, G. Desmet, S. Eeltink, J. W. van Nieuwkasteele, and P. J. Schoenmakers. Experimental study on band dispersion in channels structured with micropillars. Analytical Chemistry, 78(18):6519$6525,2006$.

[11] M De Pra, W De Malsche, G Desmet, PJ Schoenmakers, and WT Kok. Pillarstructured microchannels for on-chip liquid chromatography: Evaluation of the permeability and separation performance. Journal of Separation Science, 30(10):1453-1460, 2007.

[12] Sertan Sukas, Gert Desmet, and Han J. G. E. Gardeniers. Novel shape and placement definitions with retention modeling for solid microfabricated pillar columns for cec and hplc. Electrophoresis, 31(22):3681-3690, 2010.

[13] Jörg P. Kutter, Stephen C. Jacobson, Norio Matsubara, and J. Michael Ramsey. Solvent-programmed microchip open-channel electrochromatography. Analytical Chemistry, 70(15):3291-3297, 1998.

[14] Sergey V. Ermakov, Stephen C. Jacobson, and J. Michael Ramsey. Computer simulations of electrokinetic injection techniques in microfluidic devices. Analytical Chemistry, 72(15):3512-3517, 2000.

[15] Nickolaj J. Petersen, Rikke P. H. Nikolajsen, Klaus B. Mogensen, and Jörg P. Kutter. Effect of joule heating on efficiency and performance for microchipbased and capillary-based electrophoretic separation systems: A closer look. Electrophoresis, 25(2):253-269, 2004.

[16] Anurag S. Rathore. Joule heating and determination of temperature in capillary electrophoresis and capillary electrochromatography columns. Journal of Chromatography A, 1037(1-2):431-443, 2004.

[17] W. J. Lough and I. W. Wainer. High Performance Liquid Chromatography, Fundamental Principles and Practice. Blackie Academic \& Professional, Glasgow, 1996.

[18] JJ Van Deemter, FJ Zuiderweg, and A Klinkenberg. Longitudinal diffusion and resistance to mass transfer as causes of nonideality in chromatography. Chemical Engineering Science, 5(6):271-289, 1956.

[19] J. Calvin Giddings. Dynamics of Chromatography, Part 1: Principles and Theory. Marcel Dekker, New York, 1965. 
[20] P. Gzil, J. De Smet, N. Vervoort, H. Verelst, G. V. Baron, and G. Desmet. Computational study of the band broadening in two-dimensional etched packed bed columns for on-chip high-performance liquid chromatography. Journal of Chromatography A, 1030(1-2):53-62, 2004.

[21] James Palmer, Dean S. Burgi, and James P. Landers. Electrokinetic stacking injection of neutral analytes under continuous conductivity conditions. Analytical Chemistry, 74(3):632-638, 2002.

[22] Frantisek Svec and Alexander A. Kurganov. Less common applications of monoliths: Iii. gas chromatography. Journal of Chromatography A, 1184(12):281-295, 2008.

[23] Xiang Zhang and Fred E. Regnier. Analysis of channel-geometry effects on separation efficiency in rectangular-capillary electrochromatography columns. Journal of Chromatography A, 869(1-2):319-328, 2000.

[24] John H. Knox. Band dispersion in chromatography - a new view of a-term dispersion. Journal of Chromatography A, 831(1):3-15, 1999.

[25] John H. Knox. Band dispersion in chromatography - a universal expression for the contribution from the mobile zone. Journal of Chromatography A, 960(1$2): 7-18,2002$.

[26] J. Billen, P. Gzil, J. De Smet, N. Vervoort, and G. Desmet. Slow analyte diffusion effects on the a-term band broadening in macromolecular liquid chromatography separations. Analytica Chimica Acta, 557(1-2):11-18, 2006.

[27] Gert Desmet, David Clicq, and Piotr Gzil. Geometry-independent plate height representation methods for the direct comparison of the kinetic performance of lc supports with a different size or morphology. Analytical Chemistry, 77(13):40584070, 2005. 



\section{Chapter 4}

\section{Design and implementation of injector/distributor structures for microfabricated non-porous pillar columns for $\mathrm{CEC}$}

A previously proposed foil definition is applied in the design of injector/distributor structures for solid microfabricated column structures for capillary electrochromatography. In addition to a typical bifurcated distributor, an optimized design alternative with two different configurations is experimentally evaluated. Optimized designs yielded a flat profile for the injected sample with a maximum of $3 \%$ variation from the mean width, while it went up to $18 \%$ for the typical bifurcated distributor. The implemented electrokinetic injection approach enabled controlling the volume of the injected sample accurately without sacrificing the compactness of the device design. The width of the injected sample was directly proportional to the injection time, namely 165 and 218 $\mu \mathrm{m}$ base widths were obtained for 0.6 and $0.8 \mathrm{~s}$ of feeding, respectively. Reducing the external porosity of the distributor by $85 \%$ compared to the typical design, optimized distributors caused a decrease in the mean flow velocity of up to $70 \%$. However, having a flat initial plug shape enabled the separation of a mixture of Coumarin 440, 460, 480 and 540 at $1 \mathrm{~mm}$ downstream of the injection point in 80 seconds, while it was even not possible to detect the C440 signal for a typical bifurcated design.

This chapter has been submitted as Design and implementation of injector/distributor structures for microfabricated non-porous pillar columns for capillary electrochromatography, Sukas, S., Desmet, G. and Gardeniers, H.J.G.E. to Journal of Chromatography A. 


\subsection{Introduction}

When Regnier and his co-workers introduced the idea of microfabricated column structures for capillary electrochromatography (CEC) in 1998, they also proposed a "collocated monolithic collector" as a distributor/collector design for their "collocated monolithic support structures" (COMOSS) [1]. The coupling channel was divided into two equally wide and deep channels at every branching step until the created channel network fitted the desired column geometry. The aim was to enable uniform distribution and collection of analytes by keeping the total lateral cross-sectional area of the channels constant along the channel. It was stated that this kind of architecture also avoided solvent degassing. Several follow-up studies have since been published focusing on the effect of the geometries of support structures on performance $[2,3]$, substrate materials [4], and in-line optical detection [5]. In all these studies the original distributor/collector design was preserved. Since keeping the total cross-sectional area constant was only possible by implementing hexagonal structures for channel branching, similar shapes (hexagon and diamond) were preferred as column geometries for easy interfacing of the collector/distributor with the column. Therefore, the effect of the injected plug shape on the separation performance was not investigated.

Desmet's group published a series of theoretical and experimental papers in the field of HPLC, reporting various designs for injectors for interfacing the conventional injection/detection systems to microchips and collectors/distributors which replace the turning geometries needed to increase the length of the channels for higher separation performance [6-8].

We recently published a theoretical study in the field of CEC on the optimization of the shape and positioning of the microfabricated solid pillars as column structures [9]. A new geometry, a foil definition, was introduced to replace the basic geometrical shapes used by others. It was experimentally validated that the performance of the microfabricated column structures can be maximized by the newly proposed foil definition [10]. In that study a bifurcated injector design similar to the ones reported earlier in literature was implemented. The aim of the present study is to extend the previous work by applying the validated foil-based design methodology to 
injector/distributor structures. These structures will be optimized in order to delimit injected sample plug dispersion, while keeping the possibility to control the injected sample volume for CEC.

\subsection{Experimental}

\subsubsection{Fabrication}

Microchips were fabricated from fused silica with a simple 2-mask process as described in Chapter 3. The microchannels were dry etched in a $100 \mathrm{~mm}$ fused silica wafer with $500 \mu \mathrm{m}$ thickness (Schott Lithotech) using an LPCVD poly-Si hard mask layer. Access holes were opened from the back side of the wafer via powder blasting using an inhouse built setup. Next, a bare fused silica wafer was thermally bonded to close the channels (Figure 3.1 in Chapter 3). As a final step, the stack was diced and individual microchips were fabricated successfully (Figures 4.2 and 4.3).

\subsubsection{Microchip design and layout}

A cross layout was implemented for the microchips with injector/distributor and collector structures placed at the beginning and at the end of the separation channel, respectively. Figure 4.1 demonstrates the layout and dimensions. As mentioned in the introductory part, after theoretical optimization and experimental validation studies, the foil definition with $0^{\circ}$ tip angle (see figure with Table 4.1) was selected as the only design reference for creating geometries. Like in our previous studies, a unit cell was defined as the building block of the separation column. The method for creating the foil geometry was described in detail in Chapter 2. Setting the unit cell dimensions as main parameters to be defined, the external porosity was defined as an additional parameter to generate the shape. Table 4.1 summarizes the geometrical properties of the unit cell (set parameters) and the pillar (generated parameters). The separation column was constructed by arraying these 32 by 458 times in lateral and longitudinal directions, respectively (Figure 4.1).

The distributors were obtained by branching the main channel 5 times, yielding 
Table 4.1: Geometrical parameters of the unit cell as a building block of the separation column. External porosity: 0.4, channel depth: $10 \mu \mathrm{m}$.

\begin{tabular}{lc}
\hline & \\
\hline Unit cell length & $50 \mu \mathrm{m}$ \\
\hline Unit cell width & $10 \mu \mathrm{m}$ \\
\hline Pillar length & $47 \mu \mathrm{m}$ \\
\hline Pillar width & $6 \mu \mathrm{m}$ \\
\hline Minimum spacing & $2 \mu \mathrm{m}$ \\
\hline
\end{tabular}

32 channels at the end. As shown in Figure 4.1, two types of distributors, yielding 3 different design cases, were implemented. The first type was the optimized distributor, which had a $4 \mu \mathrm{m}$ wide inlet and distributed it to 32 channels with the same width. Therefore, the width of the main supply channels was reduced from $128 \mu \mathrm{m}$ to $4 \mu \mathrm{m}$ at one step with the curved profile shaped created by the foil definition at $200 \mu \mathrm{m}$ upstream of the injection cross (Design 1). As an alternative, the width of the main supply channels was defined as $4 \mu \mathrm{m}$ to fit with the inlet of the distributor without a reduction (Design 2). The second type was the typical bifurcated distributor (i.e. width of the branch is divided in two at each bifurcation point), which had a $128 \mu \mathrm{m}$ wide inlet and distributed it to 32 channels with a width of $4 \mu \mathrm{m}$ each (Design 3 ). All design cases were realized in two versions: short (total length of $310 \mu \mathrm{m}$ ) and long (total length of $620 \mu \mathrm{m}$ ).

The optimized distributor geometry was constructed using a modified unit cell definition similar to the one used for column design $\left(0^{\circ}\right.$ foil $)$. This time the pillar width was defined as an additional parameter to the unit cell dimensions instead of the external porosity and only the left half of the unit cell was drawn. This enabled controlling the channel widths. The inlet channel was branched into two channels with the same width as the inlet $(4 \mu \mathrm{m})$. Based on this definition, the number of half unit cells was doubled and they were arrayed in lateral direction at every branching step. Also, their dimensions were scaled down to half of the previous step, while the inlet/outlet channel widths were fixed at $4 \mu \mathrm{m}$, which is the same inlet channel width of the column unit cell, for all steps. Figure 4.2 shows a schematic drawing of the short 


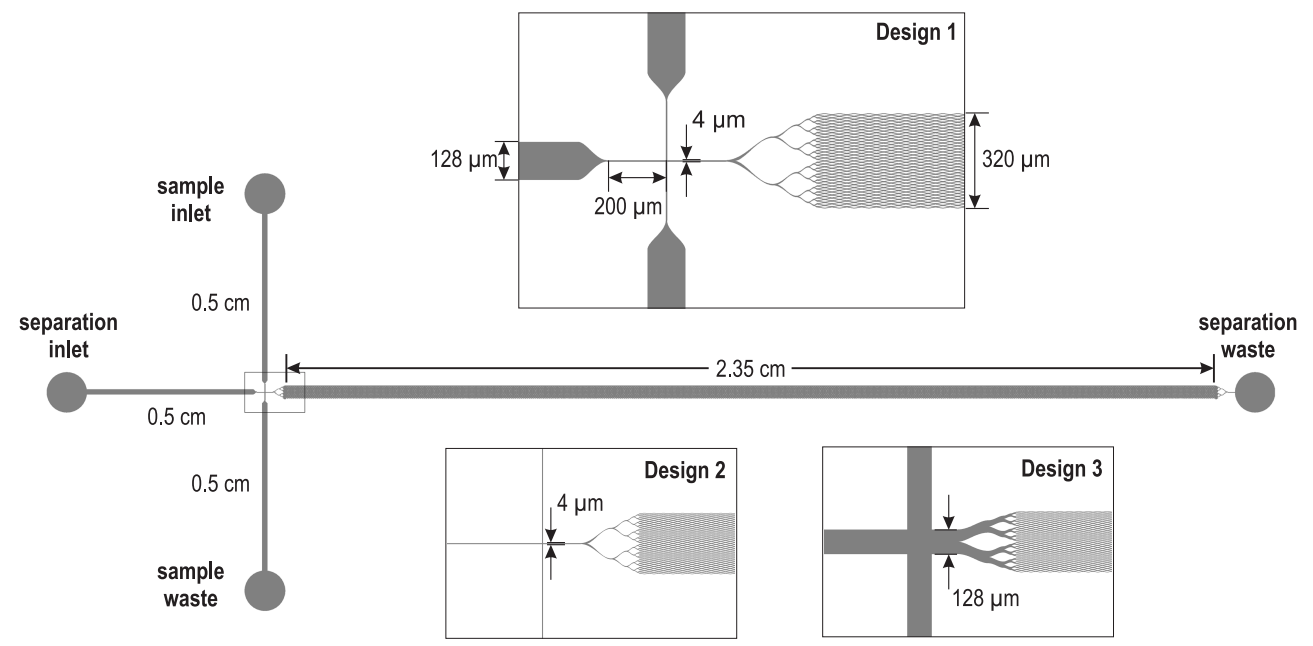

Figure 4.1: Common design of the microchips. A cross layout is implemented. Injector/distributor structures with a total length of $310 \mu \mathrm{m}$ (short version) or 620 $\mu \mathrm{m}$ (long version) are placed at $200 \mu \mathrm{m}$ downstream of the injection cross. The main supply channel with $128 \mu \mathrm{m}$ width is split into 32 channels in 5 branching steps. Design 1: Optimized distributor with reduced supply channels (from $128 \mu \mathrm{m}$ to $4 \mu \mathrm{m}$ upstream of the injection cross). Design 2: Optimized distributor with narrow supply channels (4 $\mu \mathrm{m}$ width). Design 3: Typical bifurcated distributor. Total column length and width are $2.29 \mathrm{~cm}$ and $320 \mu \mathrm{m}$, respectively. Collectors, which are the mirror image of the distributors, are placed at the end of the column. The total separation channel length is $3 \mathrm{~cm}$ wherein 28,823 pillar structures are placed. The chip drawing shows Design 1 as an example.

version of the optimized distributor and a SEM picture of the fabricated structure. In total, 5 branching steps were performed to create the geometry, yielding 32 channels in the end. The resulting external porosity for optimized distributor design was 0.06 , where it was set at 0.4 for the separation column (the right most column in Figure $4.2(\mathrm{a}))$.

Unlike the optimized distributor, the typical bifurcated geometry was constructed using the same definition as the column unit cell. In other words, the unit cell dimensions and the external porosity were defined. Half of the unit cell was drawn and the inlet channel was branched into two channels with half the width of the inlet. The number of half unit cells was doubled and they were arrayed in lateral direction at every branching step, while their dimensions were scaled down to half of the previous step (including the inlet/outlet channel widths). Therefore, the 128 

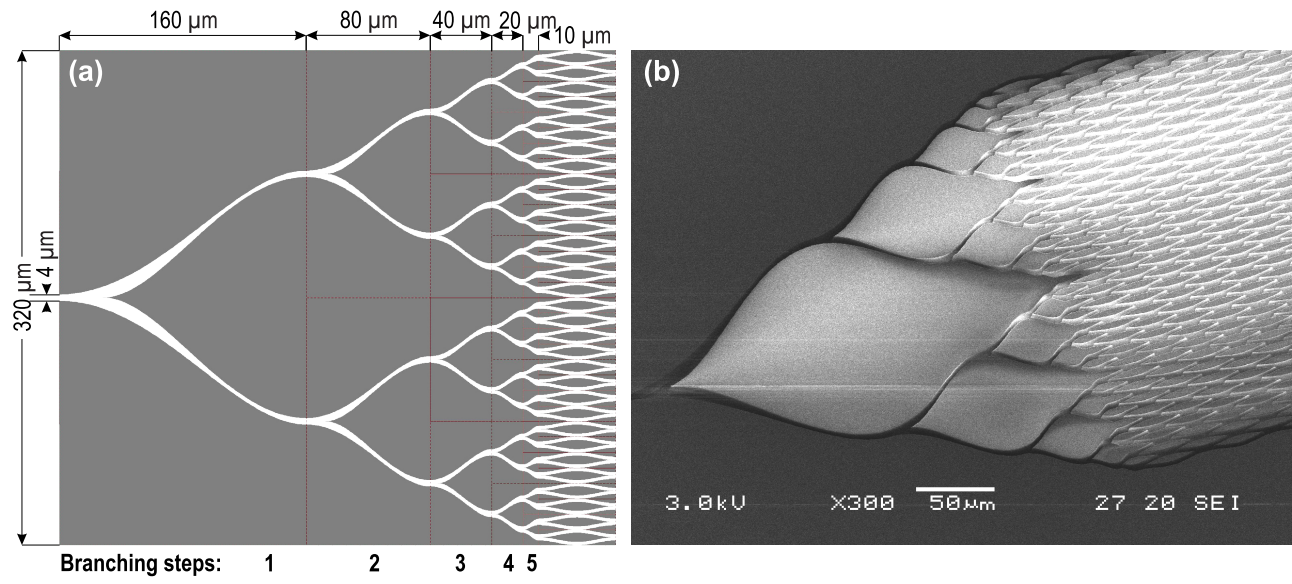

Figure 4.2: Schematic representation (a) and SEM picture (b) of the fabricated optimized distributor design (short version). External porosity: 0.06.

$\mu \mathrm{m}$ wide supply channel was distributed to 32 channels with a width of $4 \mu \mathrm{m}$, which yields the same total width as the supply channel. Figure 4.3 shows a schematic drawing of the short version of the typical bifurcated distributor and SEM picture of the fabricated structure.
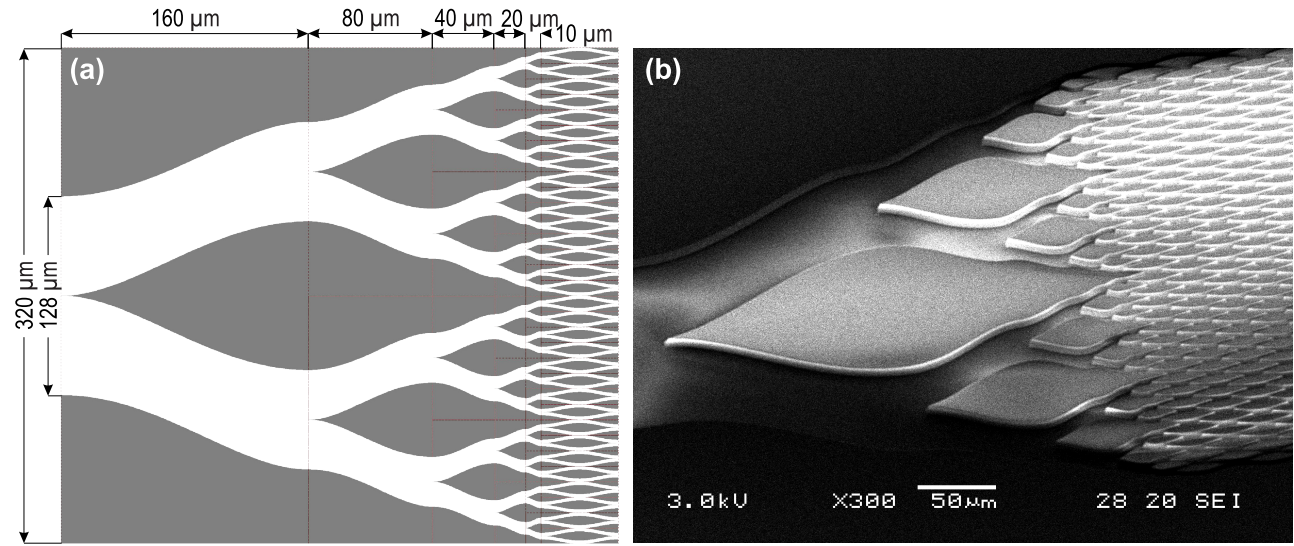

Branching steps: $\quad 1 \quad 2 \quad 3 \quad 45$

Figure 4.3: Schematic representation (a) and SEM picture (b) of the fabricated typical bifurcated distributor design (short version). External porosity: 0.4. 


\subsubsection{Chemicals}

Buffer solutions were prepared by dissolving phosphate buffer salt in DI water yielding $8.3 \mathrm{mM}$ concentration. The prepared stock solutions were mixed with acetonitrile $(\mathrm{ACN})$ in a 50:50 volumetric ratio. The coumarin dyes (C440, C460, C480, and C540) were dissolved in HPLC-grade methanol in order to prepare sample stock solutions which will be diluted while dispensing into the reservoirs during the experiments. All the required chemicals were purchased from Sigma-Aldrich (Zwijndrecht, The Netherlands).

\subsubsection{Chip coating procedure}

Inner surfaces of the microchannels were coated with hydrophobic C18 monolayers in order to enable separation experiments under chromatographic retentive conditions. The same coating procedure as described earlier in detail in Chapter 3 was applied. Methanol, dry toluene, coating solution (mixture of octadecyl trimethoxysilane and dry toluene with a 10:90 volumetric ratio), dry toluene and methanol were flushed through the microchannels, respectively.

\subsubsection{Experimental procedure}

Microchips were placed in a CNC-machined plastic (acetal copolymer) holder, which allows both interfacing the Nanoport connections for liquid pumping and having around $200 \mu \mathrm{L}$ reservoirs sealed on top of each inlet/outlet opening. First, methanol was flushed for $10 \mathrm{~min}$. with a flow rate of $10 \mu \mathrm{L} / \mathrm{min}$ through the microchannels in order to wet the entire internal surface. Then phosphate buffer $(\mathrm{pH} 7.2,8.3 \mathrm{mM}$ concentration with 50:50 ACN volumetric composition) was pumped with a flow rate of $5 \mu \mathrm{L} / \mathrm{min}$ for $20 \mathrm{~min}$. Switching between methanol and buffer streams was accomplished via a manual valve. Considering that the total internal volume of the microchips is around $50 \mathrm{~nL}$, pumping $100 \mu \mathrm{L}$ was enough to be sure that methanol was completely replaced with the buffer. After having the microchannels loaded, all the reservoirs were also filled with the buffer solution. Then $10 \mu \mathrm{L}$ of $1 \mathrm{mM}$ sample stock solution was dispensed into the sample inlet reservoir, which yielded a dilution 
to $5 \%$. Subsequently, platinum wires, which serve as the electrodes, were immersed in the reservoirs. The voltages were applied with an 8 channel high voltage power supply (Labsmith HVS448-6000D, Mengel Engineering, Virum, Denmark). Injection was performed as described in the following sections. After the injection, the sample was directed into the separation channel by applying electric fields varying from 0.1 to $1 \mathrm{kV} / \mathrm{cm}$.

\subsubsection{Detection and data processing}

Fluorescence spectroscopy was implemented as a detection method. A Leica DMI5000 M inverted microscope system (Leica Microsystems, Rijswijk, The Netherlands) which has an integrated motorized stage with electronic position control, was used for the experiments. As a light source a Leica EL6000 unit, equipped with a mercury short-arc lamp (Osram HXP-R120W/45C VIS, Leica Microsystems), was applied. Fluorescent emission from the sample was passed through a Leica filter cube: D, which consists of an excitation filter (band-pass 355-425 nm), a dichromatic mirror (455 nm) and a suppression filter (long-pass $470 \mathrm{~nm}$ ). The experiments were monitored using a Leica DFC300 FX color camera attached to the microscope. Sample peaks were recorded at positions every $5 \mathrm{~mm}$ of the separation channel starting from the point of injection for mobility and plate height measurements. Resulting movie files were first decomposed into image sequences via VirtualDub (open source software), then analyzed and concentration profiles were plotted with ImageJ (open source). As a last step before the calculations, the plotted peaks were fitted as a Gaussian profile and the variances together with the residence times were directly extracted by using OriginPro 8 software (Origin Lab Corporation, USA).

\subsection{Results and Discussion}

\subsubsection{Injection analyses}

Injection experiments were performed with uncoated devices as defined in the previous section. In order to evaluate the injection performance, snapshot images of the 
injected sample were taken at the moment that it entered the separation column (or left the distributor). Therefore these experiments consisted of two phases. First, the sample was guided to the injection cross for the typical bifurcated distributor (Design 3 ) or fed through the optimized distributors (Design 1 and 2) with the potentials shown in Figure 4.4. Second, the sample was directed to the separation column by creating a $100 \mathrm{~V} / \mathrm{cm}$ electric field through the separation channel while keeping the sample inlet and outlet reservoirs at $0 \mathrm{~V}$ (Figure 4.4).
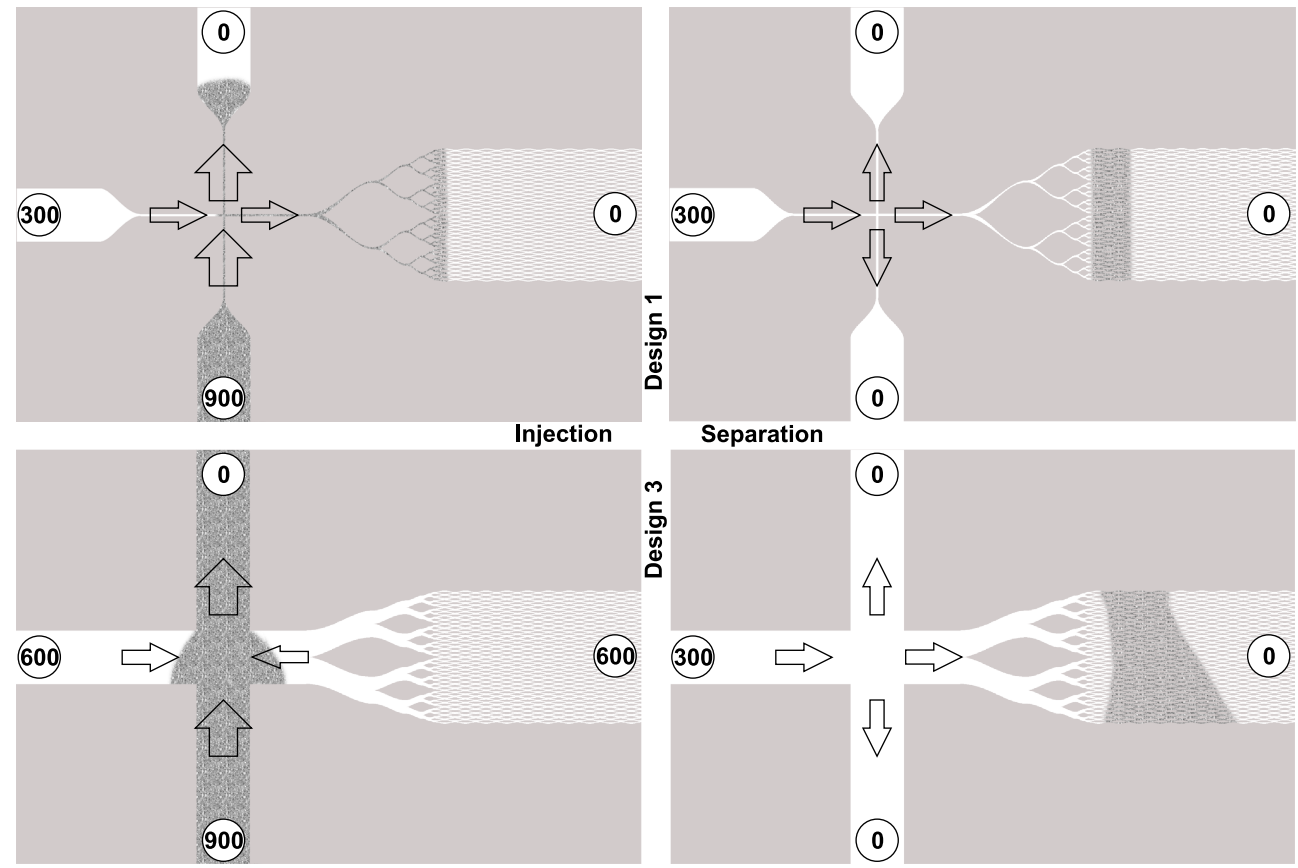

Figure 4.4: Illustration of applied injection/separation voltages and corresponding sample profiles. Arrows represent the direction of flow in the corresponding arm. The same voltages were applied for Design 1 and 2 for injection experiments, therefore only Design 1 is included here. Pinching was applied during injection for Design 3.

Figure 4.5 shows the snapshot images of the injected sample at the distributor/separation column interface for the short versions. For Design 1 and 2, Coumarin dye was fed for 0.8 and $0.6 \mathrm{~s}$, respectively. Then the electric field was switched to the separation column. For Design 3, the sample stream was kept in the injection channel for $3 \mathrm{~s}$ to reach the equilibrium before switching the electric field. As seen in Figure 4.5, Design 1 and 2 yielded almost constant width along the 
channel, while Design 3 resulted with a distorted shape. The images were processed and the base widths were calculated from the profile plots at every $50 \mu \mathrm{m}$ in lateral direction along the channel. Figure 4.6 represents the plot of the base width data. The calculated mean widths from experimental data for Design 1, 2 and 3 were 218, 165 and $255 \mu \mathrm{m}$, respectively. The deviation from the mean along the channel was only around 3-7 $\mu \mathrm{m}$ for optimized distributors (Design 1 and 2), while it was up to $50 \mu \mathrm{m}$ for typical bifurcated distributor (Design 3 ).
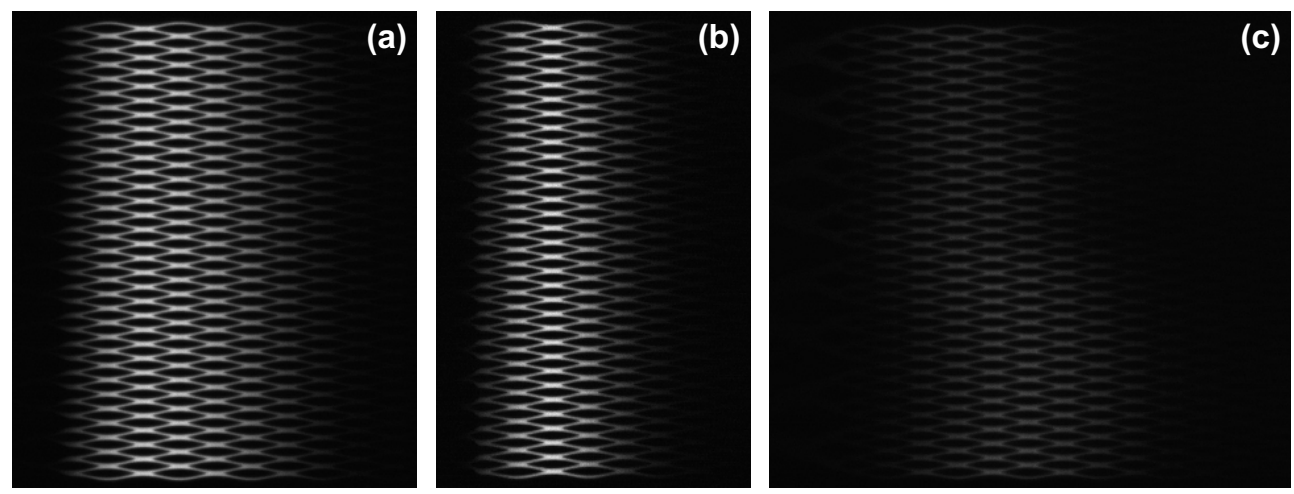

Figure 4.5: Snapshot images of the injected sample at the distributor/separation column interface for the short versions of Design 1 (a), Design 2 (b) and Design 3 (c).

The reason of the distorted shape for Design 3 was the initial profile created at the injection cross before the electric field switching. A more uniform distribution was obtained with the long version of the same distributor. Figure 4.7 shows the initially created stream in its equilibrium shape and the snapshot image of the injected sample. The injection parameters, such as applied voltages and time periods, were the same as the short version. Since the external porosity and the separation channel length was the same for both versions, the same profiles were generated during injection (Figure 4.7 (a)). Applying the same electric field through the separation channel for switching enabled direct comparison of the sample profiles at the distributor/separation column interface. Although the variance in the width for the long version was decreased to around $19 \mu \mathrm{m}$, the mean base width was $348 \mu \mathrm{m}$. Hence, using the longer distributor caused a $36 \%$ increase in the base width of the sample (higher dispersion). 


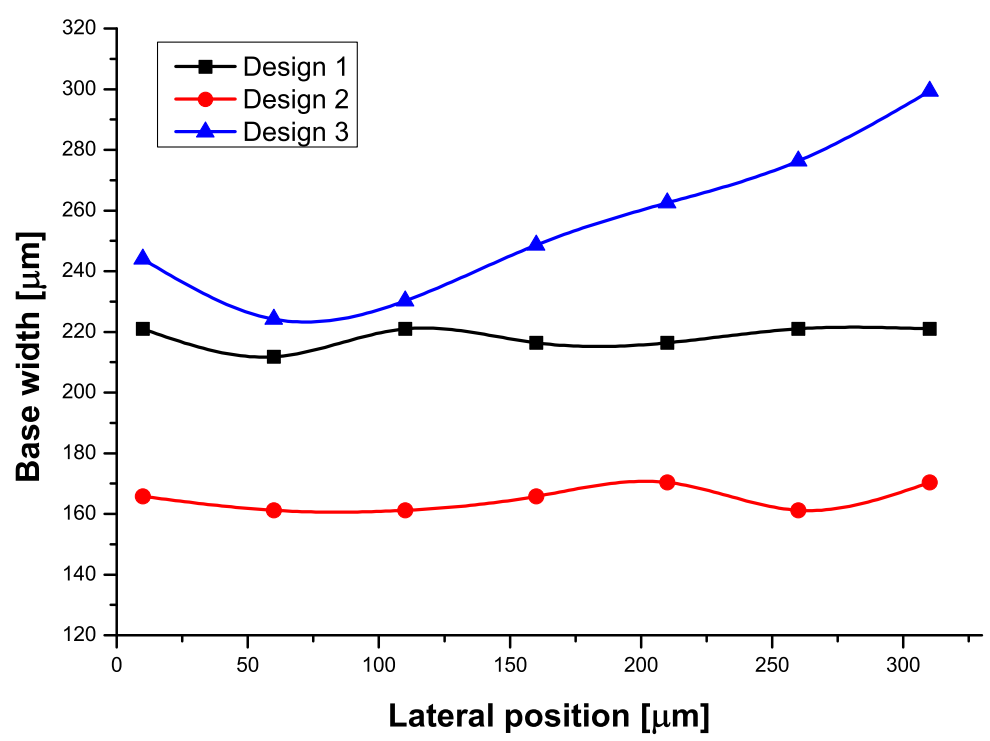

Figure 4.6: Measured base widths of the injected sample shown on Figure 4.5. The widths were measured at every $50 \mu \mathrm{m}$ in lateral direction along the channel.
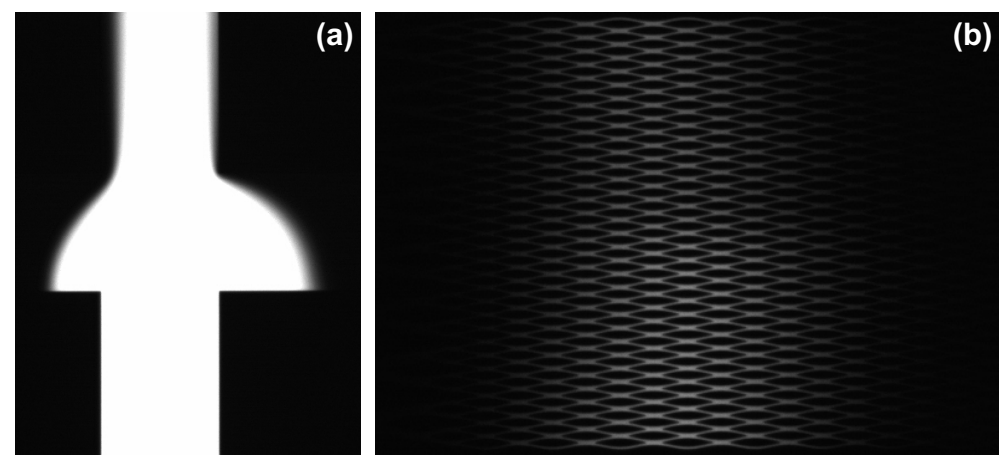

Figure 4.7: Snapshot images of the sample stream in injection channel (a) and the injected sample at the distributor/separation column interface (b) for Design 3 (long version). 
The shape of the initial profile can be changed by adjusting the pinching voltages during injection [11], which can be used for reducing the sample amount. However, the distorted shape cannot be avoided. Although reducing the sample amount could decrease the injected sample width, this would cause a decrease in the detected fluorescence intensity for the same initial sample concentrations. Lowered sensitivity causes loss of data during the detection and data processing and should be avoided. Moreover, the typical distributor design already caused a significant decrease in the detected signal. The short version of Design 3 caused $36 \%$ decrease in the amplitude of the intensity signal from injection cross (e.g. Figure 4.7 (a)) to distributor outlet (separation column inlet) (e.g. Figure 4.7 (b)). Comparing the two design alternatives, the long version of Design 3 yielded $43 \%$ lower amplitude in intensity signal when compared with the optimized designs (Design 1 and 2) for the same conditions (camera and exposure settings, initial sample concentration and volume, etc.). This is due to dispersion caused by molecular diffusion. On the other hand, optimized distributors cause no reduction in the fluorescence intensity at the injection phase while giving the ability of controlling the injected volume precisely by adjusting the duration of the feeding step. Figure 4.8 illustrates the snapshot images of the long version of Design 1 for consecutive time steps for $500 \mathrm{~V} / \mathrm{cm}$ applied electric fields after feeding with the voltages illustrated in Figure 4.4. This experiment proved that the sample volume can be adjusted precisely without any sacrifice in the compactness of the injected sample profile with the optimized designs.

\subsubsection{Design characterization experiments}

This set of experiments was performed with bare fused silica microchips without any surface treatment (i.e. no stationary phase), which ensures an operation in non-retentive conditions. The concentration profile of the fluorescent dye C480 was monitored as described in the previous section. The presence of this neutral dye at a low concentration of around $0.1 \mathrm{mM}$ caused no disturbance in the electric field distribution in the channel. Consequently, the migration of the corresponding zone of this dye expresses the mobile phase velocity at the applied electric fields. One of the key parameters to characterize an electrokinetic system is mobility. Therefore, the 

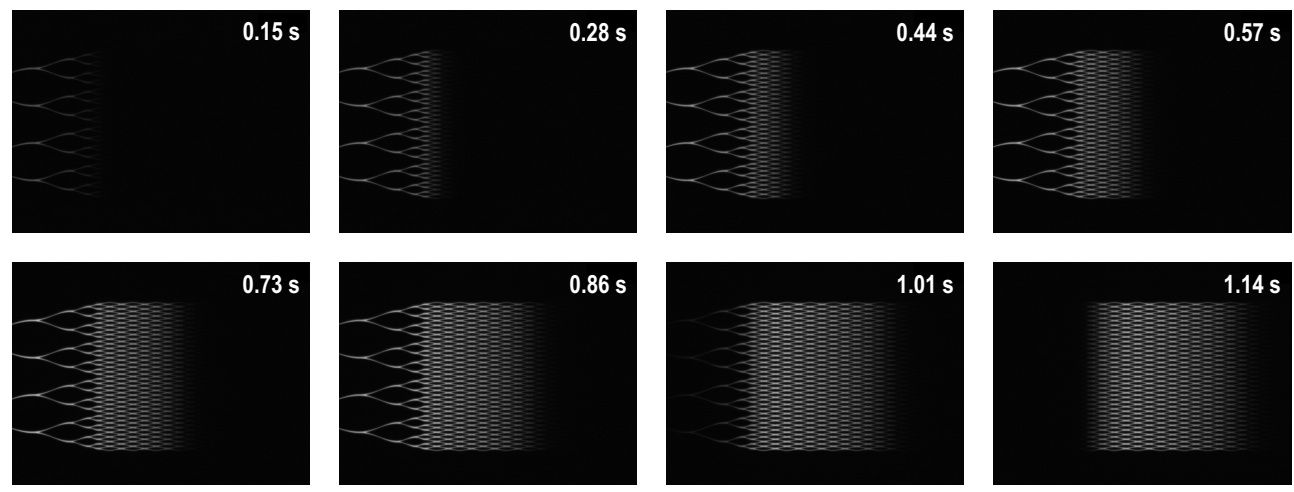

Figure 4.8: Snapshot image series of Design 3 (long version) with time stamps for the injection experiment for controlling the injected sample volume. The last frame was captured immediately after injection was completed and the sample was guided to the separation column.

first parameter to be discussed as a performance measure for the different distributor geometries is the obtained velocity at a fixed voltage. Figure 4.9 shows the variation of the mobile phase velocity with respect to the applied electric field. The relationship between these two parameters was linear, as expected. For the electric field of 800 $\mathrm{V} / \mathrm{cm}$, the measured mobile phase velocities were $0.71,0.34,1.11$ and $1.44 \mathrm{~mm} / \mathrm{s}$ for Design 1, Design 2, Design 3 and an empty channel without a separation column, respectively. These values of the electroosmotic flow (EOF) velocity, generated without surface treatment of the inner walls of the fused silica channels, are high enough for performing CEC experiments.

Being optimized for minimizing the change in the total cross sectional area in lateral direction, Design 3 caused $24 \%$ decrease in mobility when compared to an empty channel. However, employing a sharp decrease in external porosity (from 0.4 to 0.06 ) resulted with much higher voltage drops, hence a significant loss in the obtained linear velocities: Design 1 and 2 yielded $56 \%$ and $78 \%$ decrease, respectively, compared to an empty channel. Therefore, limiting the length of the narrowed $(4 \mu \mathrm{m}$ wide) main channel arms to $200 \mu \mathrm{m}$ (Design 1) instead of deploying to full length (0.5 cm long, Design 2) produced twice as high velocities. Please note that the reduction in mobility is not only caused by the distributor and collector structures but also by the separation column placed in between, which has an external porosity of 0.4. 


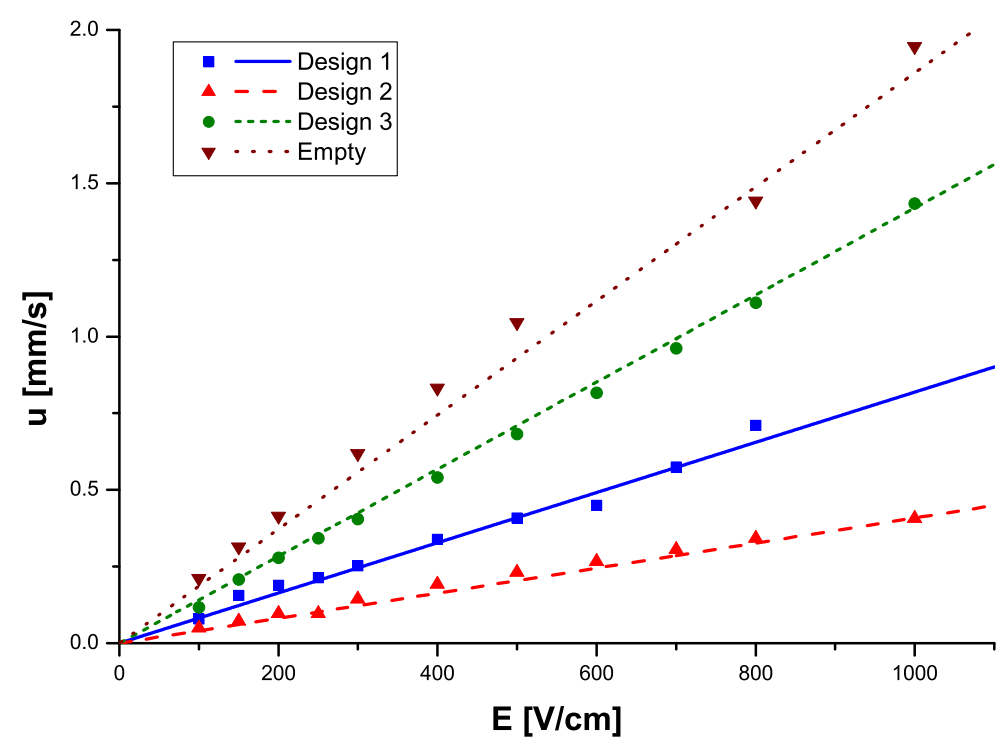

Figure 4.9: Variation of the mobile phase velocity with the applied electric field. A linear curve fit intercepting at $(0,0)$ was implemented. Measured values of the electroosmotic mobility, which is the slope of the fitted curves, are $8.19 \mathrm{E}-9 \mathrm{~m}^{2} / \mathrm{Vs}$ for Design 1, 4.08E-9 m²/Vs for Design 2, 1.42E-8 $\mathrm{m}^{2} / \mathrm{Vs}$ for Design 3, and $1.86 \mathrm{E}-8$ $\mathrm{m}^{2} / \mathrm{Vs}$ for the channel without column.

In order to check the reliability of the measurements, the monitored velocities at different points in the separation channels were compared. The variances in the measured values were always within a $2 \%$ window, which proves the reliability of the data.

\subsubsection{Separation experiment}

With the aim of representing the potential of the optimized distributor design, a separation experiment of 4 coumarin dyes (C440, C460, C480, C540) was performed at $500 \mathrm{~V} / \mathrm{cm}$ electric field. The same injection procedure as explained before was followed. Figure 4.10 illustrates the separated 4 bands: C440, C460, C480 and C540. Separation of all dyes was achieved at $1 \mathrm{~mm}$ downstream of the inlet of the separation column in less than 80 seconds with baseline resolution. 


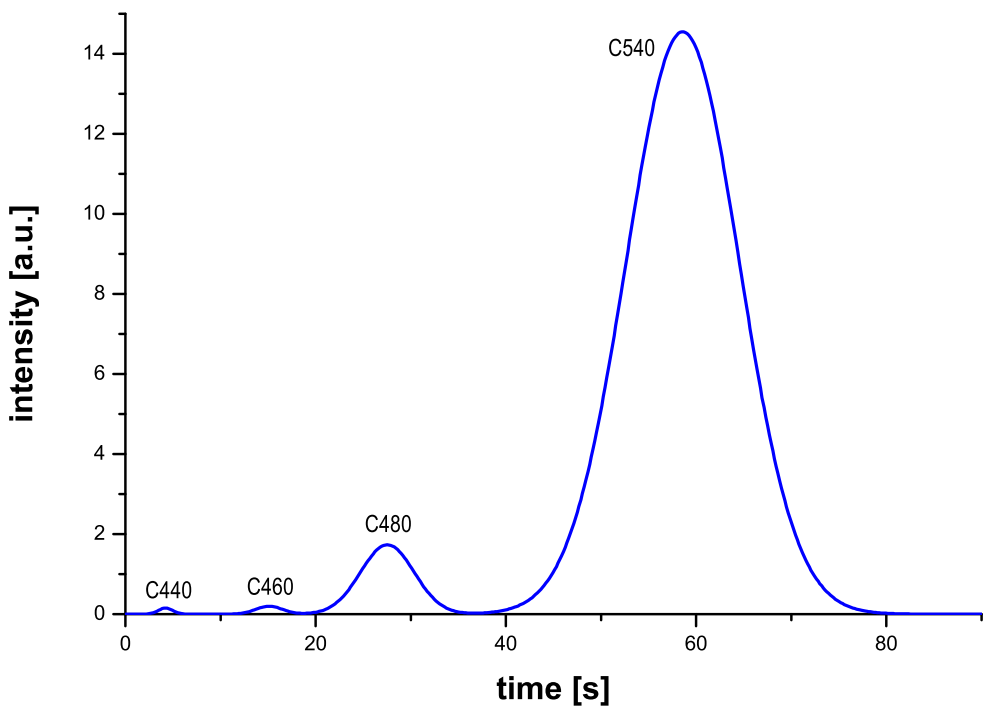

Figure 4.10: 4 coumarin dyes (C440, C460, C480, C540) separated at 500 $\mathrm{V} / \mathrm{cm}\left(\mathrm{L}_{s e p}=1 \mathrm{~mm}\right)$. Stationary phase: octadecyl trimethoxysilane, mobile phase: phosphate buffer ( $\mathrm{pH} 7.2,8.3 \mathrm{mM}$ concentration with 50:50 ACN volumetric composition). Horizontal axis represents elapsed time after injection.

\subsection{Concluding remarks}

Application and experimental validation of the previously proposed foil definition in the design of injector/distributor structures for solid microfabricated column structures for CEC was presented. The effect of the optimized distributor designs on the injection performance in terms of the compactness of the injected sample was evaluated and the optimized designs yielded flat sample profiles. The proposed design approach enabled a precise control of the injected sample volume by means of adjusting the duration of the injection/feeding operation without sacrificing the compactness. More specifically, 165 and $218 \mu \mathrm{m}$ base widths were obtained for 0.6 and $0.8 \mathrm{~s}$ of feeding, respectively. This revealed the linear relationship between the duration of the injection and the delivered sample amount.

One possible drawback of such design would be the high loss of the velocity arising from very low external porosities. Hence the analysis time would increase. However, the increased compactness of the injected plug enables separations in shorter 
separation lengths, which also decreases the analysis time.

In addition to the possibility of shorter channels, the discussed architecture would also allow a T-shaped chip layout instead of a cross arrangement [12]. The injection cross is not needed anymore since the injection is performed as a feeding operation. In other words, only one sample feeding arm would be necessary. Therefore, more compact microchips with less device area would be possible using such optimized distributor structures. For example, the width of the microchip used in this study could be lowered by a factor of 2 (from 1 to $0.5 \mathrm{~cm}$ ) by avoiding one of the injection channel arms.

\section{References}

[1] B He, N Tait, and F Regnier. Fabrication of nanocolumns for liquid chromatography. Analytical Chemistry, 70(18):3790-3797, 1998.

[2] Xiang Zhang and Fred E. Regnier. Analysis of channel-geometry effects on separation efficiency in rectangular-capillary electrochromatography columns. Journal of Chromatography A, 869(1?2):319-328, 2000.

[3] Benjamin E. Slentz, Natalia A. Penner, and Fred Regnier. Geometric effects of collocated monolithic support structures on separation performance in microfabricated systems. Journal of Separation Science, 25(15-17):1011-1018, 2002.

[4] Omar Gustafsson, Klaus B. Mogensen, and J?rg P. Kutter. Underivatized cyclic olefin copolymer as substrate material and stationary phase for capillary and microchip electrochromatography. Electrophoresis, 29(15):3145-3152, 2008.

[5] Klaus B. Mogensen, Fredrik Eriksson, Omar Gustafsson, Rikke P. H. Nikolajsen, and J?rg P. Kutter. Pure-silica optical waveguides, fiber couplers, and high-aspect ratio submicrometer channels for electrokinetic separation devices. Electrophoresis, 25(21-22):3788-3795, 2004.

[6] J. Vangelooven, W. De Malsche, J.O. De Beeck, H. Eghbali, H. Gardeniers, and G. Desmet. Design and evaluation of flow distributors for microfabricated pillar array columns. Lab on a Chip, 10(3):349-356, 2010.

[7] J. Vangelooven, S. Schlautman, F. Detobel, H. Gardeniers, and G. Desmet. Experimental optimization of flow distributors for pressure-driven separations and reactions in flat-rectangular microchannels. Analytical chemistry, 83(2):467$477,2011$. 
[8] W. De Malsche, J. Op De Beeck, S. De Bruyne, H. Gardeniers, and G. Desmet. Realization of $1 \times 106$ theoretical plates in liquid chromatography using very long pillar array columns. Analytical chemistry, 84(3):1214-1219, 2012.

[9] Sertan Sukas, Gert Desmet, and Han J. G. E. Gardeniers. Novel shape and placement definitions with retention modeling for solid microfabricated pillar columns for cec and hplc. Electrophoresis, 31(22):3681-3690, 2010.

[10] Sertan Sukas, Wim De Malsche, Gert Desmet, and Han J.G.E. Gardeniers. Performance evaluation of different design alternatives for microfabricated nonporous fused silica pillar columns for capillary electrochromatography. Analytical Chemistry, 0(0):null, 0.

[11] Sergey V. Ermakov, Stephen C. Jacobson, and J. Michael Ramsey. Computer simulations of electrokinetic injection techniques in microfluidic devices. Analytical Chemistry, 72(15):3512-3517, 2000.

[12] C.H. Tsai, R.J. Yang, C.H. Tai, and L.M. Fu. Numerical simulation of electrokinetic injection techniques in capillary electrophoresis microchips. Electrophoresis, 26(3):674-686, 2005. 



\section{Chapter 5}

\section{Fabrication of integrated porous glass for microfluidic applications}

This paper presents a method for the fabrication of integrated porous silica layers in microfluidic channel networks by microfabrication techniques. Porous silica is obtained by anodization of silicon, followed by full conversion of the porous silicon network into porous silica by means of thermal oxidation. This method can be applied to (3-D) structured microfluidic channels and the resulting porous silica layers can be employed for a wide range of application areas, such as chromatography and electrokinetics. A series of experiments are performed with various channel layouts for determining the critical parameters during anodic etching, including I$V$ characteristics and the optimal working potential for stable pore formation. Typical test structures are anodized in 5\% HF for 15 min at $1 \mathrm{~V}$, yielding an average pore size of around $5.4 \mathrm{~nm}$ and porosity of $49 \%$. Complete conversion of porous silicon into porous glass was accomplished with wet oxidation at $900{ }^{\circ} \mathrm{C}$. Average pore size and the porosity of porous glass network were around $3.8 \mathrm{~nm}$ and $34 \%$, respectively. This decrease in both pore size and porosity is caused by the increase in molar volume, when silicon oxidizes to silicon oxide. The transparency and the hydrophilicity of porous glass layers are evidenced by means of monitoring the diffusion of Rhodamine $B$ fluorescent dye through the porous network.

This chapter has been submitted as Fabrication of integrated porous glass for microfluidic applications, Sukas, S., Desmet, G. and Gardeniers, H.J.G.E. to Lab Chip. 


\subsection{Introduction}

Porous silicon (PS) is obtained by anodic etching of single crystalline silicon ( $\mathrm{Si}$ ) in hydrofluoric acid solution ( $\mathrm{HF}$ ) at room temperature. The pore formation starts at the surface, which is exposed to the HF solution and the pores penetrate commonly, with branching, inside the Si wafer following the electric field lines created by the anodic polarization. A number of studies were reported on the formation of PS and the parameters affecting the pore size, porosity and layer formation rate [1-6]. It was shown that increasing the HF concentration causes a decrease in the pore size and the porosity, while results in a higher layer thickness formation rate. Increasing the applied current density increases the pore size, porosity and layer formation rate, while there is a certain upper limit, where the electropolishing starts. This limit was determined by the voltammetry curves, which give the possibility to determine the working range for a stable pore formation avoiding electropolishing. However, all these characterization studies were performed on planar surfaces with non-processed wafers. Although partially masking of the wafer surface was reported [7,8], the effect of loading, which is defined as the ratio of the total exposed (unmasked) area to the total planar surface area of the wafer, was disregarded.

The possibility of its fabrication directly from $\mathrm{Si}$, which is the main substrate material for microfabrication, made PS applicable into various research disciplines. It was firstly used for optical purposes in microelectronics $[9,10]$, then later its application area became wider, such as in mechanical sensors [11-17], thermal insulation layers [18-21], and chemical applications [22-26]. Our group reported earlier the integration of the PS layers in ordered pillar arrays for liquid chromatography [27] and a characterization study afterwards [28]. Kutter and coworkers published a method for fabricating porous glass (PG) by means of oxidizing Si needles obtained by a reactive ion etching method giving so-called "black silicon", and used it for electrokinetic applications [29]. Detobel et al. reported a sol-gel method for coating the inner walls of the microchanels with porous silica and showed its potential for LC applications [30].

The purpose of this study is to discuss the method of fabricating stable porous 
silica layers by fully oxidizing the PS network, and also discuss its integration into microchips. PS is a semiconductor and hydrophobic material, which exhibits variable optical properties depending on its process conditions [10, 31-33]. Converting the PS layer into PG, which is a hydrophilic and optically transparent dielectric, it is aimed to extend the application areas of such fabrication methodology. The focus will be on the fabrication and the integration of porous glass layers into microstructures. The effects of HF concentration or the applied voltages on pore size and porosity have been elaborately investigated by other authors as shortly summarized above and will not be considered in the present work. However, the effect of loading will be addressed briefly.

\subsection{Experimental}

\subsubsection{Fabrication}

Test structures were designed for step-by-step optimization of the parameters of the fabrication process for conversion of PS into PG before realization of the microchips. Prior to anodization of silicon (Si), 150-175 nm thick silicon-rich nitride (SiRN) was deposited by low pressure chemical vapor deposition (LPCVD) on $100 \mathrm{~mm}$ diameter and $500 \mu \mathrm{m}$ thick, highly doped p-type silicon (p++ Si) wafers with (100) orientation and resistivity of $0.010-0.025 \Omega \cdot \mathrm{cm}$ as a first step. Next, the pattern of the structures was transferred into the SiRN layer via standard UV lithography and reactive ion etching (RIE). Subsequently, $10 \mu \mathrm{m}$ deep channels were etched with RIE or deep RIE, followed by the removal of the SiRN layer from the backside of the wafers by RIE. After this, the samples were ready for anodization and oxidation, which will be discussed in the following sections. In-between these two steps, a thick photoresist film (Ordyl BF410) was laminated on the backside of the wafers and patterned with UV-photolithography. The film served as a mask for through etching of the wafer to open the access holes for the fluidic connections, via powder blasting (with 29 $\mu \mathrm{m}$ alumina particles), using an in-house built setup. After powder blasting, the wafer was first washed with DI-water and then immersed in acetone and isopropanol, 
respectively. Finally, the processed wafers were bonded anodically with bare glass (borofloat) wafers and the stacks were diced into individual microchips (Figure 5.1).

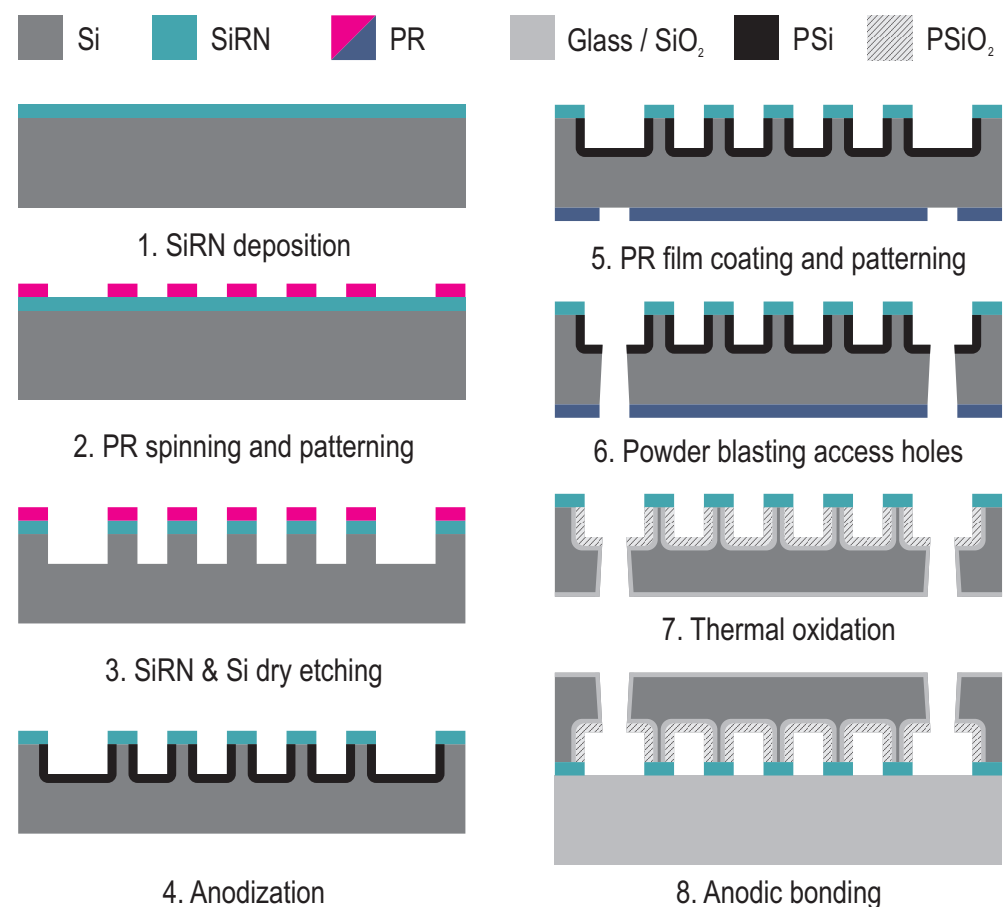

Figure 5.1: Fabrication process flow for microchip fabrication with integrated porous glass layers.

\subsubsection{Anodization}

Porous silicon was formed by electrochemical etching of the $\mathrm{p}++\mathrm{Si}$ wafer in a singlecell Teflon reservoir. The front (polished) side of the wafer was sealed with a leak-tight O-ring and exposed to aqueous hydrogen fluoride (HF) solution, while the backside was in direct contact with a $3 \mathrm{~mm}$ thick copper electrode (anode), which covered the backside completely. The counter electrode (cathode) was immersed in the solution in order to complete the circuit (Figure 5.2). The cathode was a platinum coated perforated Si wafer. A regularly distributed hole grid was created in a double side polished $\mathrm{p}++\mathrm{Si}$ wafer by means of powder blasting. After dicing into a proper size (a polygon to fit in the Teflon container), $300 \mathrm{~nm}$ thick platinum (Pt) layer was sputtered 
on the electrode, and a $400 \mu \mathrm{m}$ diameter platinum wire was knitted through the holes. The electrode was placed in the electrolyte and the platinum wire was connected to the hook-shaped probe of the power supply. In order to maintain a uniform anodization process (as the rate of formation of the porous layer is proportional to the distance between the electrode and the surface to be anodized), the electrode was positioned on a Teflon separator ring, which was placed on the wafer to be anodized: the electrode was kept in horizontal position parallel to the wafer surface with a $5 \mathrm{~mm}$ separation (Figure 5.2). A Keithley (Model 2410) high voltage source meter was used for applying a potential to the anode while the cathode was grounded.
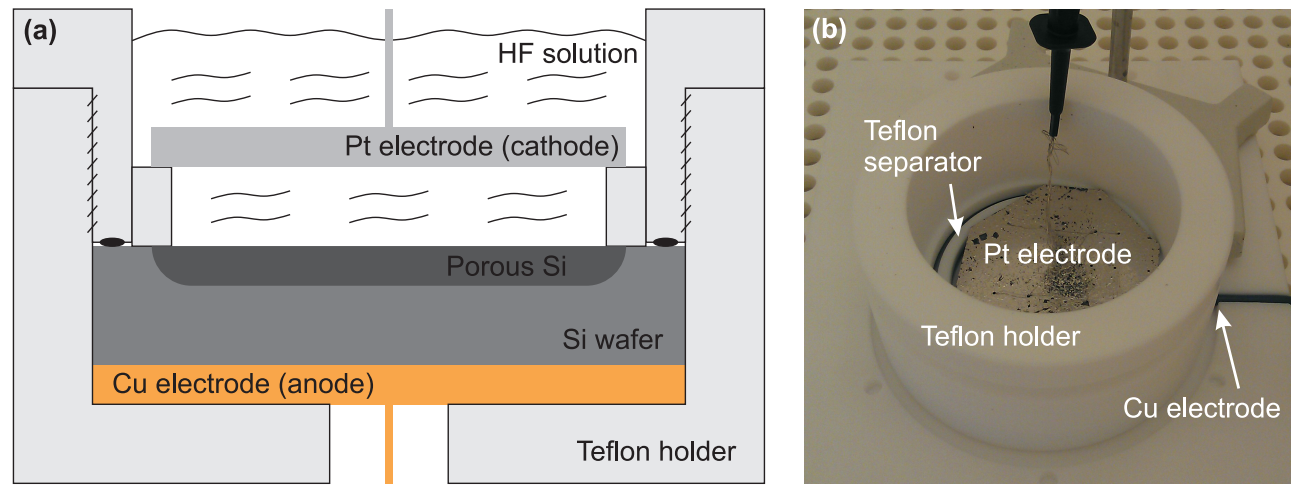

Figure 5.2: Schematic representation (a), and a picture (b) of the anodization chamber.

\subsection{Results and discussion}

\subsubsection{Anodization}

The fabricated test structures for anodization/oxidation experiments were pillars with different geometrical shapes placed as regular arrays inside $10 \mu \mathrm{m}$ deep, straight and open microchannels. As seen in step 4 in Figure 5.1, the SiRN layer was used as a mask for the anodization process, hence only the bottom surfaces and the walls of the pillars and the sidewalls of the microchannels were processed. The total surface area exposed to the $\mathrm{HF}$ solution was around $10 \mathrm{~cm}^{2}$, which resulted in a $30 \%$ loading with 
respect to the total planar surface area of the non-processed $100 \mathrm{~mm}$ wafer, which was around $34 \mathrm{~cm}^{2}$.

Figure 5.3 represents the current vs. potential characteristics (voltammograms) of the test structures for different concentrations of HF. The obtained plots can be divided into three regions. First, they start with an exponential growth, which represents uniformly distributed and stable pore formation. Then the relationship has a linear trend in the transition phase, where pores are still created but the process becomes unstable and non-uniformities are observed. After passing the current peak, electropolishing starts. As seen in Figure 5.3, increasing the HF concentration yields higher anodic currents. As the I-V curve characteristics and the effect of the HF concentration were already investigated and experimentally verified in the literature [1], it is not discussed in this paper.

One other important mechanism reported in literature is hydrogen gas evolution during the pore formation process [4]. This phenomenon and its detrimental impact on the uniformity of the porous layer was observed during the experiments. The formed hydrogen bubbles during the pore formation stick to the surface to be anodized and creates local isolated regions, thus preventing the pore formation to occur. Such nonuniformity was visible to the bare eye as a color change for even a few micron thick layers. In order to avoid sticking of the bubbles, the wettability of the surface was enhanced by adding ethanol to the HF solution. A volumetric ratio of 5:1 HF:ethanol was selected as a suitable composition for avoiding non-uniformities and too much dilution of HF solution.

To study the effect of loading on the current vs. potential relationship, in addition to the $30 \%$ loading case, open microchannels with the same depth and similar pillars with smaller dimensions were fabricated for having $5 \%$ loading. As a planar alternative without etched channels, $2 \%$ loading was obtained by only masking the surface of the Si wafer with etched windows in a SiRN layer. A non-processed Si wafer was also included in the study as a reference for $100 \%$ loading.

Figure 5.4 shows the anodic current density (current per unit exposed area) vs. potential plot of different levels of loading for both planar surfaces and etched microchannels. Increasing the loading causes a decrease in obtained current density 


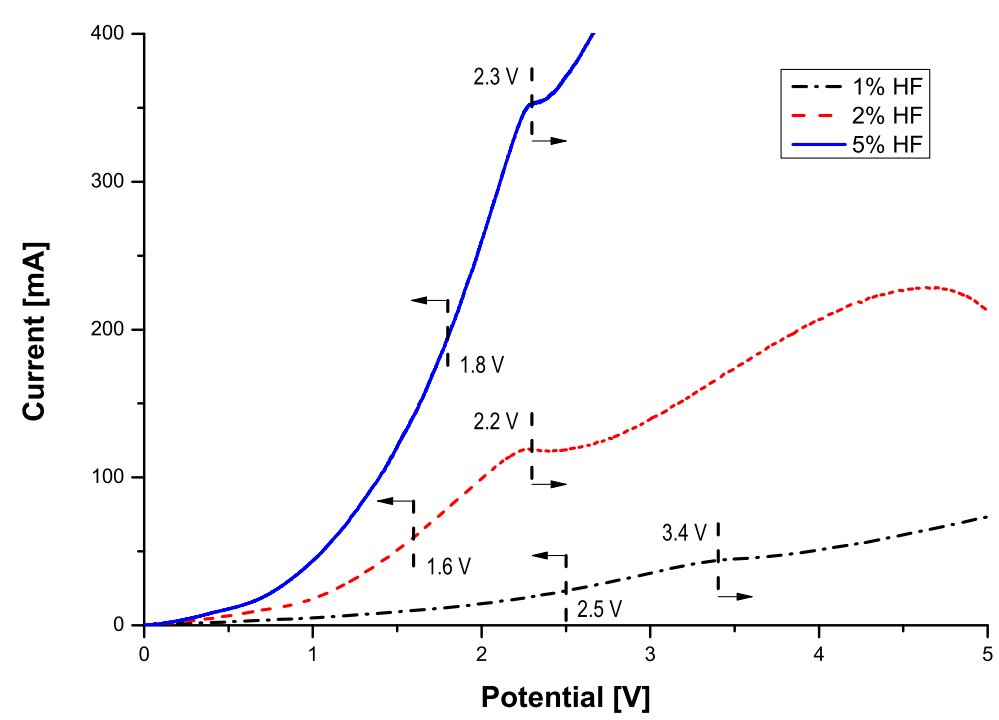

Figure 5.3: I-V curves for micromachined structures with $30 \%$ loading on $\mathrm{p}++\mathrm{Si}$ for $1 \%, 2 \%$ and $5 \% \mathrm{HF}$ solutions. The potentials were swept with $5 \mathrm{mV}$ increments and $20 \mathrm{~ms}$ step time.

and polishing occurs at lower values. However, the span of the potential in the safe zone for stable pore formation (the logarithmic region) gets larger. Therefore, having designs with low loadings should be avoided as it would be difficult to determine the applicable potential for the desired pore size and porosity because of the limited working range. Moreover, applying higher anodic currents increases the rate of evolution of the hydrogen bubbles, which would cause stability and uniformity issues as discussed earlier.

Using the data represented in Figure 5.3, $1 \mathrm{~V}$ was selected as the anodization potential for the test structures with $30 \%$ loading. A $2 \mu \mathrm{m}$ thick PS layer was obtained after 15 minutes of application in 50:10 ml 5\% HF:ethanol solution. In Figure 5.5(a), the microscope image shows the distribution of the PS layer around the pillars, which are $100 \mu \mathrm{m}$ long and $20 \mu \mathrm{m}$ wide with a depth of $10 \mu \mathrm{m}$. Selecting the applied potential within the safe range (the transition regime started around $1.5 \mathrm{~V}$ after the first logarithmic growth region), the obtained layer thickness distribution was uniform. Figure 5.5(b) shows the high resolution SEM (HR-SEM) image of the cross section of the cleaved center zone of the wafer. The uniformity was also preserved across the 


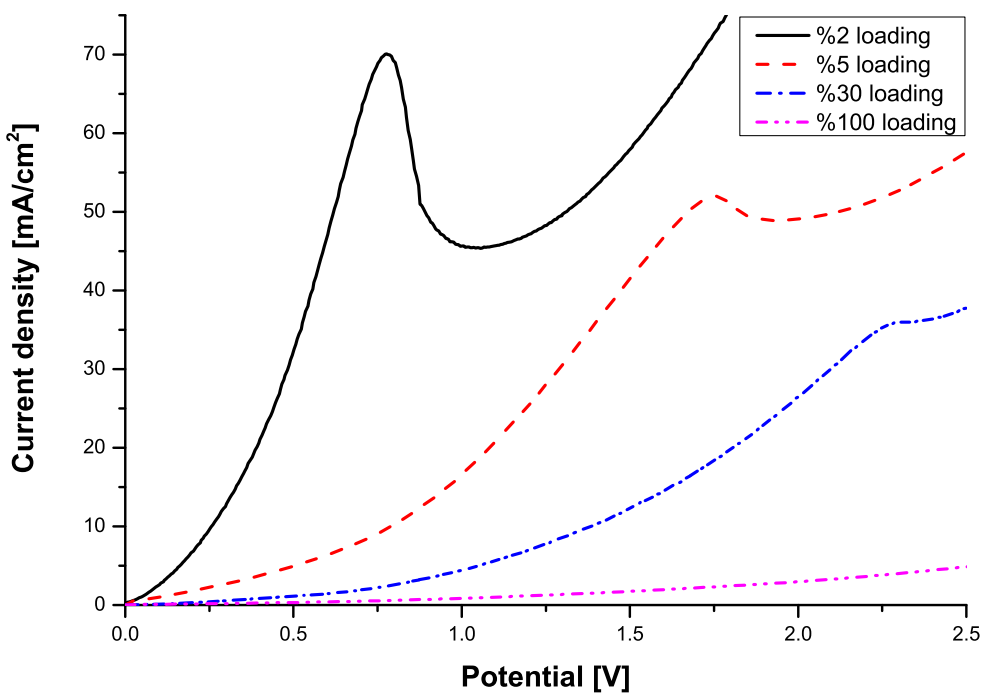

Figure 5.4: J-V curves for micromachined structures for different loadings for $5 \%$ HF solution. The potentials were swept with $5 \mathrm{mV}$ increments and $20 \mathrm{~ms}$ step time.

height of the structures.

Since the PS layer formation rate was constant during anodization, the resulting layer thickness was linearly proportional to the anodization time. Therefore, it was possible to fabricate thicker layers and even fully porous pillars. However, the growth direction of the pores was coincident with the electric field lines through the Si wafer. After the initial pore formation on the surface, propagation with branching continued in a direction perpendicular to the surface. As a result, the faces parallel to the bottom electrode plate produced straight, hence stronger field lines when compared to the side faces. For investigating the possibility of having fully porous pillars and the differences in formation rates between side and bottom surfaces, a $5 \%$ loading design was anodized in 5\% HF solution without an etch mask (the SiRN layer was removed before anodization), yielding a total surface area of around $35 \mathrm{~cm}^{2}$. The anodization current was set to $200 \mathrm{~mA}$ for 15 minutes, which was enough to convert the $10 \mu \mathrm{m}$ thick pillars into fully porous structures. Figure 5.6 shows a HR-SEM picture of the cross sectional view focused on the near-wall region. The resulting thicknesses of the PS layer was $5.65 \mu \mathrm{m}$ on the sidewalls, whilst it was $6.7 \mu \mathrm{m}$ at the bottom of the channel and $6.9 \mu \mathrm{m}$ in the bulk region as flat surfaces. Pore size and the porosity were 

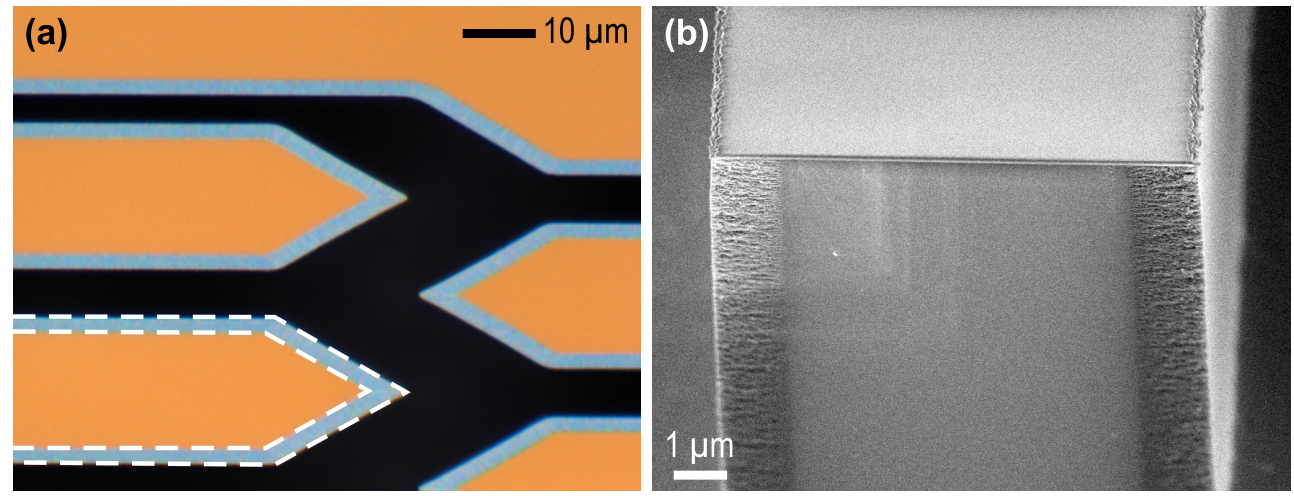

Figure 5.5: Formed PS layer after $15 \mathrm{~min}$. at $1 \mathrm{~V}$ in $5 \%$ HF. Microscope image of the hexagonal shape pillar (a). HR-SEM image of the cross section at the center of the wafer (b). The layer thickness is $2 \mu \mathrm{m}$.

determined by processing a series of HR-SEM images of surfaces and cross-sections using ImageJ software. The average pore size and the porosity were calculated to be $5.2 \mathrm{~nm}$ and $53 \%$, respectively.

Unlike the other anodization experiments reported in this paper, the masking SiRN layer was removed prior to anodization and a constant current was applied instead of a constant potential. The reason was to enable the possibility of comparing the measured pore size and porosity values with the data in literature and to confirm the validity of the measurement method. In 2008, our group reported a detailed study on anodization of non-processed p++ Si wafers without masking (100\% loading) with constant current application [28]. Etching the channels increased the total exposed surface area only by $2 \%$, which allowed a direct comparison with BET measurement data in that paper. For the same anodization conditions, the measured pore size and the porosity were $5.4 \mathrm{~nm}$ and $55 \%$, respectively as determined from BET adsorption experiments. Image processing measurements over HR-SEM images showed a good agreement with BET measurements. Therefore it was decided to use HR-SEM for determining the pore size and the porosity as a quick and easy method for further experiments. The error margin of the measurements with this method was $10-20 \%$. 


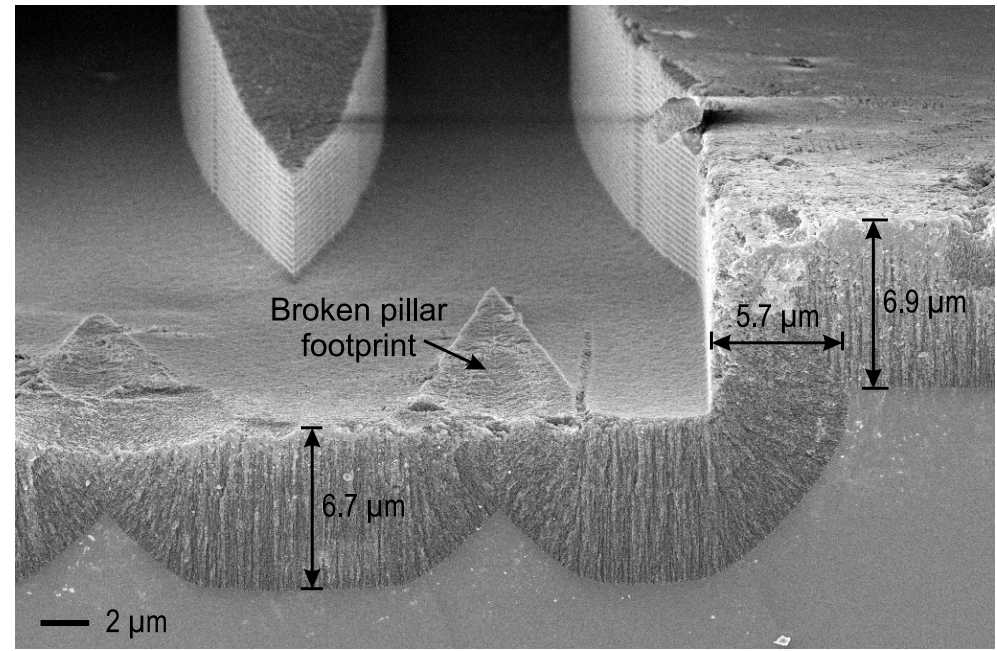

Figure 5.6: HR-SEM image of the anodization results for $5 \%$ loading design without masking (100\% loading case). Fully porous pillars were obtained after $15 \mathrm{~min}$. at 200 $\mathrm{mA}$ in $5 \% \mathrm{HF}$. Mean pore size and the porosity are $5.2 \mathrm{~nm}$ and $53 \%$, respectively.

\subsubsection{Oxidation}

Porous glass $(\mathrm{PG})$ was realized by fully oxidizing the PS skeleton via thermal oxidation. This is a diffusion driven process for bulk Si and yields 2.27 unit thickness of oxide layer for a unit thickness of Si consumed. However, it was shown that the oxidation of the PS network is driven by surface reactions instead of diffusion [34]; because freshly fabricated PS is highly reactive. In order to compare the mechanisms of the conversion processes, both dry and wet oxidation were investigated.

The most critical parameter for oxidation is the process temperature. For bulk Si processing, usually the temperatures of $1050{ }^{\circ} \mathrm{C}$ and above are preferred in order to increase the purity of produced silica [35]. Therefore the samples shown in Figure 5.6 were oxidized for full conversion of PS to PG at $1050 \mathrm{C}$ both in dry and wet environments for 80 and 15 minutes, respectively for the aimed oxide thickness of $150 \mathrm{~nm}$ (note that this value is estimated from known data for oxidation of solid, non-porous silicon), which was assumed to be larger than the thickest part of the Si skeleton. Figure 5.7 represents the HR-SEM pictures of the cross-sections of cleaved structures after oxidation. The porous structure was preserved after dry oxidation. 
Charging was observed at the interface of the PG/Si during the SEM imaging, which proves the existence of a dielectric layer. The measured thickness of this layer was 80$100 \mathrm{~nm}$. This finding supports the assumption of a surface reaction driven oxidation of the PS network followed by a diffusion driven oxidation reaction through the bulk Si layer underneath.

In contrast, wet oxidation of PS resulted in complete closure of the pores, but a similar dielectric layer was observed at the PG/Si interface (which can only be a silica layer in this case). Closure of the pores could be assumed as an indication to an increase in wall thickness of the PS skeleton, which would indicate the existence of the diffusion driven oxidation, in contrast to the surface reaction driven process which was concluded for dry oxidation. However, the smoothness of the surface of the cross section of the structures in Figure 5.7(b), which were porous prior to the oxidation reflects another important mechanism during high temperature heat treatments: the viscous flow of silica, which takes place at the temperatures higher than $950-1000{ }^{\circ} \mathrm{C}$ [36]. Therefore, oxidation within the viscous flow range, which may cause complete closure of the pores, should be avoided.

Preserving the porous structure with dry oxidation, while having complete closure of pores with wet oxidation at the same temperature, was interpreted as that the oxidation process starts with surface reactions because of the highly reactive nature of the porous silicon structure, but then continues as a diffusion driven process for longer oxidation times. This proposition is in agreement with the fact that the oxidation continues at bulk Si underneath the PG layer after complete conversion from PS.

Evaluating the use of dry oxidation for obtaining PG, the focus was given to wet oxidation for expanding the possibilities regarding electrokinetic applications, which require fluidic channels with an electrical isolation layer thick enough to withstand high potentials. Please note that PS formation and subsequent oxidation can serve as an alternative to oxidation of solid crystalline $\mathrm{Si}$, especially for thick insulation layers. However, the insulation layer mentioned here is the dielectric layer, which is needed to insulate the Si substrate from the electric field created through the ionic liquid in the microchannels by means of the applied electric potentials. Therefore the critical points related to the application and the realization of the Si-based microchips with 

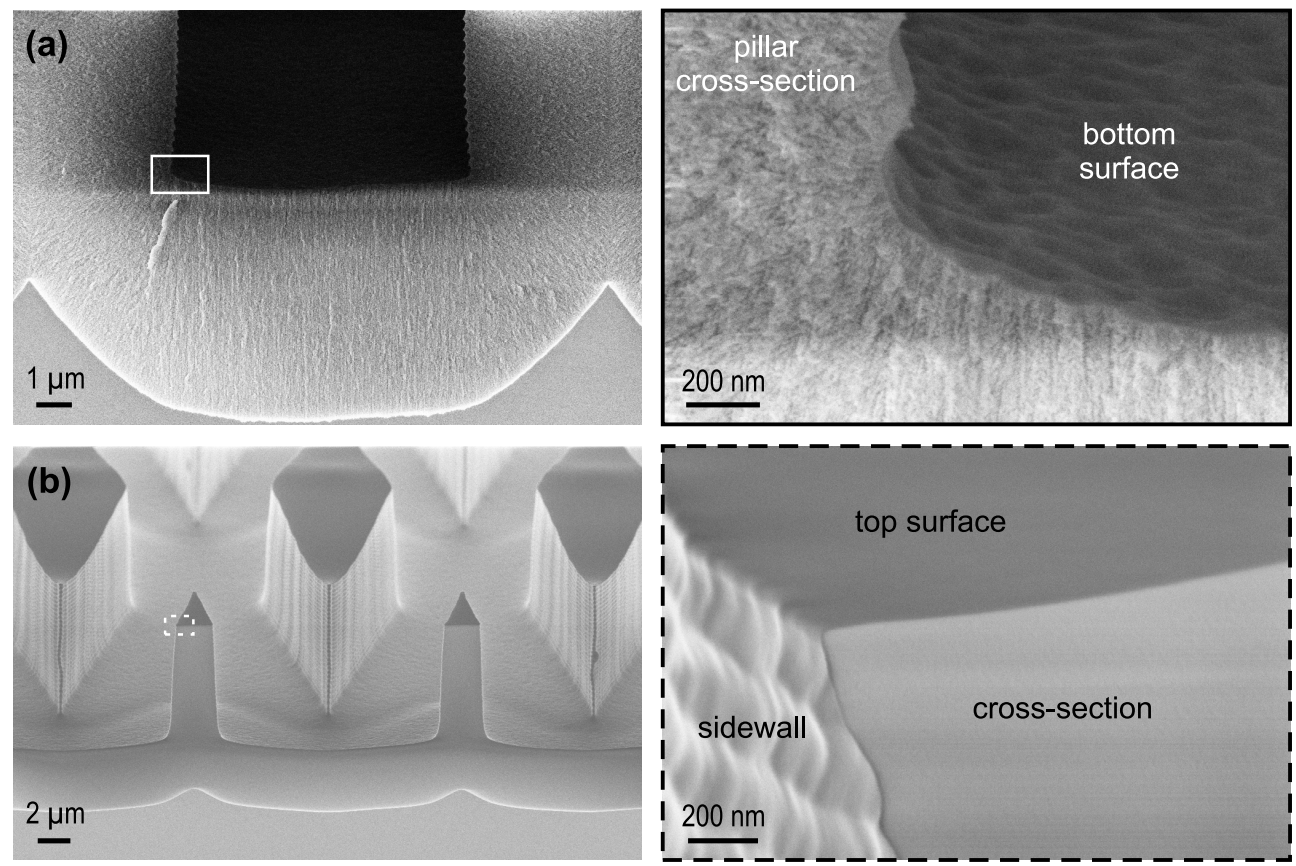

Figure 5.7: Dry (a) and wet (b) oxidation of the sample shown in Figure 5.6 at $1050{ }^{\circ} \mathrm{C}$.

integrated PG and silica layers in their interior were investigated. The first parameters to be investigated are pore size and porosity, which are reduced due to oxidation. It was stated earlier that the dependency of the pore size, porosity and porous layer growth rate on the concentration of HF solution and/or the applied electric potential differs for every design and a separate optimization study has to be performed for every case to find the right parameters for the needs of the application. Such relationship was determined for the test structures, whose I-V relationships were shown in Figure 5.4, for giving an insight to the reader about the mechanisms of the process steps.

In order to avoid closure of the pores due to viscous flow of silica, the optimum temperature was set to $900{ }^{\circ} \mathrm{C}$ for wet oxidation of the PS network. Figure 5.8 shows close-up HR-SEM pictures of the porous network of the same structures as shown in Figure 5.5 before and after complete conversion of PS into PG. Since it was not possible to obtain reliable data with BET measurements for such small sample volumes [27] and it was shown that the image processing gives a good estimate, the 
mean pore size and the porosity calculations were performed by analyzing the HRSEM images. Calculated porosities for PS and PG were around $49 \%$ and $34 \%$, while the average pores sizes were around $5.4 \mathrm{~nm}$ and $3.8 \mathrm{~nm}$, respectively. Hence the oxidation process resulted in around $31 \%$ decrease in the porosity and $29 \%$ decrease in pore size.
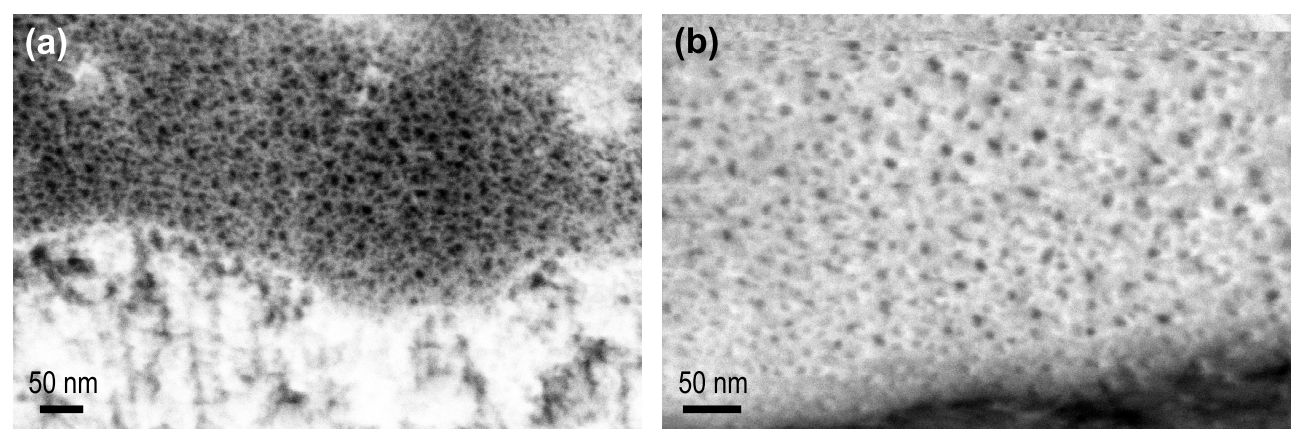

Figure 5.8: HR-SEM pictures of PS before (a) and PG after (b) oxidation. Porosity: 49\%, pore size: $5.4 \mathrm{~nm}$ for PS. Porosity: $34 \%$, pore size: $3.8 \mathrm{~nm}$ for PG. Please note that the uniform portions of above images together with the other images were used for processing.

The reduction in pore size and porosity were directly dependent on the initial states. Shrinkage of pore size means expansion of the skeleton wall, which is defined by the initial wall thickness. The applied potentials and currents for anodization experiments were selected for obtaining an average pore size of around $5 \mathrm{~nm}$. HRSEM analyses showed that the maximum thickness of the walls of the PS skeleton were around $100 \mathrm{~nm}$. However, only $7 \%$ of the counted pores were in the range of 5 $\mathrm{nm}$ and the size distribution was between 2 to $30 \mathrm{~nm}$. This indicates that the local reduction in pore size and porosity after oxidation are dependent on the morphology. Since the anodization was performed on 3-D structures, the initial state of the pore (hence the shrinkage after oxidation) is also dependent on its location, as the intensity of the electric field lines created during the anodization process changes with the morphology.

Having the maximum wall thickness around $100 \mathrm{~nm}$, an hour of wet oxidation at $900{ }^{\circ} \mathrm{C}$ would be enough for full conversion of PS into PG. However, significantly longer oxidation times were required to generate a thick insulation layer to avoid 
electrical breakdown, when applying high voltages during electrokinetic applications. For that purpose, a set of $30 \%$ loading test structures was fabricated (etched via DRIE for $10 \mu \mathrm{m}$ channel depth) and anodized in $5 \% \mathrm{HF}$ at the potential of $0.5 \mathrm{~V}$ for 10,20 and 30 minutes. These samples were oxidized (wet) at $900{ }^{\circ} \mathrm{C}$ for 20 hours. Figure 5.9 shows HR-SEM pictures of the cross-sections of the pillars cleaved at the same position (center of the wafer) for each sample. The obtained porous layer thicknesses were $1.1 \mu \mathrm{m}, 2.3 \mu \mathrm{m}$ and $3.5 \mu \mathrm{m}$ for $10 \mathrm{~min}, 20 \mathrm{~min}$ and $30 \mathrm{~min}$, respectively (Figure 5.9). The resulting silica thickness underneath the porous layers was $1.1 \pm 0.5 \mu \mathrm{m}$ (Figure 5.9), which yielded around $1.5 \mu \mathrm{m}$ increase in total thickness of the pillar, which was $10 \mu \mathrm{m}$ prior to oxidation. As a reference, a non-processed $\mathrm{p}++\mathrm{Si}$ wafer was oxidized under the same conditions, yielding a silica layer thickness of $806 \pm 10$ $\mathrm{nm}$. This evidences that the presence of the porous layer does not have a negative effect on the rate of the oxidation process through the bulk Si layer underneath. In other words, oxygen can easily diffuse through the porous skeleton and react with bulk Si to enable oxidation. Interestingly, the measured silica layer underneath the porous network was $40 \%$ thicker than that of the non-processed Si wafer. The possible explanation for this evidence can be that the size of the pores close to the bulk $\mathrm{Si}$ was significantly small when compared to the outer part (Figure 5.9), so that the complete closure of these pores could happen during the oxidation and the resulting silica layer could be the combination of oxidized bulk and porous Si.

Expansion of the pillars during the oxidation caused an increase in not only their thickness but also their height because of the SiRN layer, which was used as a mask (Figure 5.1). Expansion differences between Si/silica and PG on the sides of the pillars caused upward bending of the SiRN layer on top of the pillar (illustrated in Figure 5.9). This is a well-known phenomenon: it is called the birds beak effect, which occurs during the selective oxidation of Si (LOCOS process) [37]. The measured height differences were $474 \mathrm{~nm}, 572 \mathrm{~nm}$ and $663 \mathrm{~nm}$ for the total anodization times of 10 $\min , 20 \mathrm{~min}$ and $30 \mathrm{~min}$, respectively.

In order to have a closed channel system, a glass wafer has to be bonded anodically as a last step of the fabrication process (Figure 5.1). The above mentioned height difference caused by the bending of the SiRN layer may result in an improper bonding. 

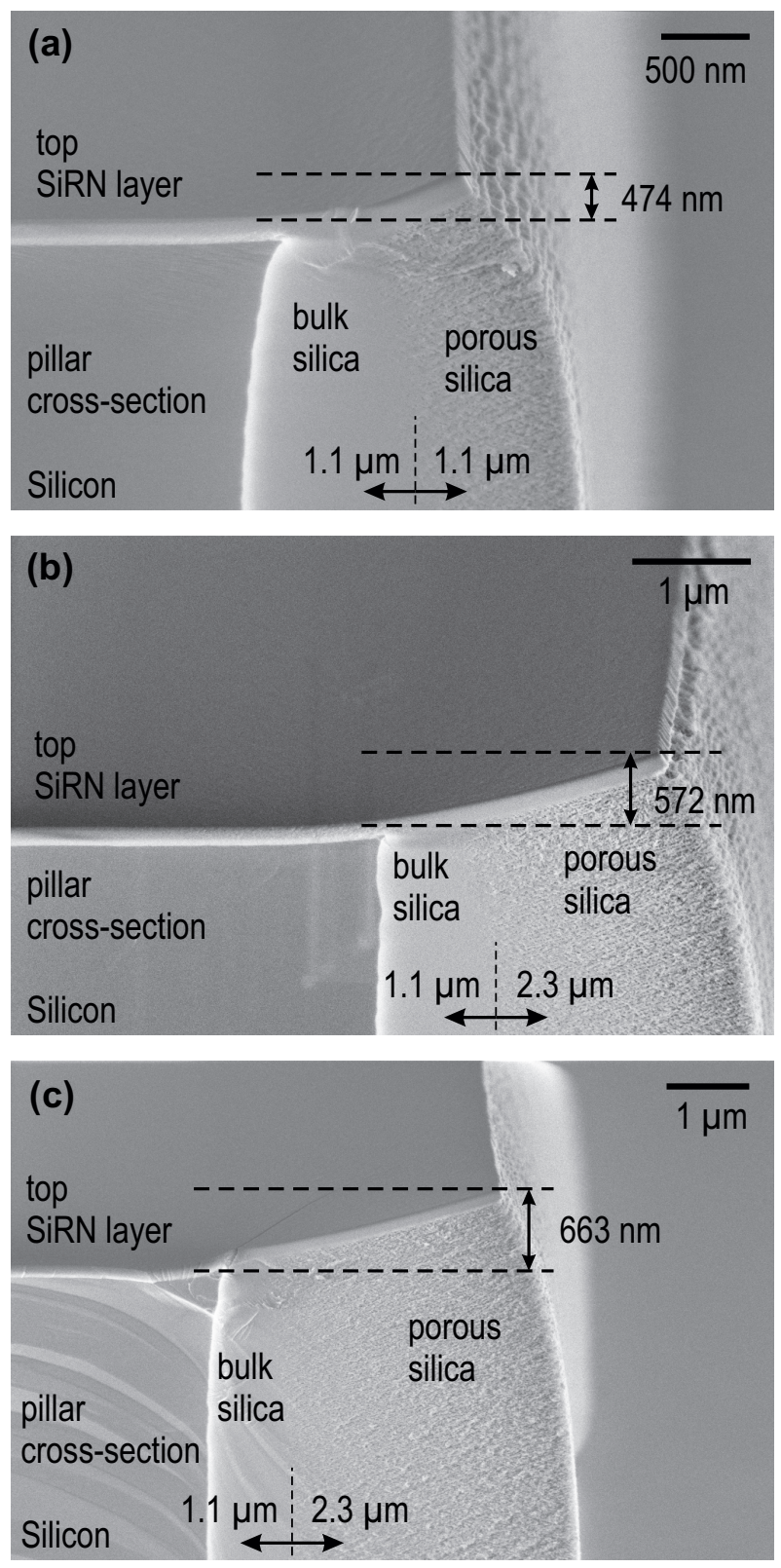

Figure 5.9: HR-SEM pictures of 30\% loading design for $10 \mathrm{~min}$ (a), $20 \mathrm{~min}$ (b), and $30 \mathrm{~min}$ (c) of anodization at $0.5 \mathrm{~V}$ in $5 \% \mathrm{HF}$ followed by 20 hours of wet oxidation at $900{ }^{\circ} \mathrm{C}$. 


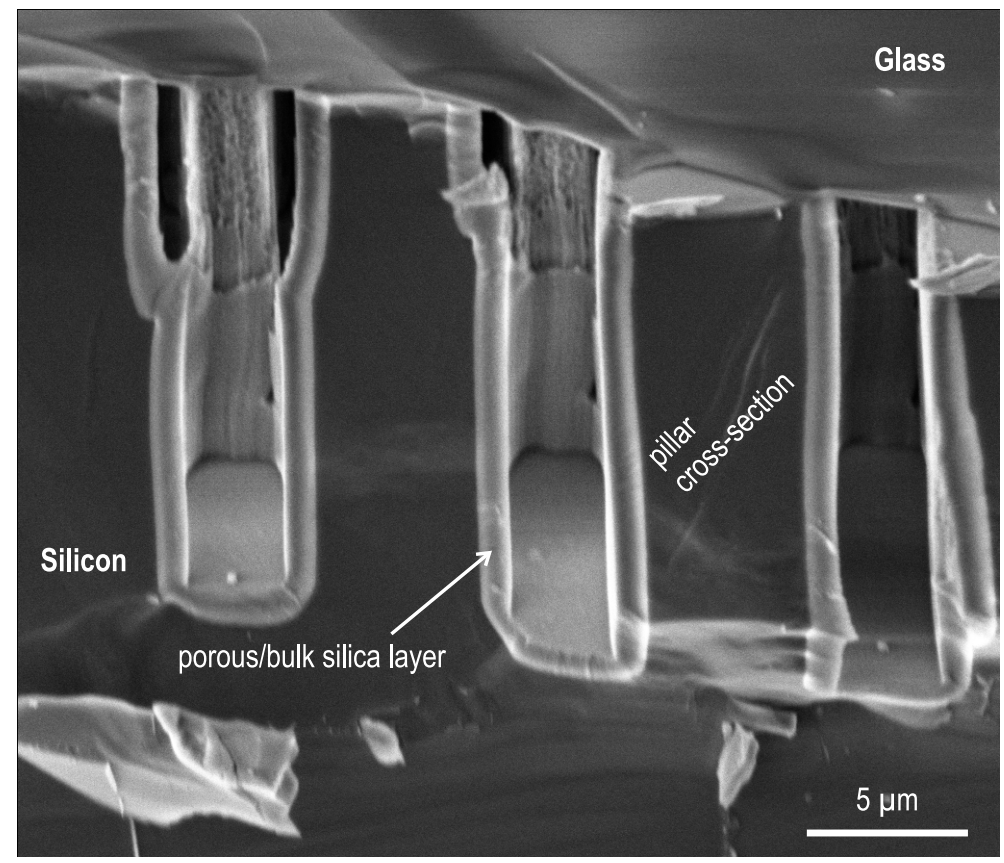

Figure 5.10: SEM image of a cleaved microchip. PG layer thickness is $1 \mu \mathrm{m}$, silica isolation layer thickness is $400 \mathrm{~nm}$. Pillar thickness and height are 6 and $10 \mu \mathrm{m}$, respectively.

The anodization and oxidation times, hence the layer thicknesses of the PS and silica should be adjusted in order to restrict the amount of bending to a safe margin for enabling a proper bonding. Figure 5.10 shows a SEM picture of a cleaved cross-section of a bonded microchannel with $1 \mu \mathrm{m}$ PG thickness and a $400 \mathrm{~nm}$ thick silica layer underneath.

\subsubsection{Characterization}

Although HR-SEM pictures demonstrated that the PS network and the bulk Si underneath were oxidized successfully, the full conversion of the PS skeleton into PG needed to be confirmed experimentally. As a simple way, the sample shown in Figures 5.7(a) was dipped into $1 \%$ HF solution for 5 minutes in order to etch away the PG layer. Figure 5.11 represents the SEM picture of the remaining structures after removal of the PG/silica layer. The HF etching process resulted in conical structures 
in case of fully anodized/oxidized circular pillars with a rough surface. The conical shape of the remaining Si core underneath the fully porous pillars was defined by the pore direction perpendicular to the exposed silicon surface, and this direction was again defined by electric field lines during the anodization. The etching solution was checked after etching for any trace of non-oxidized Si skeleton and nothing was observed. This demonstrated that PS was fully converted into PG, since $1 \% \mathrm{HF}$ solution did not etch PS.

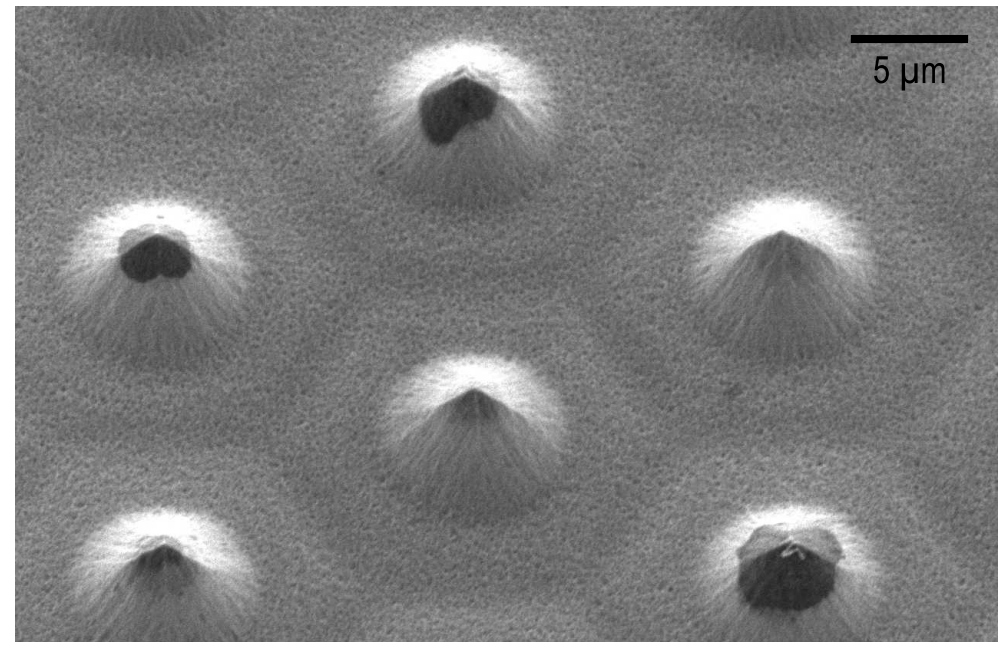

Figure 5.11: SEM picture of the leftover conical structures after removal of the $\mathrm{PG} /$ silica layer of the fully porous circular pillars in $1 \% \mathrm{HF}$.

In addition to the etching experiments, fluidic measurements were performed with the $30 \%$ loading design, which was described in the previous section. $4 \mathrm{~cm}$ long, straight microchannels had $1 \mathrm{~mm}$ diameter reservoirs on both ends. As shown in Figure 5.12(a), the selected channel for the experiments accommodated hexagonal pillars, whose length and the width were $100 \mu \mathrm{m}$ and $20 \mu \mathrm{m}$, respectively. The PG layer thickness was $2.2 \mu \mathrm{m}$. A droplet of $10 \mu \mathrm{L}$ of $1 \mathrm{mM}$ Rhodamine B solution (Sigma-Aldrich, Zwijndrecht, The Netherlands) was placed into a reservoir in one end of the open channel. Fluorescent images were captured at the center of the channel while the solution was diffusing through the PG network. The change in intensity of the captured images was monitored in order to measure the rate of increase in the amount of the sample brought about by diffusion. Figure 5.12(b) shows the change in 
the intensity with respect to the elapsed time for the region of interest (ROI) shown in Figure 5.12(a). Figure 5.13 represents a series of snapshot images of the ROI where the fluorescent dye diffused into the PG layer captured at different times. This experiment indicated that the obtained porous layer was totally transparent, which is not the case for PS. In addition, it was not possible to have the liquid diffuse into the PS layer because of the hydrophobic nature of its surface. PG was highly hydrophilic, which allowed diffusion and spreading of Rhodamine B through the entire PG network easily.

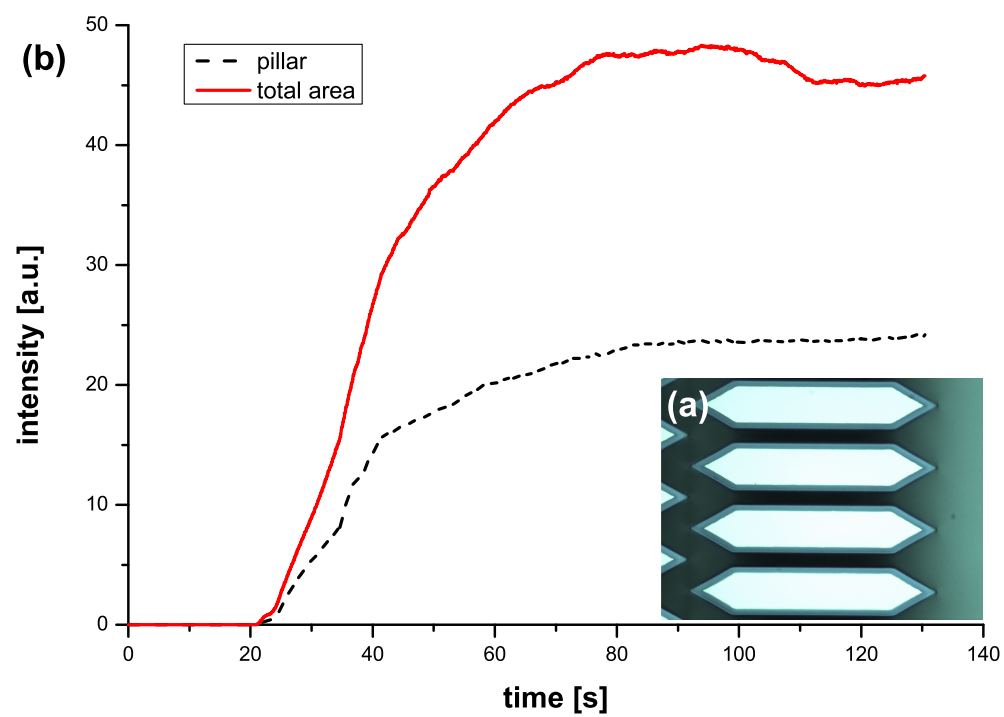

Figure 5.12: Microscope image of the hexagonal pillars before dye injection (a). The length and the width of the pillars are $100 \mu \mathrm{m}$ and $20 \mu \mathrm{m}$, respectively. The PG layer thickness is $2.2 \mu \mathrm{m}$. The average intensity graphs (vs. elapsed time) of the entire region shown in (a) and PG layer around a single pillar (b).

As seen in Figure 5.13, the tips of the structures were brighter than the sides, which indicates that a higher amount of sample accumulated there. This phenomenon was observed for structures with corners or sharp tips, while the rounded shapes, such as circles, yielded a uniform distribution of Rhodamine B over the porous layer. This is due to a higher field strength at sharp edges during anodization, as compared to a flat surface. As was mentioned earlier, the direction of the pore propagation coincides with the direction of the electric field lines during the anodization process. Besides, 

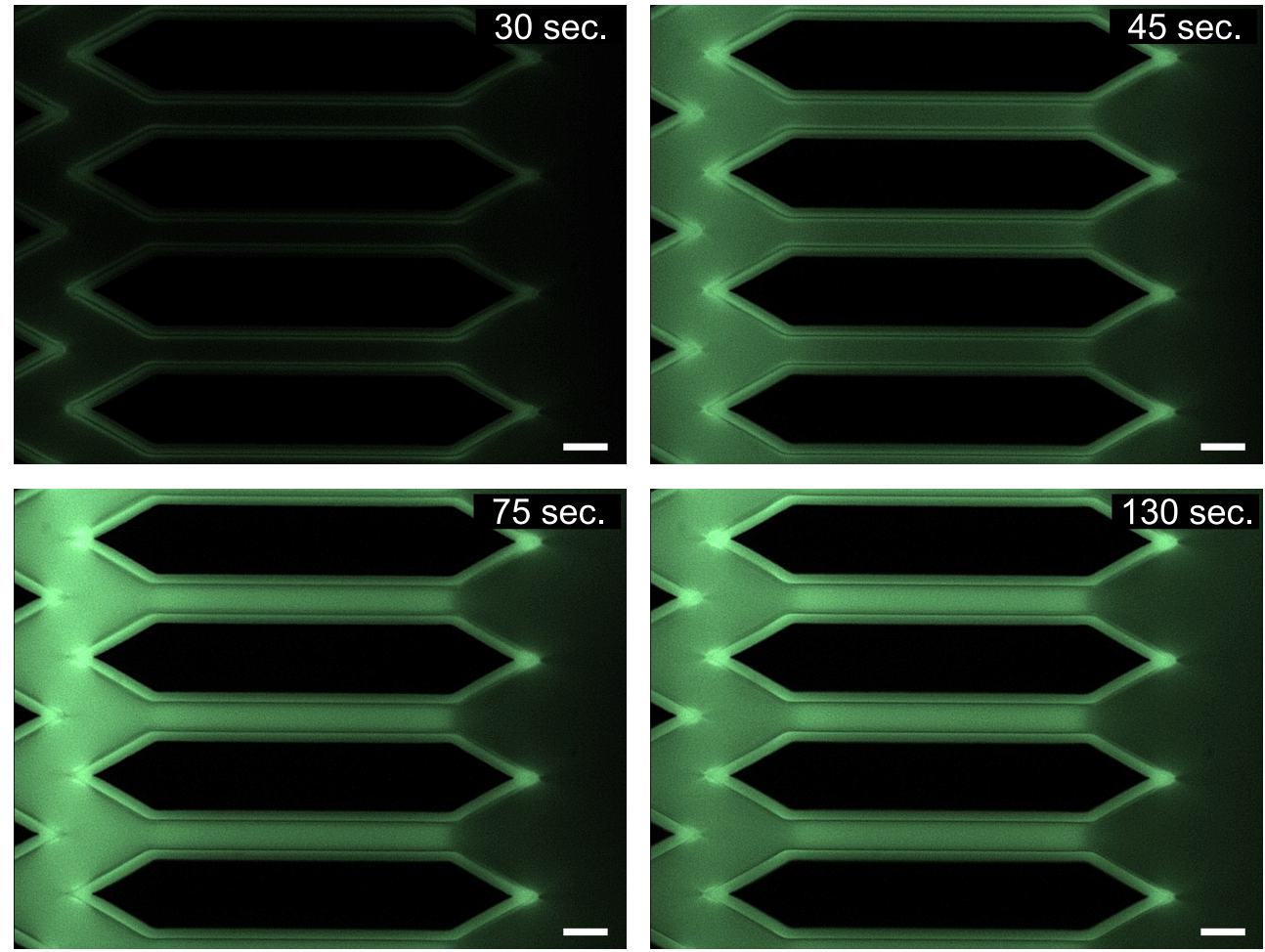

Figure 5.13: Diffusion of Rhodamine dye into the PG network. Dye arrived at the region of interest (center point of a $4 \mathrm{~cm}$ channel) around 21 seconds after placement of the droplet into the reservoir. Snapshot images with timestamps illustrate the increase in the amount of diffused solution, which reached to a balance in around 1 minute.

the field lines, as vectorial quantities, are always perpendicular to the surface exposed to the solution. As a result, the pores are formed on the surface, continue to grow in the direction perpendicular to it, merge when they coincide and result with a canal, which can deliver higher amount of sample (Figure 5.14).

After investigating the PG network physically and optically on open channels, some electrical measurements were also performed with closed channels. Simple cross layout microchips without any pillars were used for the experiments. The width and the height of the channels were $160 \mu \mathrm{m}$ and $10 \mu \mathrm{m}$, respectively. The integrated PG layer thickness was $1 \mu \mathrm{m}$ with an isolating solid silica layer underneath of $400 \mathrm{~nm}$. Channels were filled with 10 mM, pH 9 sodium tetraborate buffer (Sigma-Aldrich, 


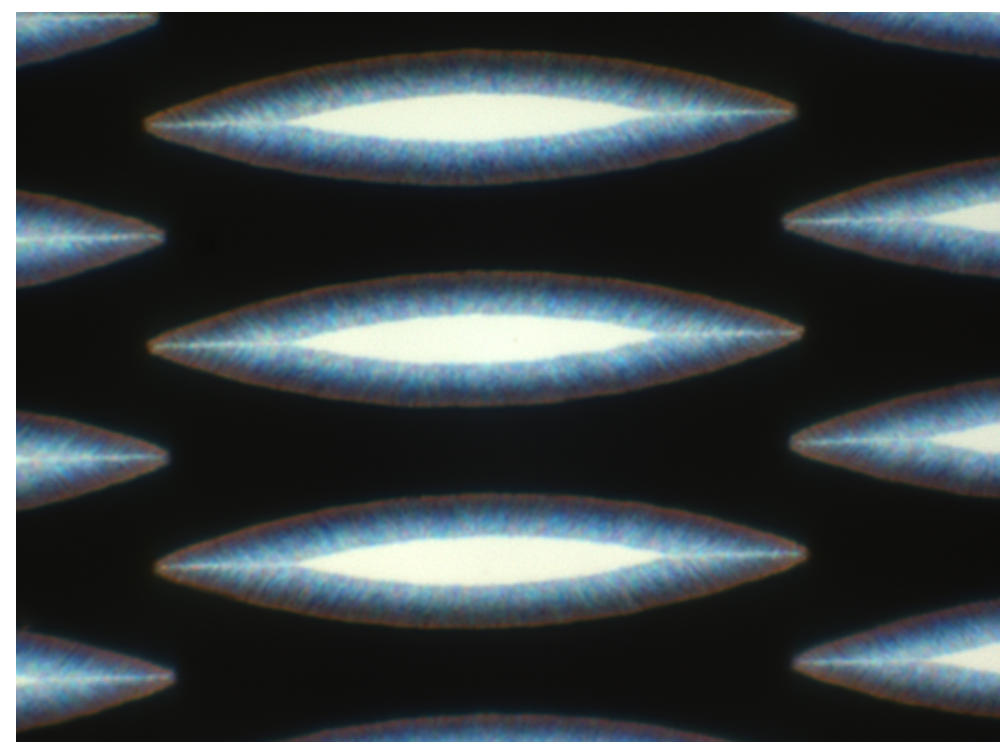

Figure 5.14: Microscope image (top view) of custom shape pillar after anodization. $\mathrm{SiRN}$ layer was removed. The bright region in the middle is a non-porous Si core, which highly reflects the light. Straight nanochannels, which are open at the tip of the structures, are created due to combined pore formation. Please note the color change due to the differences in pore size and porosity.

Zwijndrecht, The Netherlands) with a 50\% acetonitrile (Sigma-Aldrich) volumetric composition and a neutral fluorescent dye, Coumarin 480D (Sigma-Aldrich) was used for flow measurements. C480D was injected electrokinetically and its migration was monitored. A Leica DMI5000 M inverted microscope system (Leica Microsystems, Rijswijk, The Netherlands) which has an integrated motorized stage with electronic position control, was used for the experiments. As a light source a Leica EL6000 unit, equipped with a mercury short-arc lamp (Osram HXP-R120W/45C VIS, Leica Microsystems), was applied. Fluorescent emission from the sample was passed through a Leica filter cube: D, which consists of an excitation filter (band-pass 355-425 $\mathrm{nm}$ ), a dichromatic mirror (455 nm) and a suppression filter (long-pass $470 \mathrm{~nm}$ ). The experiments were monitored using a Leica DFC300 FX color camera attached to the microscope. In order to measure the electroosmotic mobility, an increasing electrical potential was applied up to the dielectric breakdown limit. The maximum allowable voltage was $400 \mathrm{~V}$, indicating a breakdown limit of $10 \mathrm{MV} / \mathrm{cm}$ (it is typically 8-12 
$\mathrm{MV} / \mathrm{cm}$ for thermal oxide of bulk $\mathrm{Si}$ ). The measured electroosmotic mobility was 2.6E-9 $\mathrm{m}^{2} / \mathrm{Vs}$, while the same chip design fabricated from fused silica with solid (non-porous) walls yielded $1.86 \mathrm{E}-8 \mathrm{~m}^{2} / \mathrm{Vs}$.

During the experiments it was discovered that the processes discussed in this paper may also be used for another interesting purpose, namely fully released cagelike structures composed of porous silicon. This was done as follows: For producing a typical I-V curve during anodization, the applied voltage was swept from 0 to a certain value, which may exceed the electropolishing limit. This leads to removal of the solid silicon layer behind the porous layer, and therewith creates free standing porous walls. This method is related to older work at our institute, giving porous tube-in-tube structures [7]. Figure 5.15(a) shows the results of two voltage sweep applications in 5\% $\mathrm{HF}$ with the range of $0-5 \mathrm{~V}$ and $0-15 \mathrm{~V}$, respectively. The sample was $5 \%$ loading design and the potential limit for polishing was $1.7 \mathrm{~V}$ (Figure 5.4). Therefore, sweeping until this potential resulted in a PS layer, passing this limit, electropolishing started and continued till the end of the application. The duration of the first sweep was $56.5 \mathrm{~s}$. Then the second sweep, performed for $67.9 \mathrm{~s}$, caused thicker walls and higher void volumes. After the anodization, the SiRN layer on the top surface was removed. As a result, two free standing vertical and parallel porous walls with a void volume in between were successfully fabricated.

Another voltage sweep was applied for the same design in $5 \% \mathrm{HF}$ for the range of $0-10 \mathrm{~V}$ and a duration of $324 \mathrm{~s}$. Increasing the time of the application caused significantly larger void volume behind the porous wall. Therefore, the porous walls collapsed because of the electrostatic forces when the SiRN layer was removed (Figure $5.15(\mathrm{~b}))$. Such detached structures composed of porous walls can be fabricated in any geometry and transported with typical micro manipulators for integrating in microsystems.

\subsection{Concluding remarks}

A method for fabricating the integrated PG layers in structured microchannels using microfabrication technology was presented. Determining the fabrication process steps, 

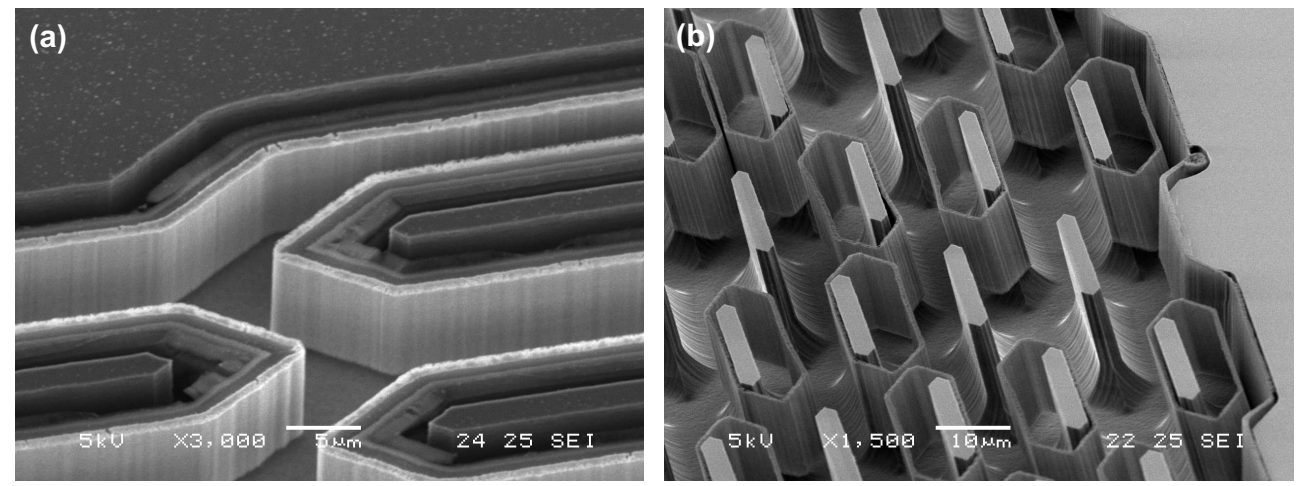

Figure 5.15: SEM pictures of free standing porous walls obtained by voltage sweep applications in $5 \% \mathrm{HF}$. (a) $0-5 \mathrm{~V}$ for $56.5 \mathrm{~s}+0-15 \mathrm{~V}$ for $67.9 \mathrm{~s}$. (b) $0-10 \mathrm{~V}$ for $324 \mathrm{~s}$.

the anodization parameters were investigated for fabricating stable PS layers. The relationship between the applied voltage and the obtained current was revealed for such systems. Experiments showed that each design option has its own I-V characteristics. In other words, such I-V characterization curves should be produced for every design in order to determine the optimal working potential range for proper formation of PS. Complete conversion of a PS network into PG was performed by means of thermal oxidation (wet or dry). The effect of oxidation on pore size and porosity was determined. The critical parameters for realization of the Si based microchips with integrated $\mathrm{PG}$ was discussed. In order to validate the technique, successful full conversion of PS into PG was confirmed with HF etching of PG and flow visualization of fluorescent dye through the PG layer with microscopy.

\section{References}

[1] XG Zhang, SD Collins, and RL Smith. Porous silicon formation and electropolishing of silicon by anodic polarization in hf solution. Journal of the electrochemical society, 136(5):1561-1565, 1989.

[2] W. Lang, P. Steiner, and H. Sandmaier. Porous silicon: a novel material for microsystems. Sensors and Actuators A: Physical, 51(1):31-36, 1995.

[3] L. Canham. Properties of Porous Silicon, volume 18. INSPEC, The Institution of Electrical Engineers, London, 1997. 
[4] H. Saha, SK Dutta, SM Hossain, S. Chakraborty, and A. Saha. Mechanism and control of formation of porous silicon onp-type si. Bulletin of Materials Science, 21(3):195-201, 1998.

[5] B. Hamilton. Porous silicon. Semiconductor science and technology, 10(9):1187, 1999.

[6] XG Zhang. Morphology and formation mechanisms of porous silicon. Journal of the Electrochemical Society, 151(1):C69-C80, 2004.

[7] R.W. Tjerkstra, GE Gardeniers, J.J. Kelly, and A. van den Berg. Multi-walled microchannels: free-standing porous silicon membranes for use in/spl mu/tas. Journal of Microelectromechanical Systems, 9(4):495-501, 2000.

[8] T. Defforge, M. Capelle, F. Tran-Van, and G. Gautier. Plasma-deposited fluoropolymer film mask for local porous silicon formation. Nanoscale research letters, 7(1):344, 2012.

[9] A. Halimaoui, C. Oules, G. Bomchil, A. Bsiesy, F. Gaspard, R. Herino, M. Ligeon, and F. Muller. Electroluminescence in the visible range during anodic oxidation of porous silicon films. Applied physics letters, 59(3):304-306, 1991.

[10] AG Cullis, LT Canham, and PDJ Calcott. The structural and luminescence properties of porous silicon. Journal of Applied Physics, 82(3):909-965, 1997.

[11] R.C. Erson, R.S. Muller, and C.W. Tobias. Investigations of porous silicon for vapor sensing. Sensors and Actuators A: Physical, 23(1):835-839, 1990.

[12] J. Das, SM Hossain, S. Chakraborty, and H. Saha. Role of parasitics in humidity sensing by porous silicon. Sensors and Actuators A: Physical, 94(1):44-52, 2001.

[13] J. Das, S. Dey, S.M. Hossain, Z.M.C. Rittersma, and H. Saha. A hygrometer comprising a porous silicon humidity sensor with phase-detection electronics. IEEE Sensors Journal, 3(4):414-420, 2003.

[14] GM O'Halloran, M. Kuhl, PJ Trimp, and PJ French. The effect of additives on the adsorption properties of porous silicon. Sensors and Actuators A: Physical, 61(1):415-420, 1997.

[15] GM O'Halloran, PM Sarro, J. Groeneweg, PJ Trimp, and PJ French. A bulk micromachined humidity sensor based on porous silicon. In TRANSDUCERS'97 Chicago., volume 1, pages 563-566. IEEE, 1997.

[16] ZM Rittersma, WJ Zaagman, M. Zetstra, and W. Benecke. A monitoring instrument with capacitive porous silicon humidity sensors. Smart materials and structures, 9(3):351, 2000.

[17] C. Pramanik and H. Saha. Piezoresistive pressure sensing by porous silicon membrane. IEEE Sensors Journal, 6(2):301-309, 2006. 
[18] P. Maccagnani, R. Angelucci, P. Pozzi, A. Poggi, L. Dori, GC Cardinali, and P. Negrini. Thick oxidised porous silicon layer as a thermo-insulating membrane for high-temperature operating thin-and thick-film gas sensors. Sensors and Actuators B: Chemical, 49(1):22-29, 1998.

[19] V. Lysenko, B. Remaki, and D. Barbier. Double-sided mesoporous silicon formation for thermal insulating applications. Advanced Materials, 12(7):516519, 2000.

[20] D. Papadimitriou, C. Tsamis, and AG Nassiopoulou. The influence of thermal treatment on the stress characteristics of suspended porous silicon membranes on silicon. Sensors and Actuators B: Chemical, 103(1):356-361, 2004.

[21] D Dominguez, B Bonvalot, M T Chau, and J Suski. Fabrication and characterization of a thermal flow sensor based on porous silicon technology. Journal of Micromechanics and Microengineering, 3(4):247, 1993.

[22] M.P. Stewart and JM Buriak. Chemical and biological applications of porous silicon technology. Advanced Materials, 12(12):859-869, 2000.

[23] J Drott, K Lindstrm, L Rosengren, and T Laurell. Porous silicon as the carrier matrix in microstructured enzyme reactors yielding high enzyme activities. Journal of Micromechanics and Microengineering, 7(1):14, 1997.

[24] M. Bengtsson, J. Drott, and T. Laurell. Tailoring of porous silicon morphology in chip integrated bioreactors. physica status solidi (a), 182(1):533-539, 2000.

[25] C.C. Striemer, T.R. Gaborski, J.L. McGrath, and P.M. Fauchet. Charge-and sizebased separation of macromolecules using ultrathin silicon membranes. Nature, 445(7129):749-753, 2007.

[26] T. Pichonat and B. Gauthier-Manuel. A new process for the manufacturing of reproducible mesoporous silicon membranes. Journal of membrane science, 280(1):494-500, 2006.

[27] W. De Malsche, D. Clicq, V. Verdoold, P. Gzil, G. Desmet, and H. Gardeniers. Integration of porous layers in ordered pillar arrays for liquid chromatography. Lab Chip, 7(12):1705-1711, 2007.

[28] RM Tiggelaar, V. Verdoold, H. Eghbali, G. Desmet, and JGE Gardeniers. Characterization of porous silicon integrated in liquid chromatography chips. Lab Chip, 9(3):456-463, 2008.

[29] R.C. de Andrade Costa, K.B. Mogensen, and J.P. Kutter. Microfabricated porous glass channels for electrokinetic separation devices. Lab Chip, 5(11):1310-1314, 2005 .

[30] F. Detobel, S. De Bruyne, J. Vangelooven, W. De Malsche, T. Aerts, H. Terryn, H. Gardeniers, S. Eeltink, and G. Desmet. Fabrication and chromatographic performance of porous-shell pillar-array columns. Analytical Chemistry, 82(17):7208-7217, 2010. 
[31] Y. Kanemitsu. Porous silicon: Microstructure, optical properties and application to light emitting diodes. In R. Tsu Zhe Chuan Feng, editor, Porous silicon, pages 363-392. Singapore: World Scientific, 1994.

[32] LT Canham. Silicon quantum wire array fabrication by electrochemical and chemical dissolution of wafers. Applied Physics Letters, 57(10):1046-1048, 1990.

[33] SD Campbell, LA Jones, E. Nakamichi, F.X. Wei, LD Zajchowski, and DF Thomas. Spectral and structural features of porous silicon prepared by chemical and electrochemical etching processes. Journal of Vacuum Science \& Technology B: Microelectronics and Nanometer Structures, 13(3):1184-1189, 1995.

[34] T. Unagami. Oxidation of porous silicon and properties of its oxide film. Jpn. J. Appl. Phys, 19(2):231-241, 1980.

[35] S.T. Pantelides and W.A. Harrison. Electronic structure, spectra, and properties of 4: 2-coordinated materials. i. crystalline and amorphous sio $\{2\}$ and geo $\{2\}$. Physical Review B, 13(6):2667-2691, 1976.

[36] E.P. EerNisse. Viscous flow of thermal sio- $\{2\}$. Applied Physics Letters, 30(6):290-293, 1977.

[37] J. Hui, TY Chiu, S. Wong, and WG Oldham. Selective oxidation technologies for high density mos. IEEE Electron Device Letters, 2(10):244-247, 1981. 



\section{Chapter 6}

\section{Conclusion}

During the early phases of this study (beginning of the year, 2008), a decade had passed since the first introduction of the use of the pillar columns for microchip electrochromatography in 1998. However, there were only few papers published since then on this topic and none of them proposed a systematic approach for the design and characterization of such systems. As stated in the introductory part, it was aimed to propose novel methods for microchip CEC applications with microfabricated pillar columns in a systematic way. In this chapter, it is intended to describe the way of thinking behind the reported studies in this thesis and briefly mention about the future prospects. 


\subsection{Summary}

Being performed by a mechanical engineer, this work was carried out with an engineering methodology. An engineer sets a goal, identifies the challenges, proposes solutions and verifies them. The first goal was to make the best column design ever. The main challenge was to generate a generic design rule which performs the best in all working conditions. To overcome this challenge, computational models were constructed to design and optimize the pillar shapes instead of fabricating and experimenting the outcome of the incremental design changes. The solution domain was a microfluidic environment, hence it was a flow problem. Therefore the cross section of an airplane wing, airfoil, was selected as a design base as the reasons of this choice were discussed in detail in Chapter 2. The geometry definition was modified and optimized. Then it was set as the only design rule for generating the shape of the pillars. Finalizing the shape definition, computational studies continued to set another rule to define the distribution of the pillars throughout the channel (how to place them inside the channel) based on preserving the hydrodynamic balance for maximizing the performance. Finally coupling with a first order retention modeling, the shape and placement definitions were compared with the ones from literature. The proposed designs yielded a superior performance "on paper".

In order to accomplish the first goal, in other words to verify that the proposed design methodology is better, microchips were fabricated and tested under both nonretained and retained conditions. As presented in detail in Chapter 3, experimental results showed that the foil shape performed the best in all working conditions in "real life". This experimental study was also informative for understanding the characteristics of microchip CEC devices with pillar columns. However, the applied first order retention modeling was far from giving a good estimation.

Another identified problem for such systems was the distorted initial profile (or the shape) of the injected sample when the typical bifurcated distributor (a legacy from the pioneers of pillar column technology) was used. Therefore an optimized distributor structure was needed for the electrokinetic injection. This was a good chance (and a challenge) to test the applicability of the proposed foil definition as a 
general design rule. The challenge was to design a distributor for injecting the sample with a perfectly flat profile. As reported in Chapter 4, this definition was used to design an injector structure by means of computational modeling. Implementing experimentally, a perfectly flat profile was obtained. An extra advantage of the optimized injector was the ability of controlling the injected sample volume precisely by adjusting the duration of feeding of sample during injection without sacrificing the flatness of the profile. However, high voltage drops through these injectors caused a decrease in electrosmotic flow velocity when compared with the typical bifurcated ones.

In addition to the design related challenges mentioned above, the most important application related issue for solid pillars was the loadability problem. The only way to increase the volume and the surface at the same time was deploying porous layers over the pillars. The chemical synthesis methods were not preferred because of the uniformity and repeatability issues of the techniques. The way of having integrated porous layers over the pillar columns was reported by De Malsche et al. [1] where they anodized the Si pillars and obtained a porous silicon (PS) layer over them. The challenge was to adapt it to use with the electrokinetic applications. As reported in detail in Chapter 5, the substrate material changed to silicon (from fused silica), it was anodized to obtain a PS layer over the pillars and the PS layer was converted into porous glass (PG) with an insulating solid silica layer underneath using thermal oxidation. In addition to showing the applicability of this technique, a detailed study on the method development, which provided information on all the critical steps of the fabrication process, was performed in order to enable this technology for future researches.

\subsection{Future perspectives}

The potential of the computational methods as a design tool was shown in Chapter 2. Taking this one step further, the perfect column design can be reached by topology optimization methods. These are mathematical models that aim to optimize the material distribution within a given design domain for a given set of loads and 
boundary conditions. Implementation of topology optimization methods in flow problems were already reported in literature [2-4]. Figure 6.1 shows a minimum drag body, which is generated using a topology optimization method, in a creeping flow condition. A similar approach as in Chapter 2 can be applied, avoiding bounding of the geometry definition to a predefined foil shape but using topology optimization methods for creating the column design.

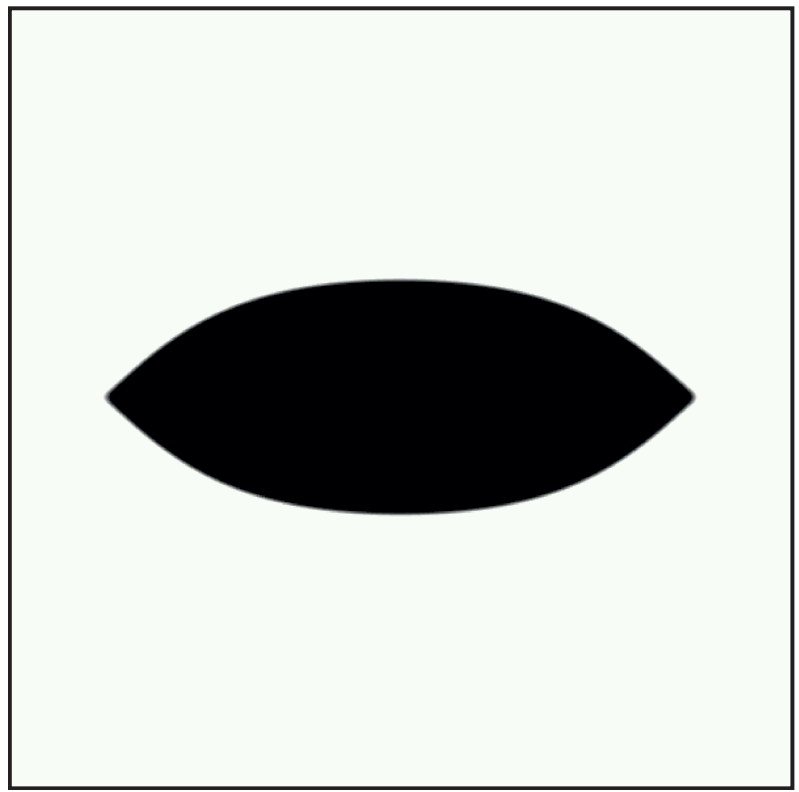

Figure 6.1: Minimum drag body suspended in Stokes flow. Black pixels are interpreted as a solid and white pixels are interpreted as a fluid [4].

Characterization of the microchip capillary electrochromatography systems was reported in Chapter 3. Experimental studies can be extended in order to evaluate the channel depth and trans-channel coupling effects on performance. Microchips can be fabricated with various channel depths with a fixed channel layout and the results can be interpreted to find an optimum depth per design. Also, the same pillar designs with various aspect ratios (length to width ratio) can be fabricated for testing the effect of different levels of re-mixing of the sample passing over the pillars. Increasing the aspect ratio of the structures results with less coupling zones, yielding lower level of re-mixing at those. Decreasing the aspect ratio of the structures causes the opposite. 
Optimized distributor structures, which produces a flat sample profile with a pre-concentration effect were presented in Chapter 4. They can also be used to decrease sample dispersion at turning geometries. The distributor and collector can be placed before and after the channel turn, respectively and sample dispersion can be minimized. Therefore longer channel lengths can be realized with more compact geometries as reported earlier [5].

Successful fabrication of integrated porous glass layers in microchips was reported in Chapter 5. Solving all the technical problems of the fabrication process, the next step would be the implementation of such systems in capillary electrochromatography applications. A similar study as in Chapter 3 can be performed and the results can be compared with the solid pillars for evaluating the potential of proposed fabrication method. The knowledge gained during the anodization studies, showed that this fabrication method has a potential of being used in various applications. As discussed earlier in Chapter 5, free standing porous walls can be fabricated by performing electropolishing after proper pore formation. Figure 6.2 shows a SEM picture of such application on cylindrical pillars. The SiRN (silicon-rich silicon nitride) masking layer also served as a support for porous walls. When the SiRN layer was removed, porous silicon walls attached to bulk Si because of the electrostatic attraction force (see Figure 6.3). Using an electrostatic manipulator, porous silicon walls can be detached from the location at which they are fabricated and moved to another location for integrating them into another microsystem. Figure 6.4 shows a SEM picture of detached micro pipes made from porous silicon, placed on a Si surface. An important advantage of this method is the possibility of defining any desired shape for defining the cross section of the pipes and their wall thickness.

After being converted into porous glass from porous silicon, the material gains hydrophilic surface properties and becomes optically transparent. A hydrophilic, transparent and porous dielectric has a potential to be used for many fluidic applications. A striking example would be a photo-catalytic application where it is used as a support structure to provide the needed high surface area, which cannot be obtained by solid supports. 


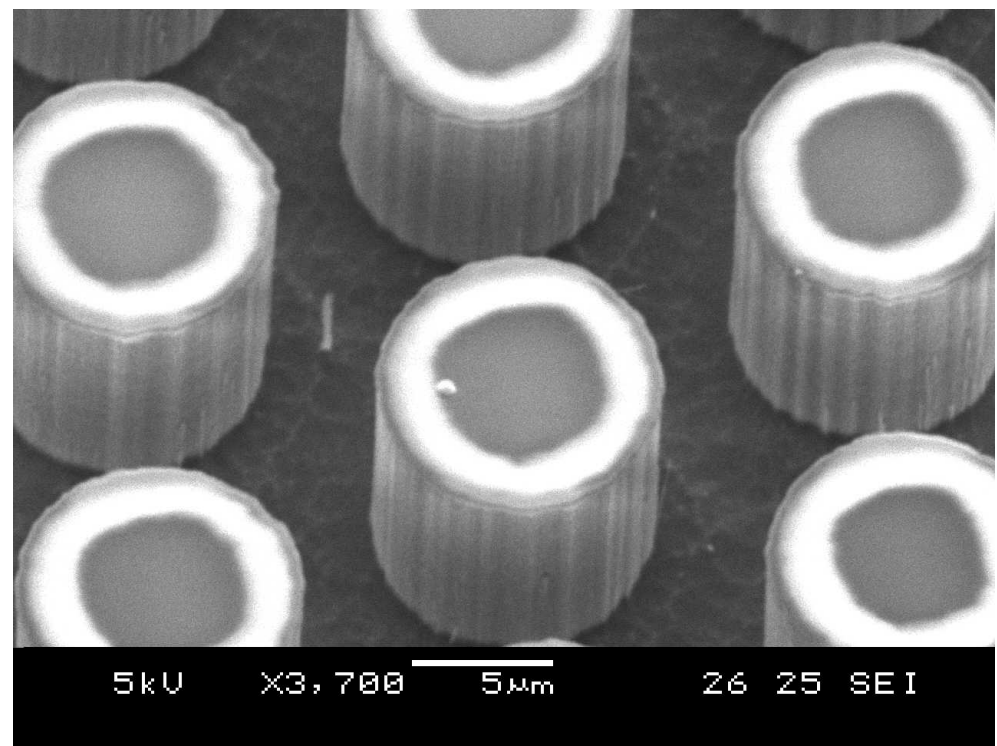

Figure 6.2: SEM image of cylindrical pillars after a pore formation-electropolishing cycle. The part of the SiRN mask layer on the void volume (outer ring) glows because of a higher charging level during electron microscopy, compared with the area on $\mathrm{Si}$ (central area).

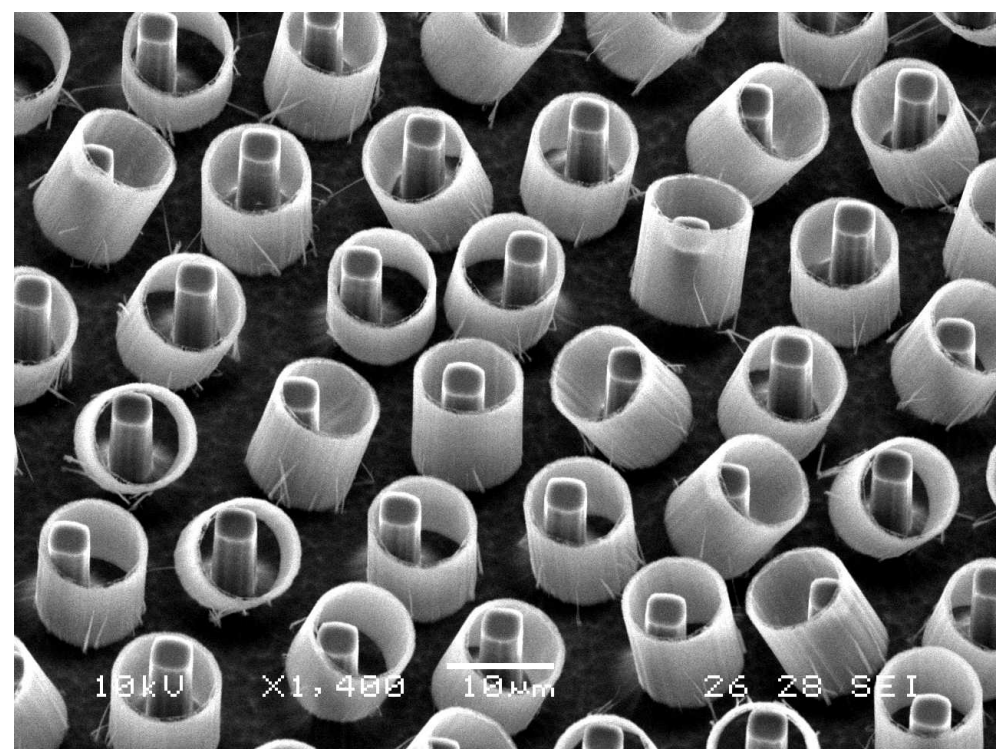

Figure 6.3: SEM image of porous silicon walls, which attached to left-over Si pillars because of the electrostatic attraction forces after the SiRN layer was removed with dry etching. 


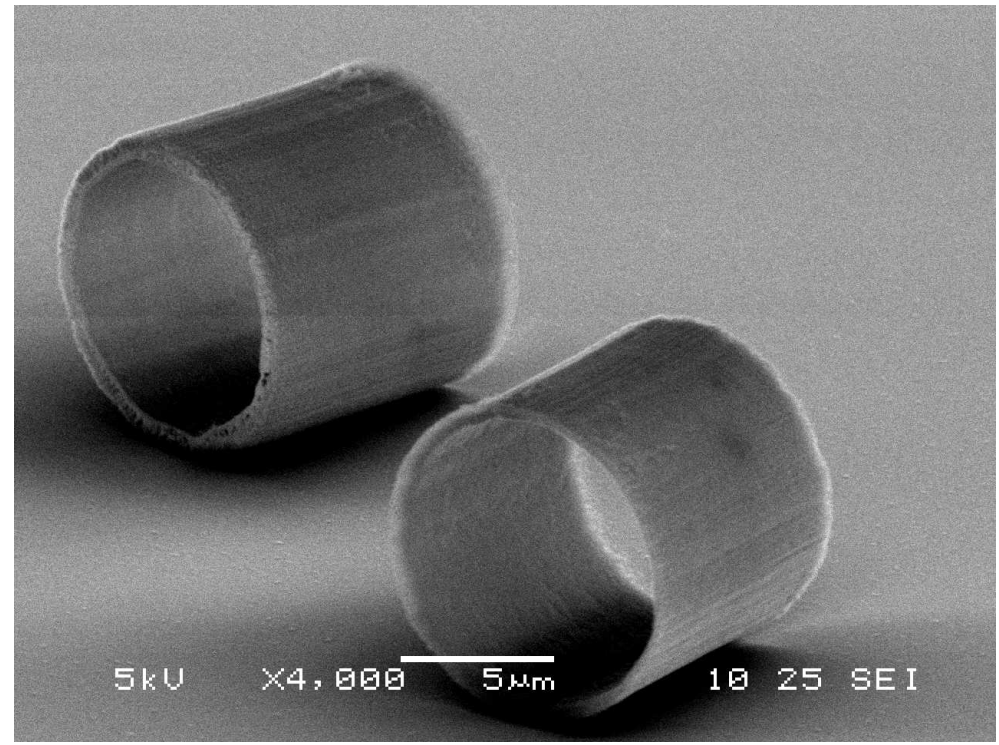

Figure 6.4: SEM picture of detached micro pipes made from porous silicon placed on a silicon surface.

\section{References}

[1] W. De Malsche, D. Clicq, V. Verdoold, P. Gzil, G. Desmet, and H. Gardeniers. Integration of porous layers in ordered pillar arrays for liquid chromatography. Lab Chip, 7(12):1705-1711, 2007.

[2] F. Okkels, L.H. Olesen, and H. Bruus. Applications of topology optimization in the design of micro-and nanofluidic systems. In Technical Proceedings of the 2005 NSTI Nanotechnology Conference and Trade Show.

[3] Fridolin Okkels and Henrik Bruus. Scaling behavior of optimally structured catalytic microfluidic reactors. Physical Review E, 75:016301, Jan 2007.

[4] N. Aage, T.H. Poulsen, A. Gersborg-Hansen, and O. Sigmund. Topology optimization of large scale stokes flow problems. Structural and Multidisciplinary Optimization, 35(2):175-180, 2008.

[5] W. De Malsche, J. Op De Beeck, S. De Bruyne, H. Gardeniers, and G. Desmet. Realization of $1 \times 10^{6}$ theoretical plates in liquid chromatography using very long pillar array columns. Analytical Chemistry, 84(3):1214-1219, 2012. 



\section{Samenvatting}

Bij het aanvatten van deze studie was reeds een decennium voorbij gegaan sinds de introductie van pillaarkolommen voor capillaire elektrochromatografie (CEC) in 1998. Gedurende deze tijdspanne verschenen nauwelijks artikels omtrent dit onderwerp en hierbij werd nooit een systematische aanpak voor het design en de karakterisatie van dergelijke systemen voorgesteld. In dit proefschrift worden nieuwe methodes voor microchip CEC voorgesteld gebaseerd op microvervaardigde pillaarkolommen.

Het eerste doel bestond erin om het best mogelijke kolomdesign te verwezenlijken. De belangrijkste uitdaging bestond erin om een generische designregel te definiren waarbij een superieure performantie bij alle operationele omstandigheden bekomen wordt. Hiertoe werden computationele modellen opgesteld om zodoende de optimale pillaarvorm te bekomen, in plaats van de alternatieve strategie om de experimentele invloed op te meten van incrementele wijzigingen van de designvariabelen. Het oplossingsdomein was een microfluidische omgeving, wat maakte dat het probleem van fluidische aard was. Hierdoor werd de doorsnede van een vliegtuigvleugel, ook een propellerblad genoemd, geselecteerd als ontwerpbasis. De geometrische definitie werd vervolgens als enige ontwerpvariabele gemodificeerd en geoptimaliseerd om de vorm van de pillaren te bepalen. Om de vormdefinitie te bepalen die de performantie kan maximaliseren, werden computationele studies aangewend om een andere ontwerpregel vast te leggen om zo de positionering van de pillaren doorheen het microfludisch kanaal te bepalen, gebaseerd op het behouden van de hydrodynamische balans. Ten slotte werd een eerste orde retentiemodellering gekoppeld met de vormings- en positioneringsdefinities en werden deze vergeleken met literatuurwaarden. Hierbij werd theoretisch een superieure performantie voorspeld.

Om te verifiren dat de voorgestelde ontwerpmethodologie beter is, werden microchips vervaardigd en getest bij zowel geretenteerde als niet-geretenteerde omstandigheden. De experimentele resultaten toonden aan dat de vleugelvorm ook de beste resultaten gaf in de praktijk, en dit bij alle omstandigheden. Deze experimentele studie heeft ook tot een beter inzicht geleid in de karakteristieken van microchip 
CEC modules met pillaarkolommen, ondanks de beperkte kwaliteit van de eerste orde retentiemodellering.

Een andere uitdaging was het initieel verstoorde profiel van genjecteerde tracer stalen wanneer de karakteristieke steeds opsplitsende distributor, initieel voorgesteld door de pioniers van pillaarkolomtechnologie, werd gebruikt. Het bleek noodzakelijk om een geoptimaliseerde struktuur te bepalen voor de electrokinetische injectie. Dit was bovendien een goede gelegenheid om de toepasbaarheid van het de vleugelvorm als algemene ontwerpregel te valideren. De belangrijkste uitdaging hierbij bestond erin de distributor zo te ontwikkelen dat een perfect recht profiel bekomen wordt. Deze definitie werd gebruikt om de injectiestruktuur te ontwerpen aan de hand van computationele modellering. Ook experimenteel werd aangetoond dat een recht profiel bekomen kan worden. Een bijkomend voordeel van de geoptimaliseerde injector was dat de mogelijkheid om het genjecteerde staalvolume te controleren door de duur van het aanvoeren van het staal te variren, zonder in te boeten op de rechtheid van het profiel. De hoge elektrische weerstanden gaven echter aanleiding tot een afname in elektroosmotische mobiliteit in vergelijking met de klassieke opslitsende distributoren.

Een andere belangrijke uitdaging was de belaadbaarheid van de strukturen. De enige manier om het volume en het oppervlak gelijktijdig te laten toenemen was door een poreuze laag aan te leggen aan de pillaren. Om redenen van uniformiteit en reproduceerbaarheid werd verkozen geen chemische synthesemethodes uit te voeren. Een strategie om poreuze lagen te integreren werd gentroduceerd door De Malsche et al. In 2007, waarbij silicium pillaren werden geanodiseerd waardoor er een poreuze laag op ontstaat. De uitdaging bestond erin deze methode aan te passen zodat het substraat ook geschikt is voor elektrokinetische toepassingen. Het bleek mogelijk om na anodizatie de poreuze siliciumlaag om te zetten naar poreus glas, waarbij een onderliggende thermisch geoxideerde silica laag een functie krijgt als elektrische weerstand. Naast het aantonen van de toepasbaarheid van deze technologie werd ook een gedetailleerde studie uitgevoerd betreffende de methodeontwikeling, om het pad te effenen voor verder onderzoek in deze richting. 


\section{Acknowledgements}

The journey that I started more than 5 years ago, finally has come to an end. I expect a happy ending and these years hopefully will bring me a doctor degree after all. Despite all my efforts, this could not happen alone of course. So I want to thank all people for their support. Not only the ones that I worked with, but everyone that helped me to have a better time here.

Before everything, I would like to thank all committee members for accepting the invitation and spending their time for me.

As a matter of fact, I start with Han for giving me the opportunity. I feel myself lucky that I had the chance to work with him. He always gave me the freedom and let me choose my own path. That way I have developed myself in many aspects and learned from my mistakes. All aside, he cared my happiness before the deadlines or papers and that was quite important for me. Thank you Han, I hope we will have another opportunity sometime to work together again...

I would like to thank Gert for making up the project, creating the chance for my $\mathrm{PhD}$ and for the nice collaboration. I want to thank Selm for helping me for making measurements with his setup in early phases of my study and also welcoming me in his house for my stay there. Also many thanks to Jeff for helping me out in their lab.

And Wim... A successful, hardworking colleague with many creative ideas and a very good friend. Whenever I was down, you always motivated me and gave me the courage to continue. You know I never liked the way you work in the cleanroom, but I always enjoyed a lot working with you in there. I am sure we will find ways to collaborate further and always keep in touch as good friends. I wish you, Sofie and little Alfred a healthy, happy long life...

Our technician, talented kart driver and professional filmmaker: Stefan. Thank you for all the technical support and our fun conversations, especially for the ones in the cleanroom. And thank you for being my paranymph. I hope someday you will see that apple is not the best fruit...

Special thanks to my officemate and a very good friend, Anıl. It was really fun 
to go out with you for dinner after work. There is no need to write longer here, I am sure we will keep in touch. I wish you and Marisa a healthy, happy long life, too.

I want to thank my other officemates: Liza, Sreenath and Svetlana for nice and fun conversations. Jacqueline, thank you very much for assisting me for almost any trouble I had here. Engin, thank you for our long conversations. And the rest of MCS: Roald, Vincent, Kevin, Jacob, Selm, Wojtek, David, Nikolay, Piotr, Maciej, Bilge, Regina, Brigitte, Roland, Katsuhiro, Reyes, Takayuki and all the other members that I couldn't recall their names, thank you very much for making our group a very nice and fun working environment!

As I mentioned before, I started my journey in MCS group five years ago and spent the last year in BIOS group. I am grateful to Edwin for creating me the chance to meet Séverine and start working with her. Séverine, thanks a lot for your support and understanding during my thesis writing, I really appreciate that. I want to thank my current officemates Yawar, Rogier, Bjorn and Trieu and the whole BIOS group!

I spent too many hours in the cleanroom and I want to thank all the cleanroom stuff for keeping the Nanolab up and running. Mark, thank you for the nice SEM pictures. Kees, thank you for our funny conversations and assistance.

People who know me also know that football is my passion. I started playing futsal in the very first week of my stay here and played with many many people. I want to thank all my teammates from CPM and BIOS teams from internal staff competition. Many thanks to all guys that I have been playing together on weekends. Thank you Soup-a-Stars for many victories we had together and we will have many more, I am sure. Of course, special thanks go to my team: Zaal 4. Emilio, Muharrem, Mark, Erwin, Gerard, Çağrı, Roger, Ufuk, Teo, Joris and Chris, as I told you several times already, I am proud to be your captain. Thanks a lot for keeping the team spirit!

My second paranymph, very good and old friend, Fehmi. Thank you for your friendship, nice times we had together, long and relaxing conversations. In short, thank you for being aside of me. I wish you and Neşe, long, healthy and happy life together. Also a lot of luck for your new career back in Turkey.

I want to thank all my other Turkish friends, Kamil, Cem, Seçkin, Ramazan, Can, Oğuzcan, Kardelen, Arda, Engin, Özlem, Hasan, Berker and the rest of the Turkish community here. I had lunches with them, joined many crazy parties and I am looking forward for the new ones!

Perdahcıoğlu family... My second sister Didem, Semih and yeğenim Tunç. I love you and feel your support with me all the time. I am so happy to have you in my life. Stay there! Didem, don't worry, everything will be just fine :)

Slowly coming towards the end, I would like to thank to my family. My dad Tahsin, mom Selma and sister Serap. Thanks million times for your love, support 
and encouragement. You always trust me in anything and it was so special for me. My father-in-law Hüseyin, mother-in-law Seyhan and brother CelalCan, thank you for accepting me in your family and your support.

Although being a fan of Fenerbahçe mostly was not fun for last couple of years, I am proud of it. All my weekends were filled with the excitement of Fenerbahçe's matches and it will never change. I want to specially thank Alex de Souza, our living legend, just because of being a fantastic player and personality.

Last but not the least, my wife, my angel, my Özlem... Thanks again and again for your endless, limitless love. Somehow you make me feel it at every moment which is really a fantastic experience and a privilege. I am sure it wouldn't be possible for me to manage anything without you and your support. You trust me in any case, about anything and make me believe in myself, too. I am the luckiest husband ever. Never leave me alone!

Sertan 